\title{
Single Component
}

Adsorption Isotherms 
- The following slides contain single component adsorption isotherms for the amorphous material structures

- The adsorption isotherms are computed for $\mathrm{H}_{2}$ and $\mathrm{N}_{2}$ at 77 $\mathrm{K}, \mathrm{Ar}$ at $87 \mathrm{~K}, \mathrm{CO}_{2}$ at $273 \mathrm{~K}$ and $298 \mathrm{~K}$, and $\mathrm{CH}_{4}$ at $298 \mathrm{~K}$

- The adsorption isotherms for PIMs are restricted to adsorbate loadings less than $3 \mathrm{mmol} / \mathrm{g}$

- The word file Amorphous_Material_Database_SI.docx contains the force field parameters for the framework and sorbate molecules used in the Monte Carlo simulations

- Section 3c. in the manuscript describes the single component adsorption isotherms of the aCarbon-Bhatia-id001 material 


\section{PIM-Colina-id001}
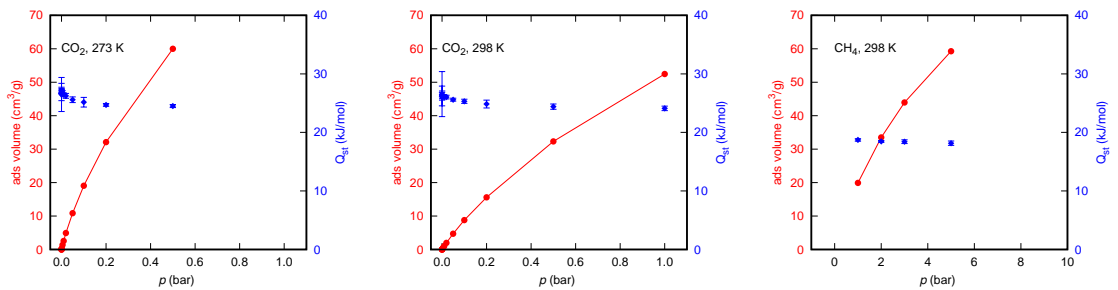


\section{PIM-Colina-id002}
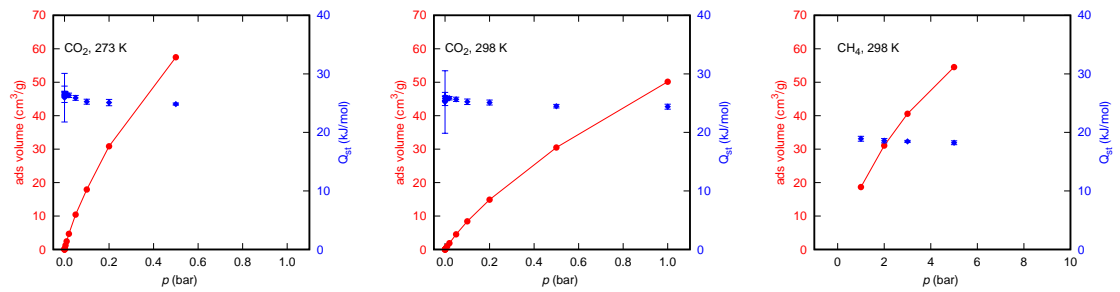


\section{PIM-Colina-id003}
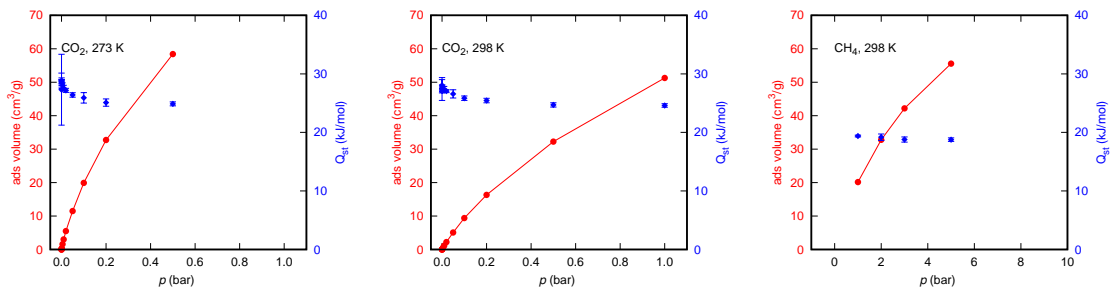


\section{PIM-Colina-id004}
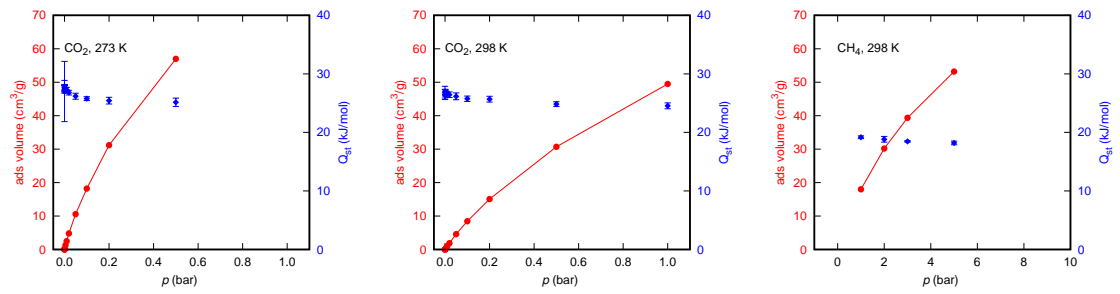


\section{PIM-Colina-id005}
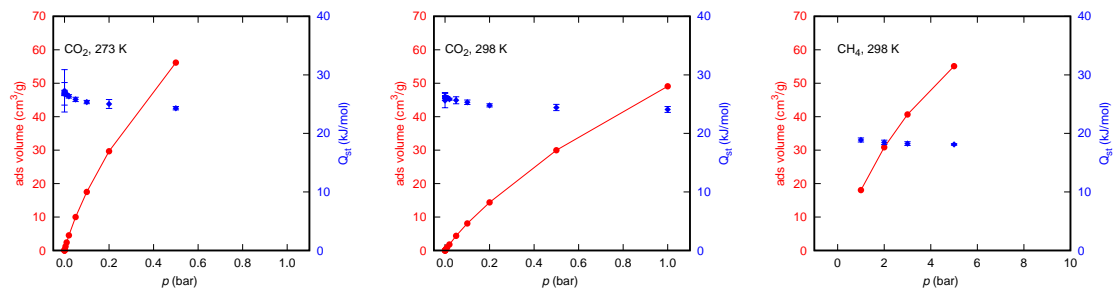


\section{PIM-Colina-id006}
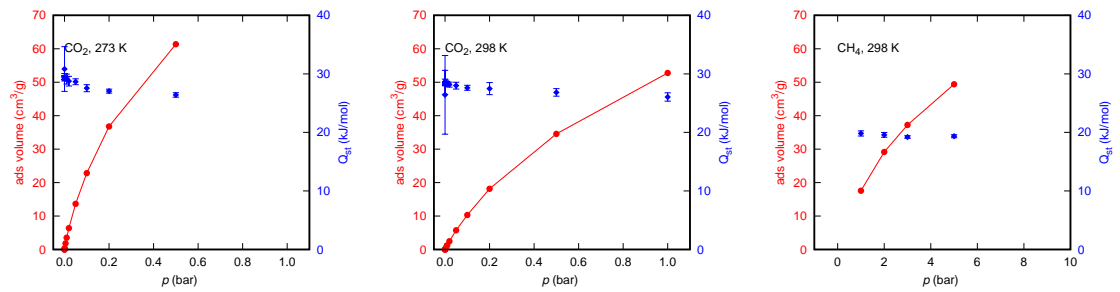


\section{PIM-Colina-id007}
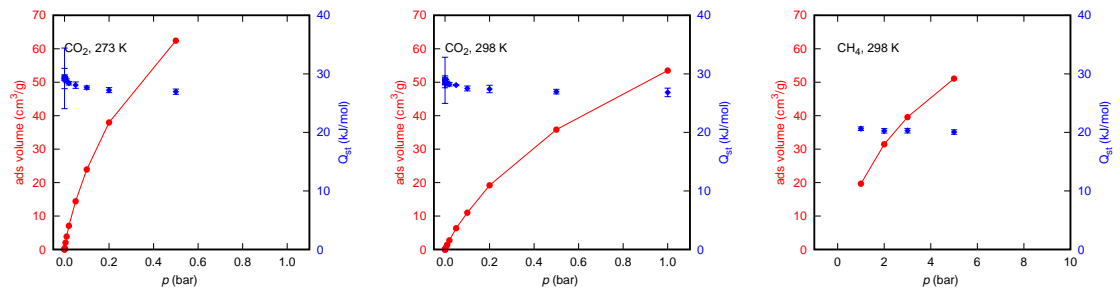


\section{PIM-Colina-id008}
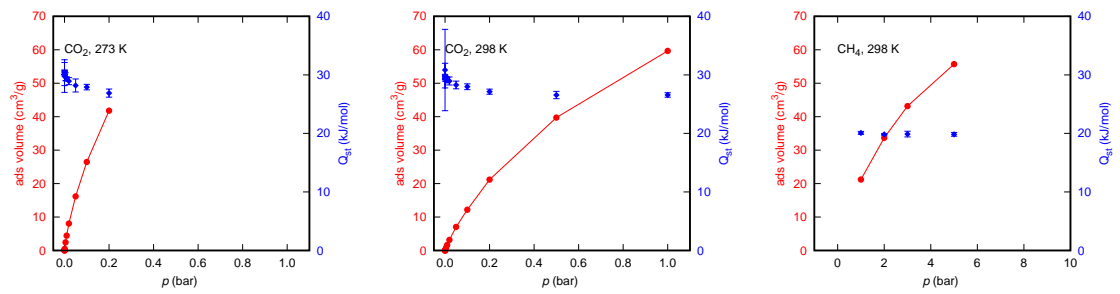


\section{PIM-Colina-id009}
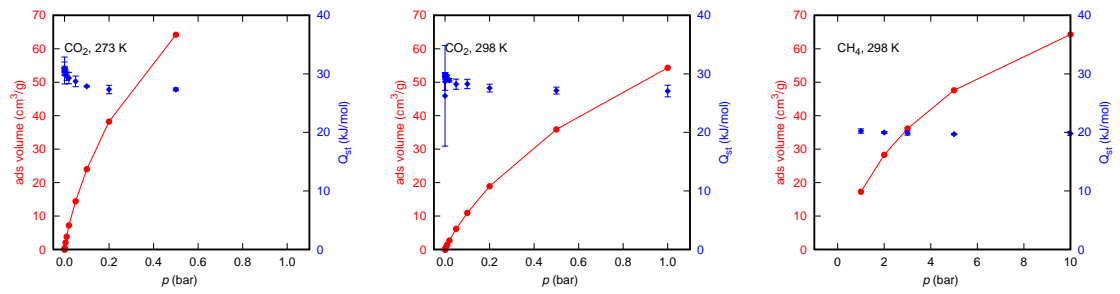


\section{PIM-Colina-id010}
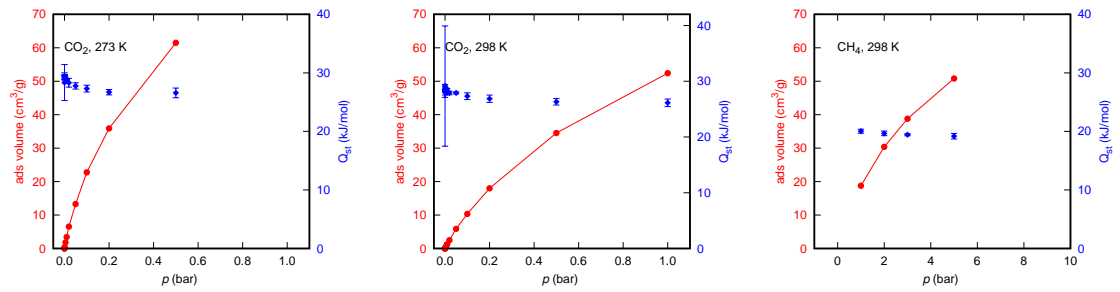


\section{PIM-Colina-id011}
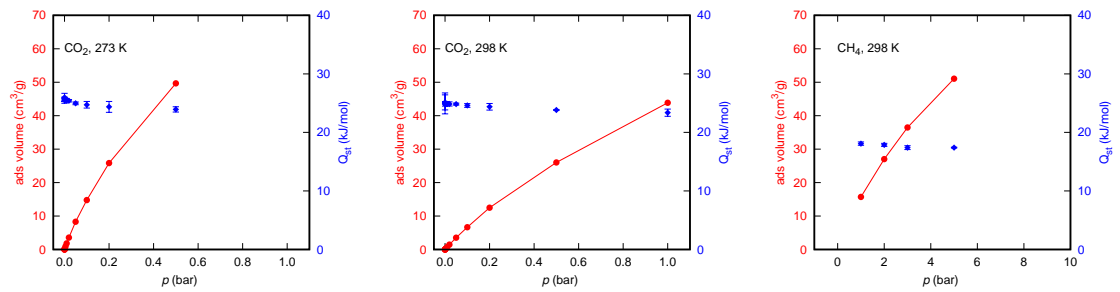


\section{PIM-Colina-id012}
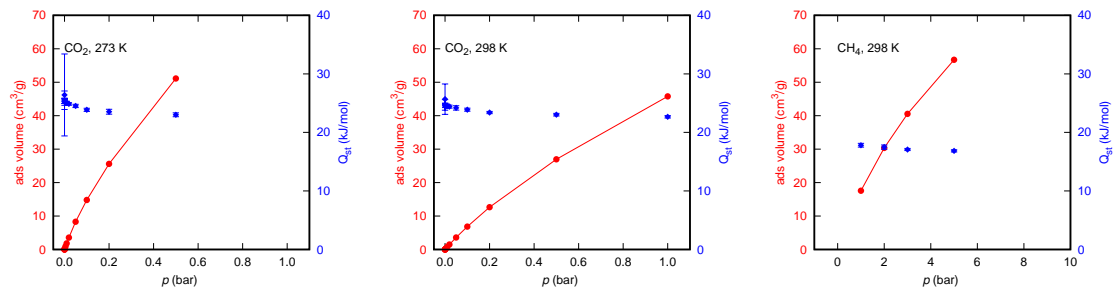


\section{PIM-Colina-id013}
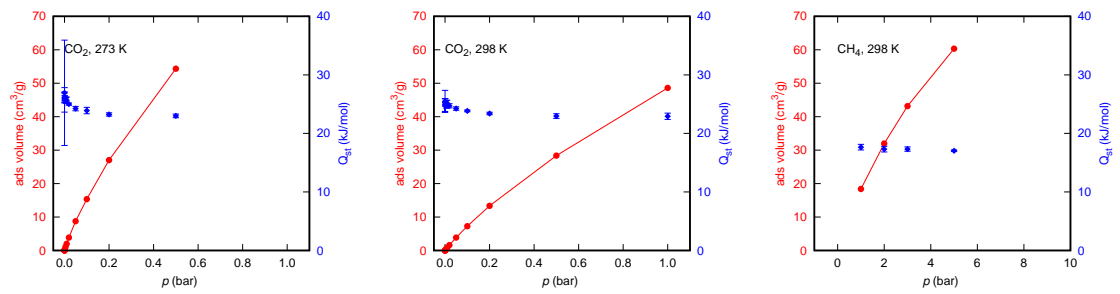


\section{PIM-Colina-id014}
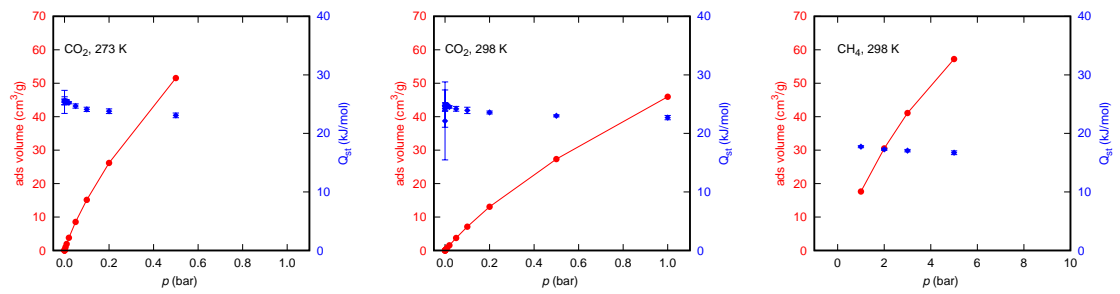


\section{PIM-Colina-id015}
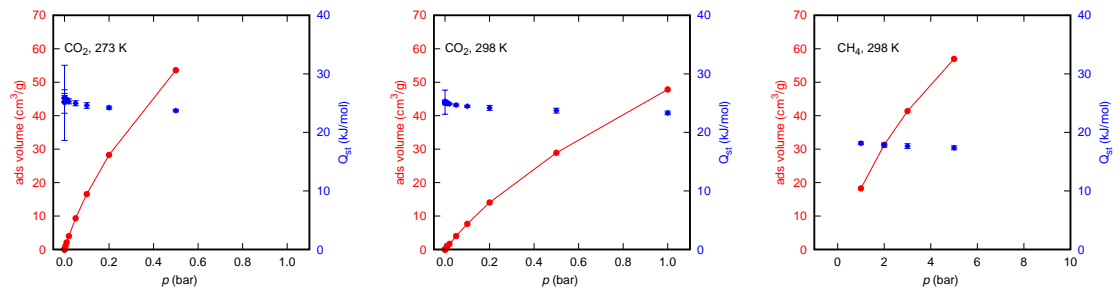


\section{PIM-Colina-id016}
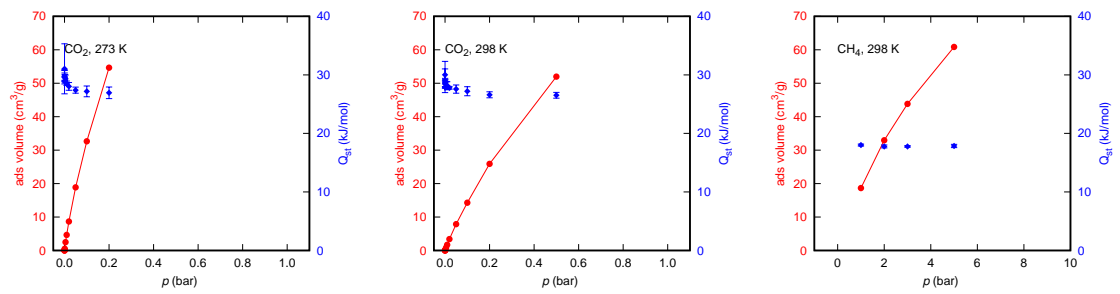


\section{PIM-Colina-id017}
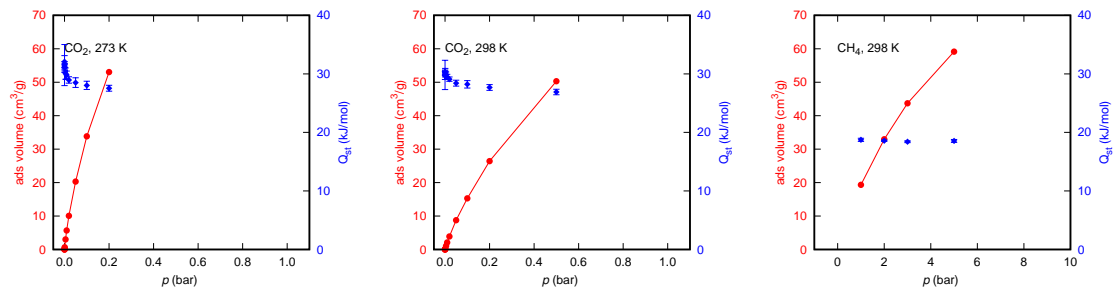


\section{PIM-Colina-id018}
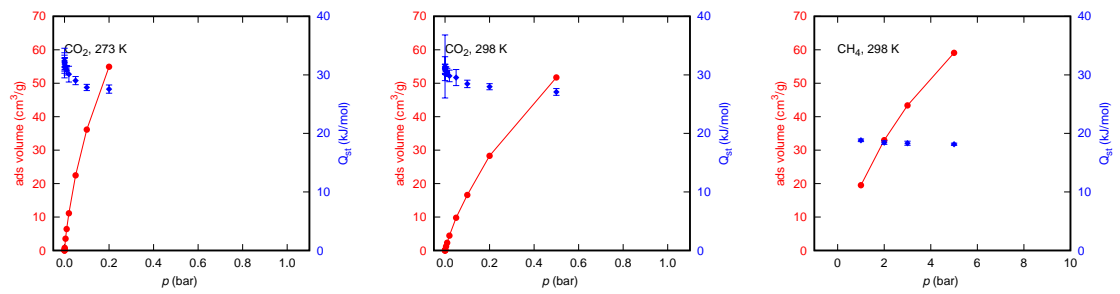


\section{PIM-Colina-id019}
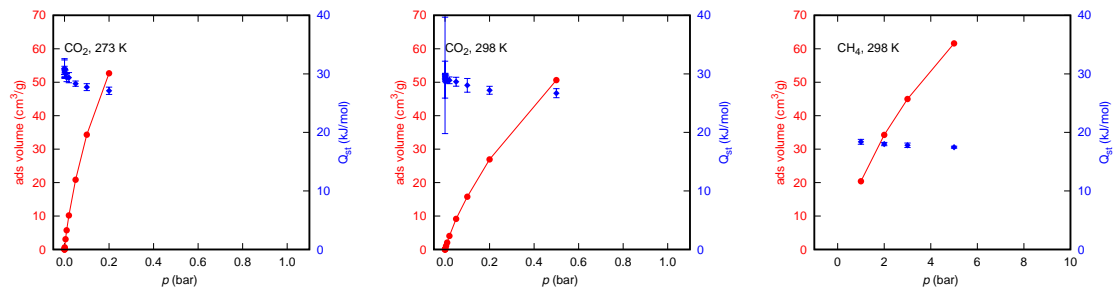


\section{PIM-Colina-id020}
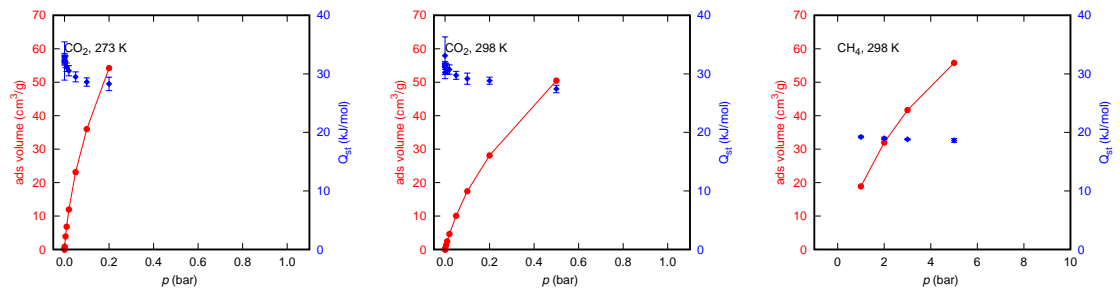


\section{PIM-Colina-id021}
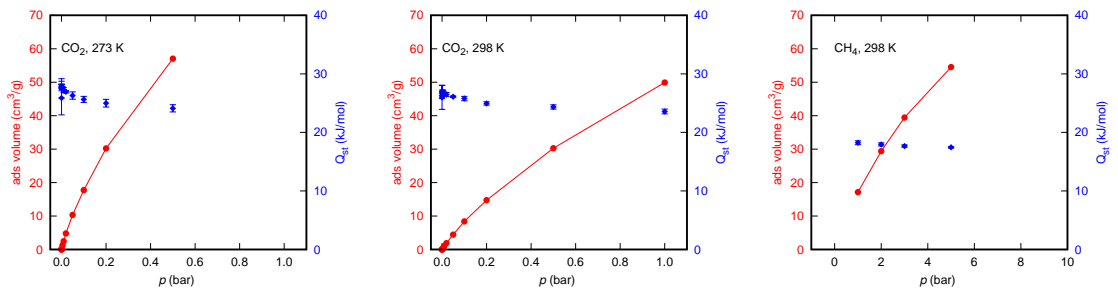


\section{PIM-Colina-id022}
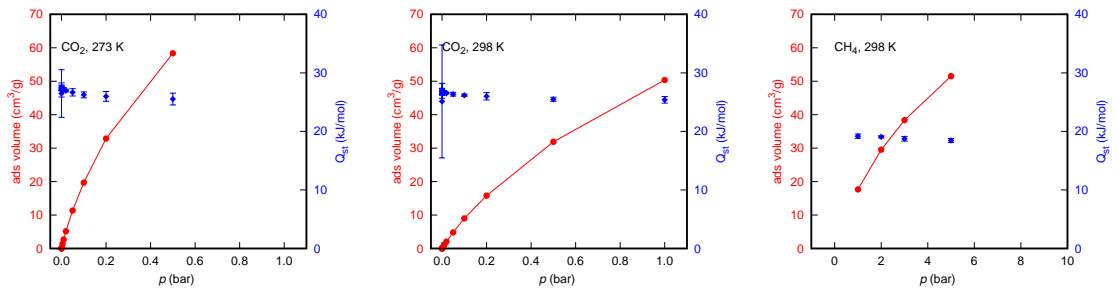


\section{PIM-Colina-id023}
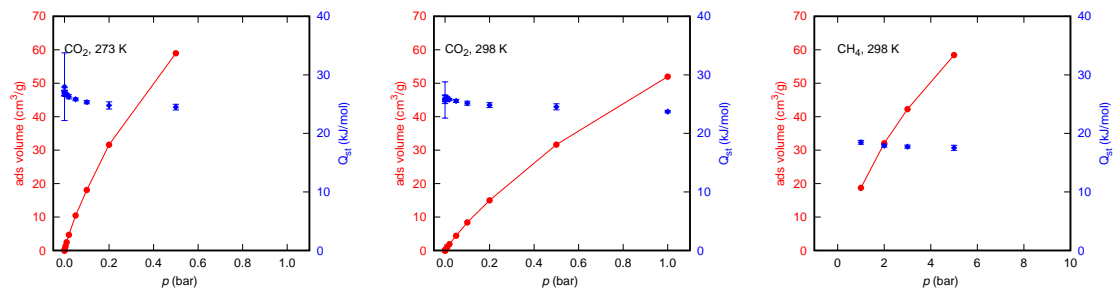


\section{PIM-Colina-id024}
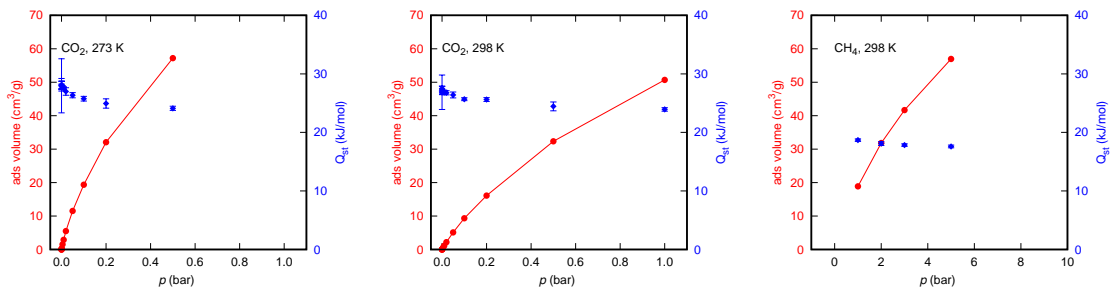


\section{PIM-Colina-id025}
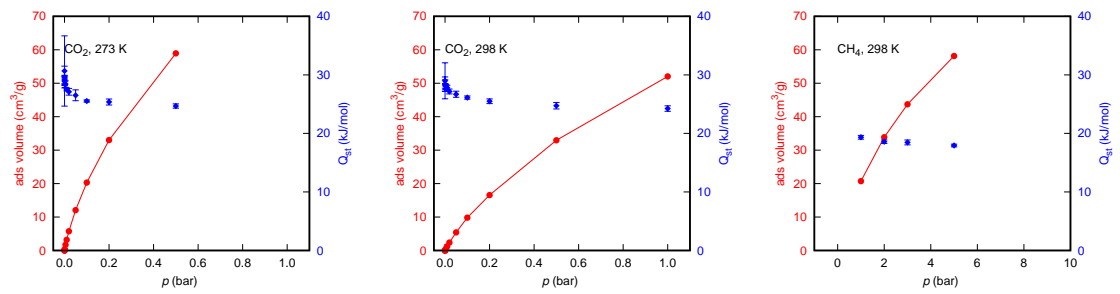


\section{PIM-Colina-id026}
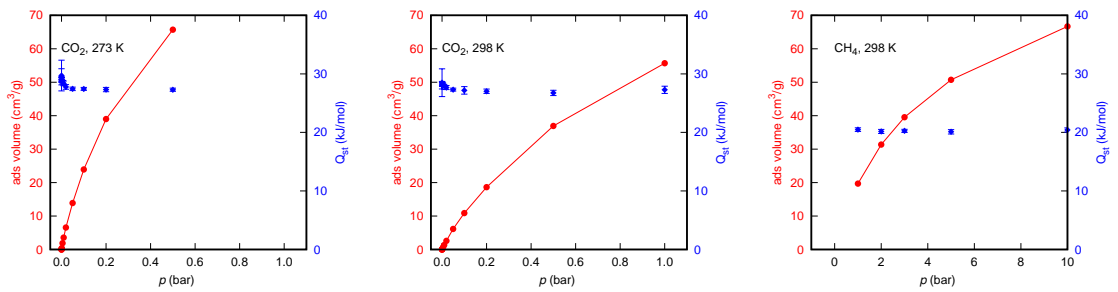


\section{PIM-Colina-id027}
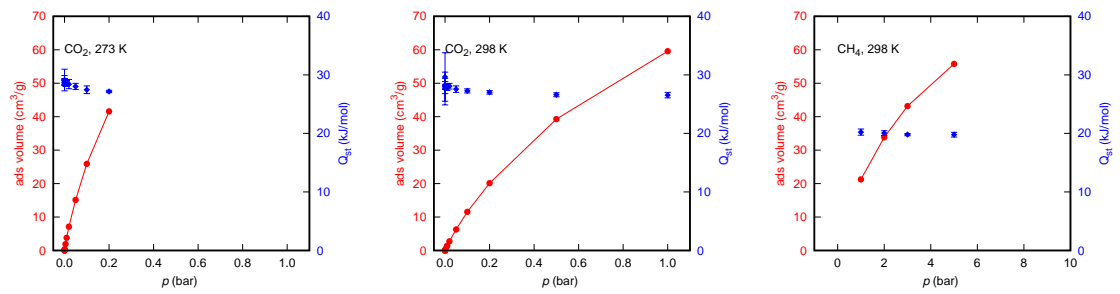


\section{PIM-Colina-id028}
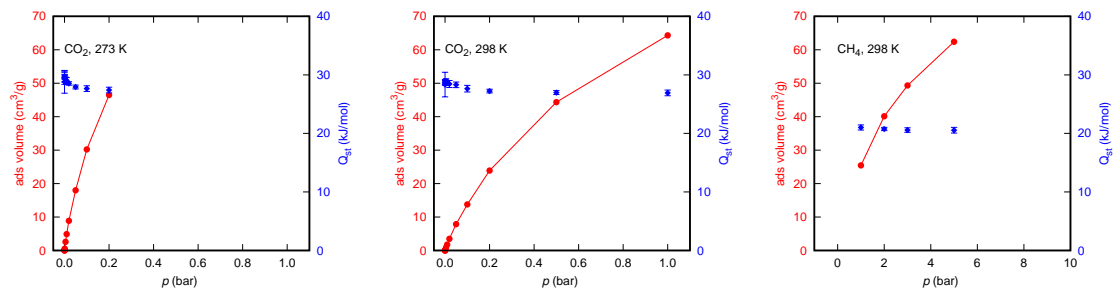


\section{PIM-Colina-id029}
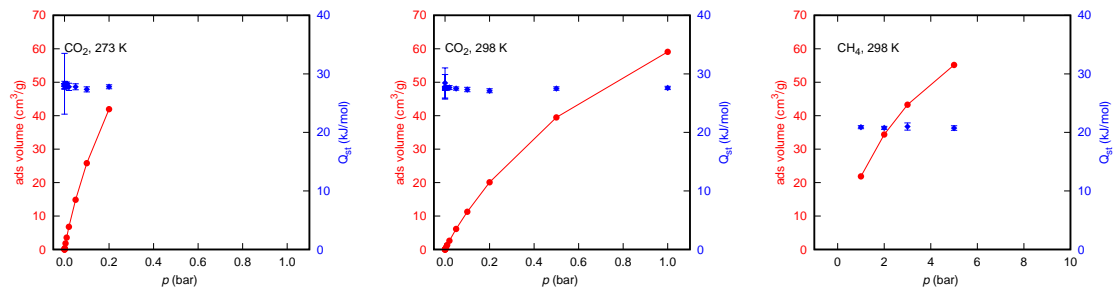


\section{PIM-Colina-id030}
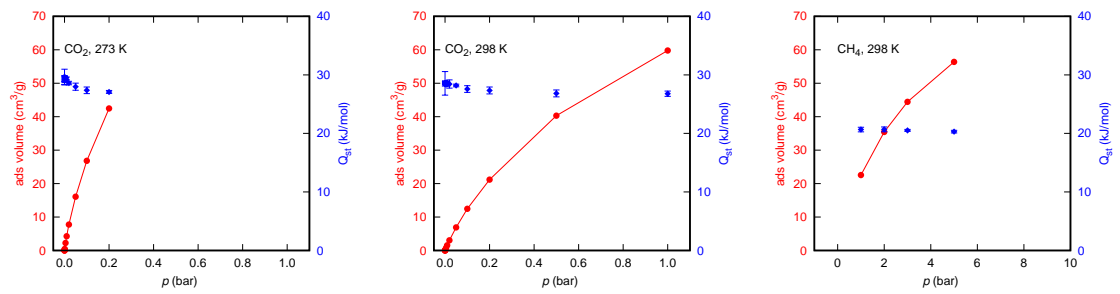


\section{PIM-Colina-id031}
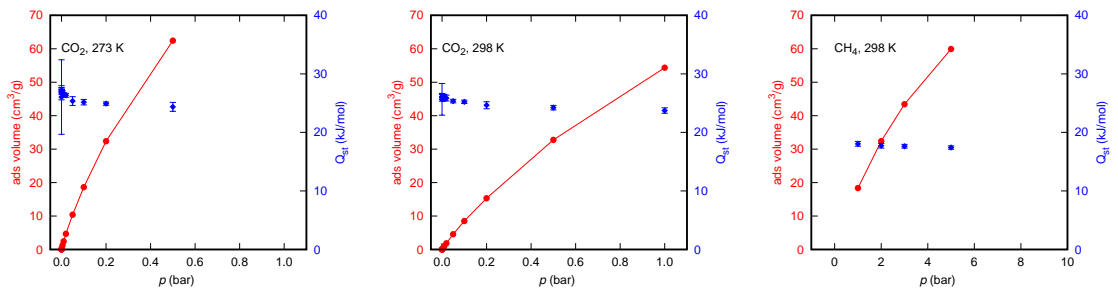


\section{PIM-Colina-id032}
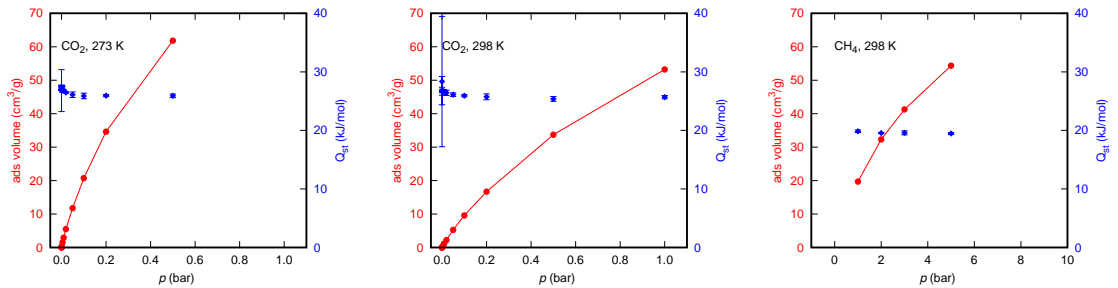


\section{PIM-Colina-id033}
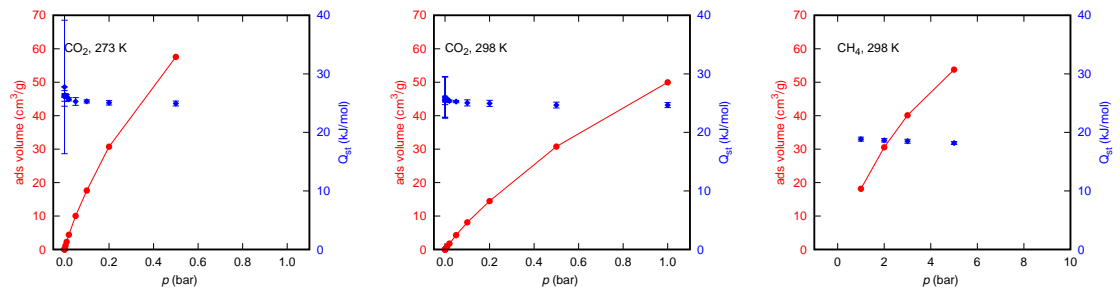


\section{PIM-Colina-id034}
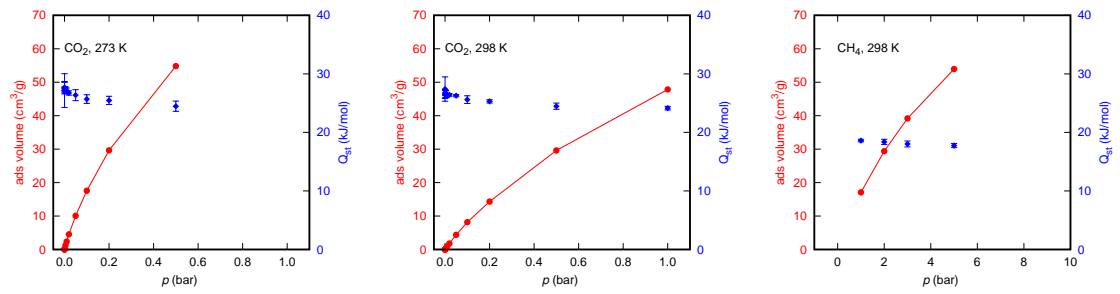


\section{PIM-Colina-id035}
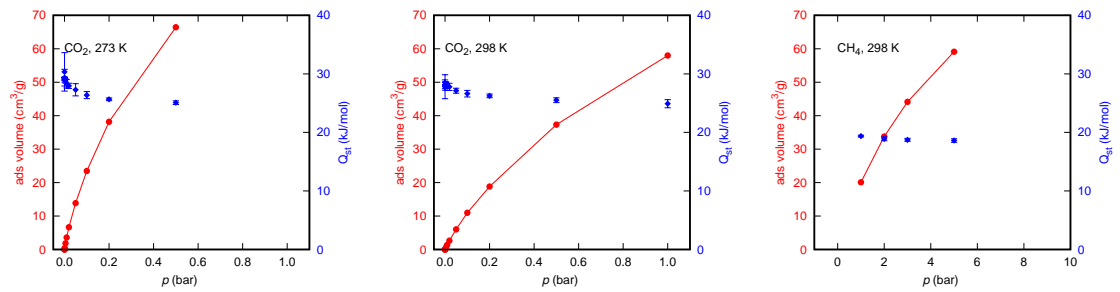


\section{PIM-Colina-id036}
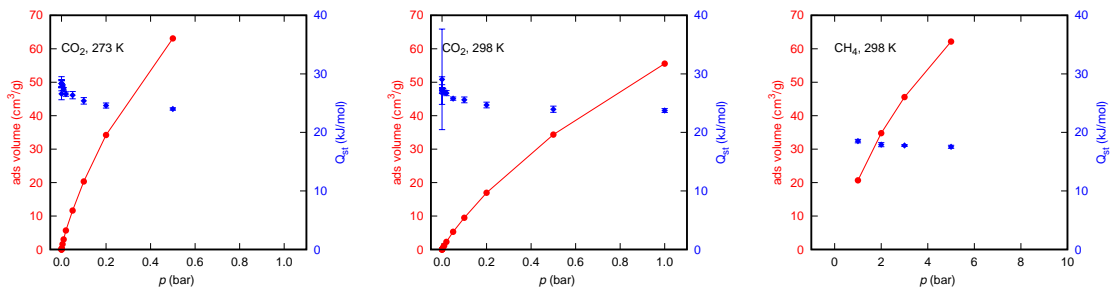


\section{PIM-Colina-id037}
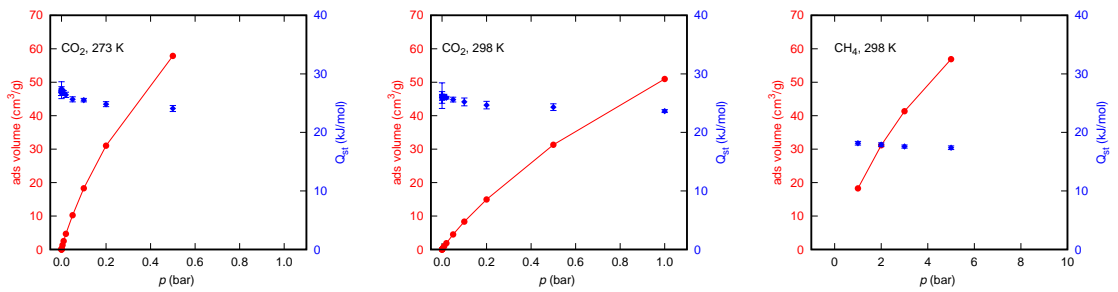


\section{PIM-Colina-id038}
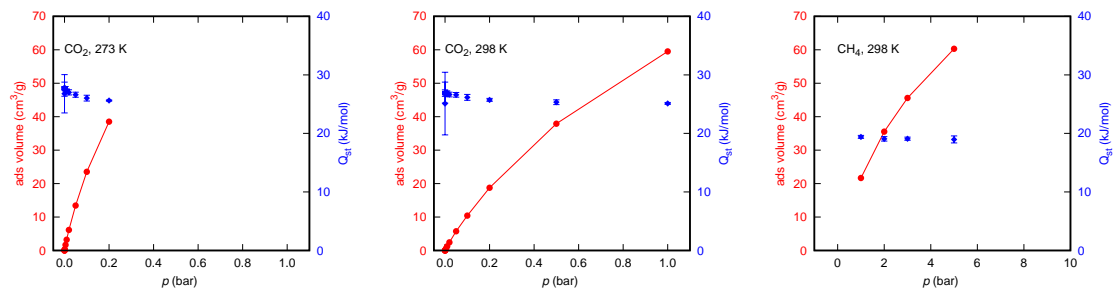


\section{PIM-Colina-id039}
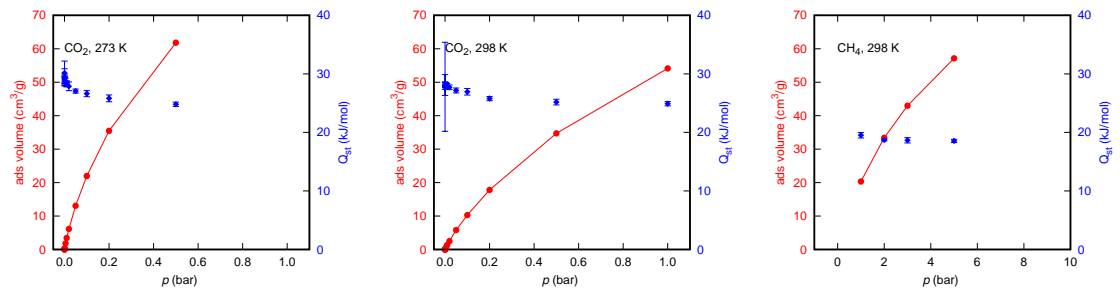


\section{PIM-Colina-id040}
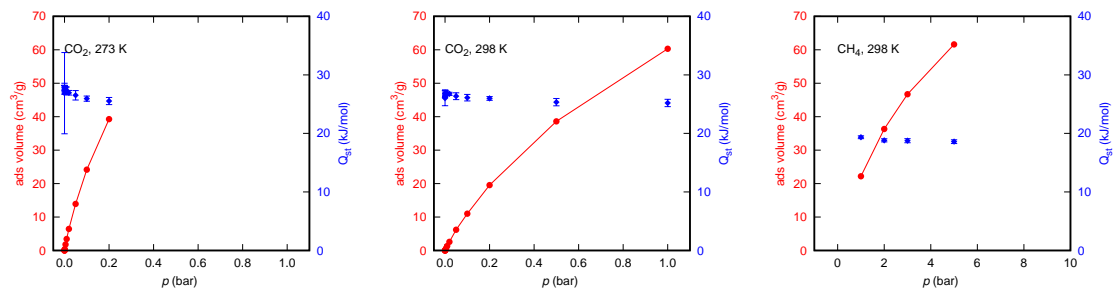


\section{PIM-Colina-id041}
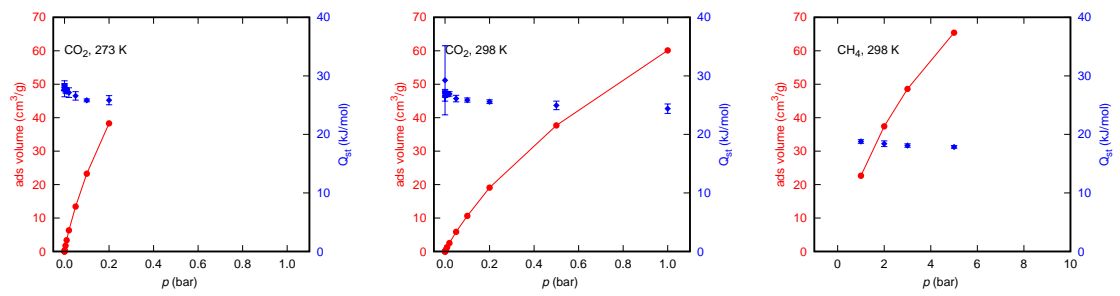


\section{PIM-Colina-id042}
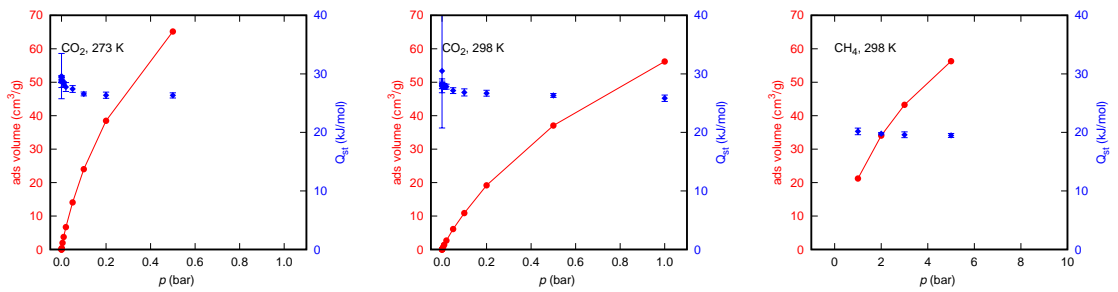


\section{PIM-Colina-id043}
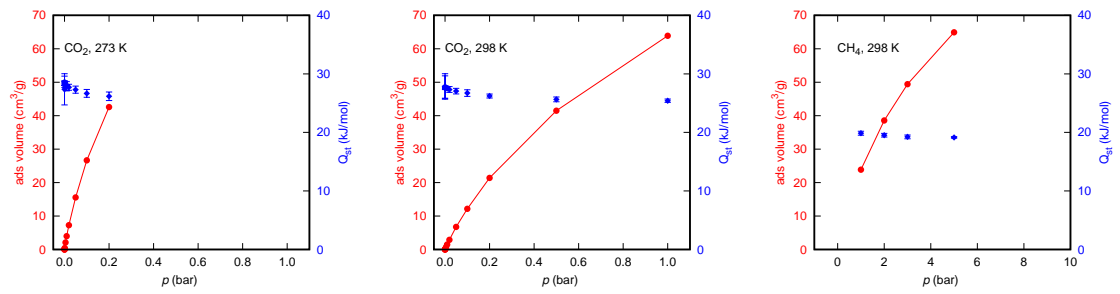


\section{PIM-Colina-id044}
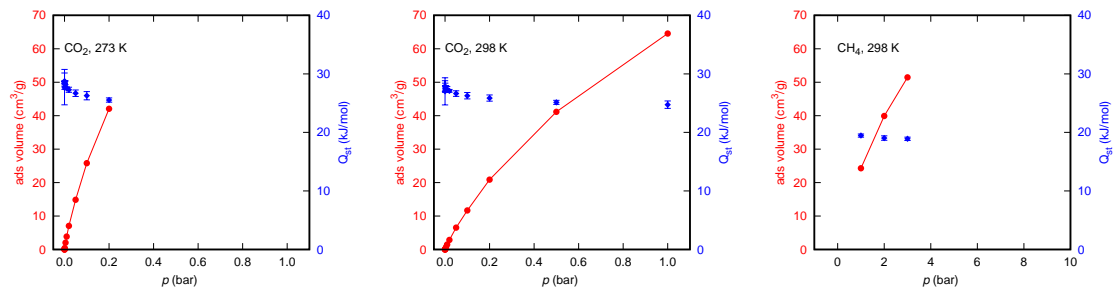


\section{PIM-Colina-id045}
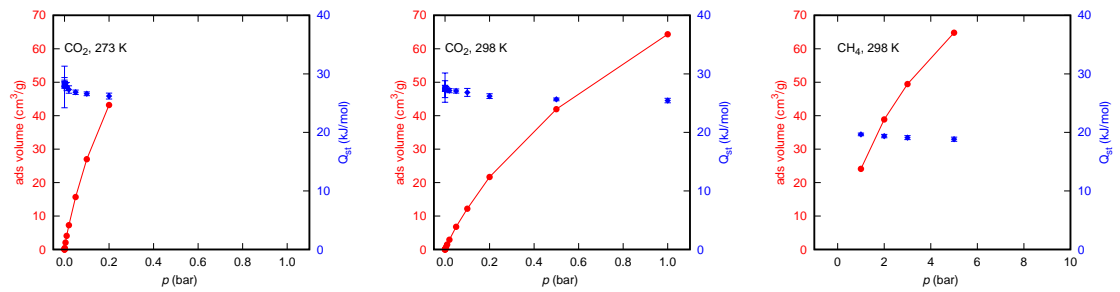


\section{PIM-Colina-id046}
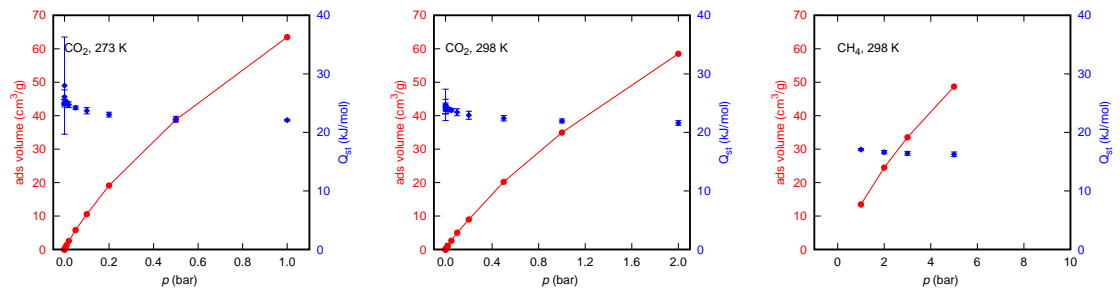


\section{PIM-Colina-id047}
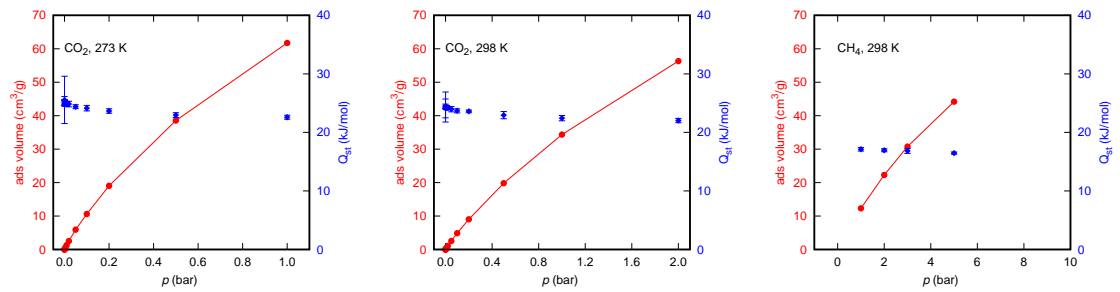


\section{PIM-Colina-id048}
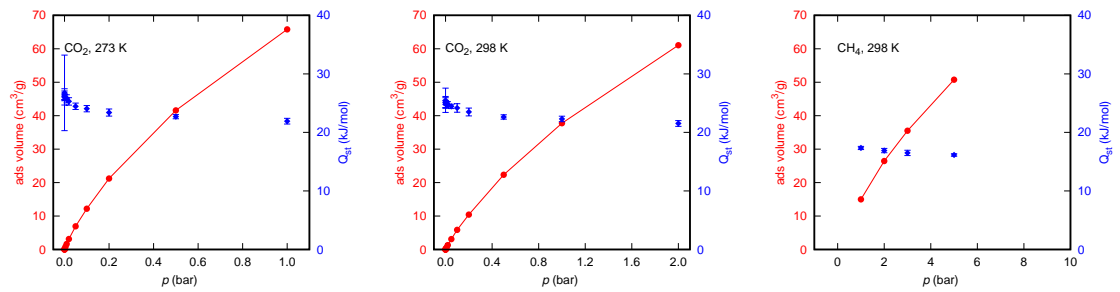


\section{PIM-Colina-id049}
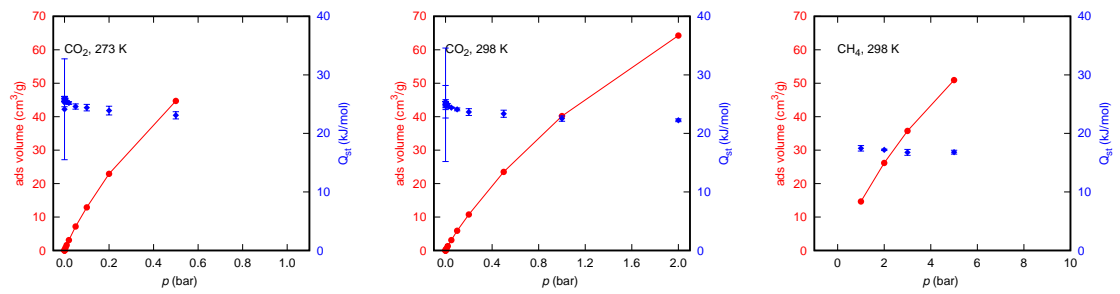


\section{PIM-Colina-id050}
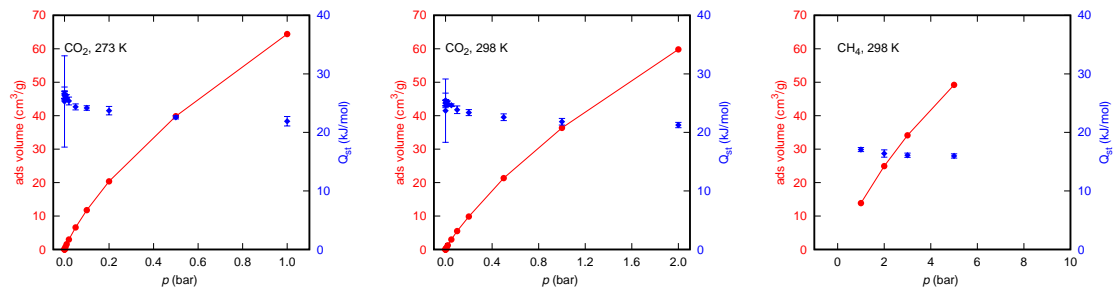


\section{PIM-Colina-id051}
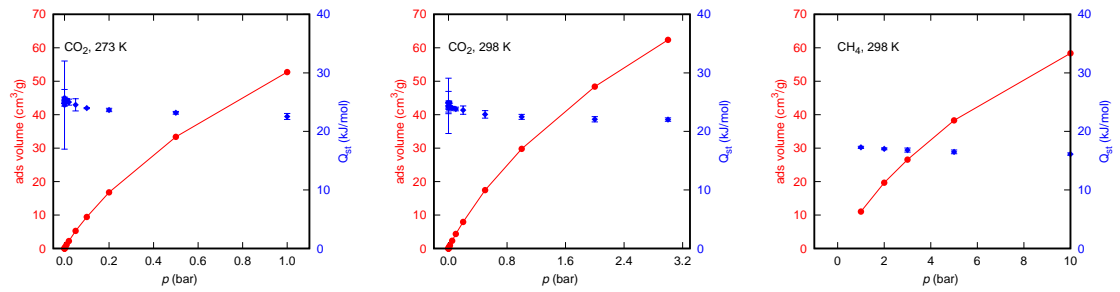


\section{PIM-Colina-id052}
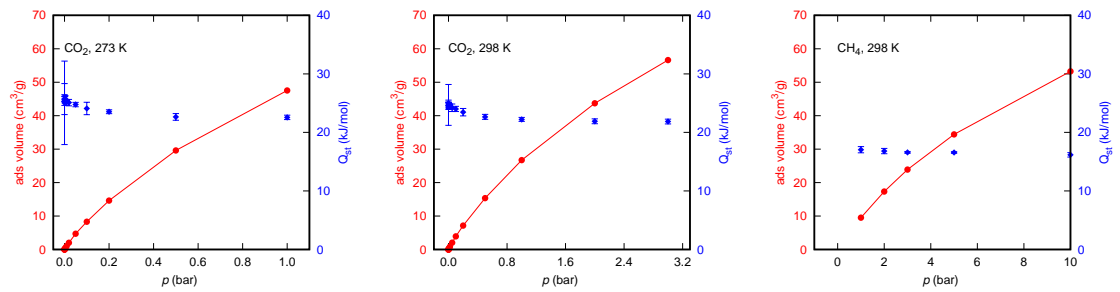


\section{PIM-Colina-id053}
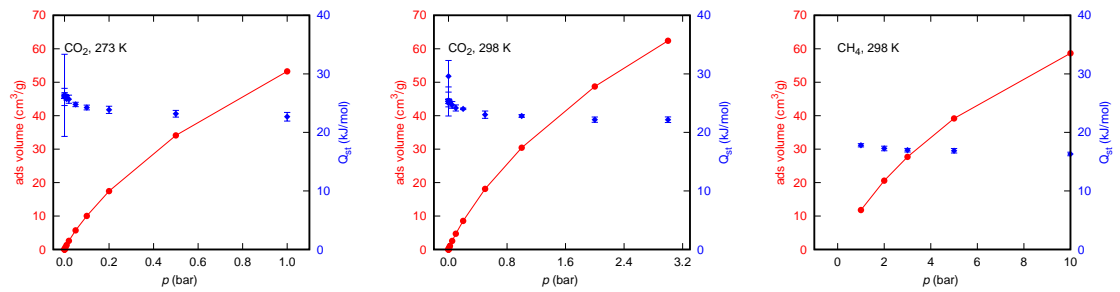


\section{PIM-Colina-id054}
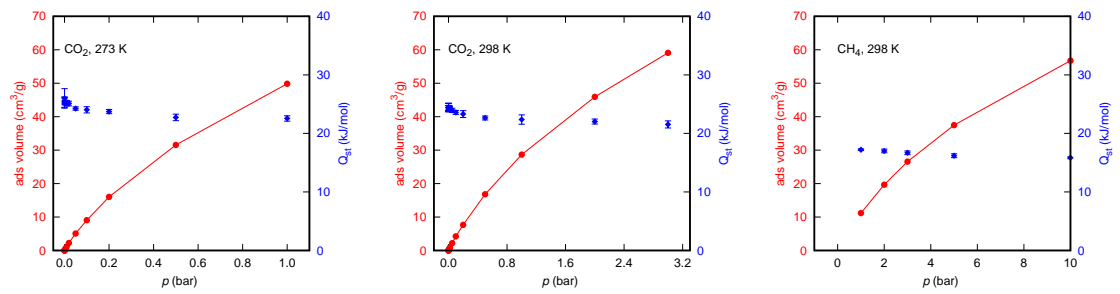


\section{PIM-Colina-id055}
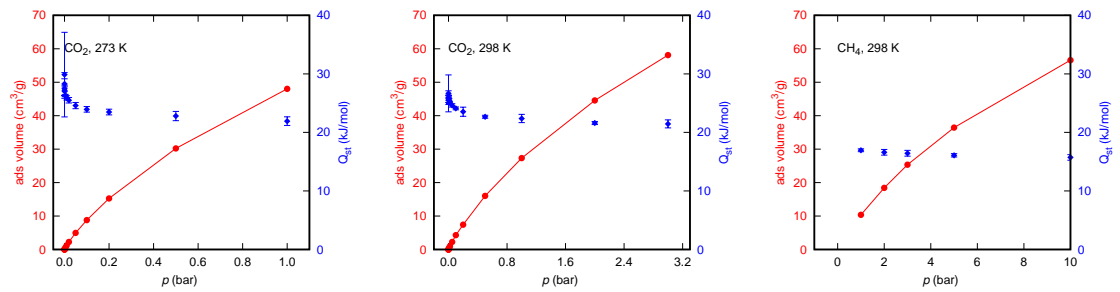


\section{PIM-Colina-id056}
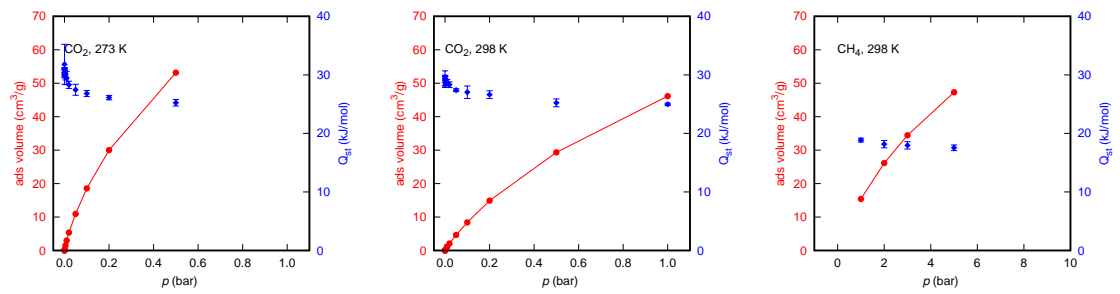


\section{PIM-Colina-id057}
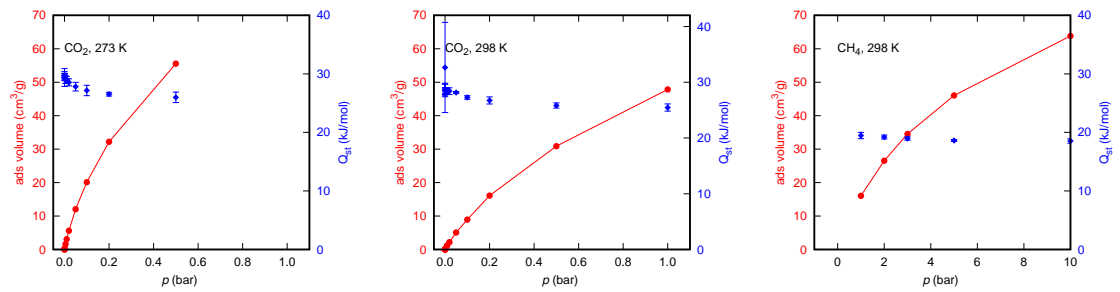


\section{PIM-Colina-id058}
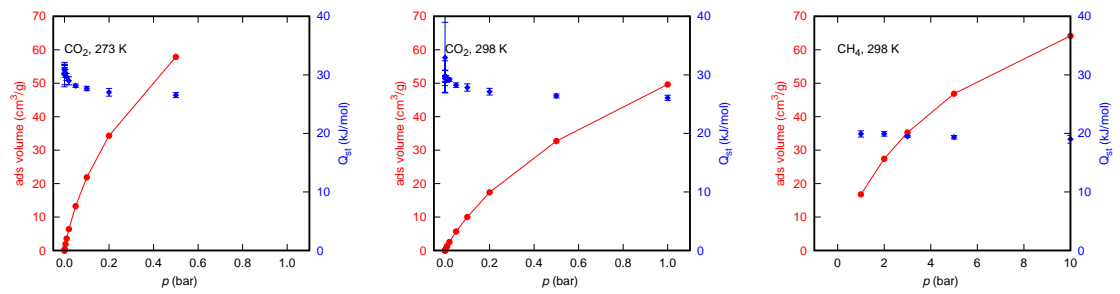


\section{PIM-Colina-id059}
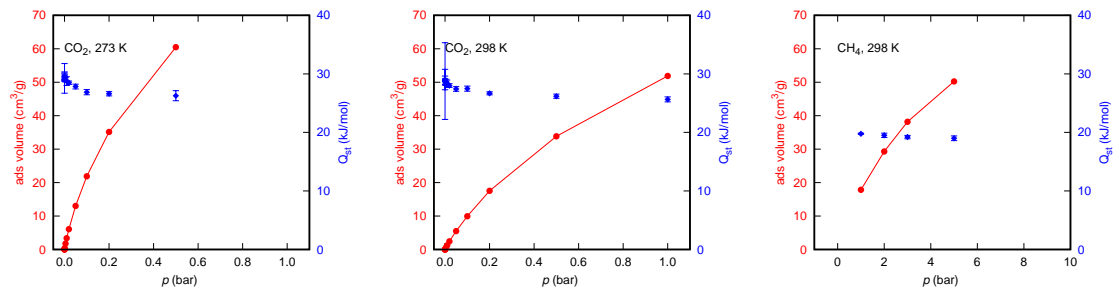


\section{PIM-Colina-id060}
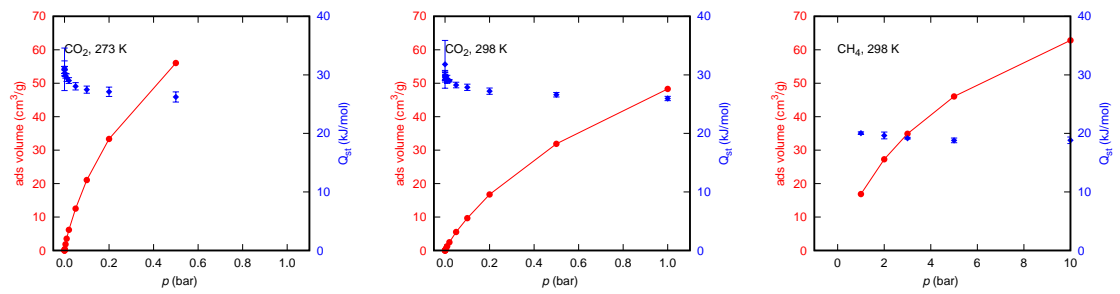


\section{PIM-Colina-id061}
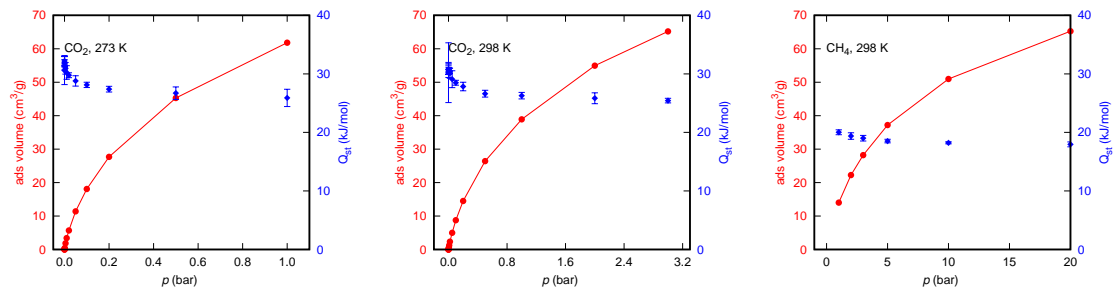


\section{PIM-Colina-id062}
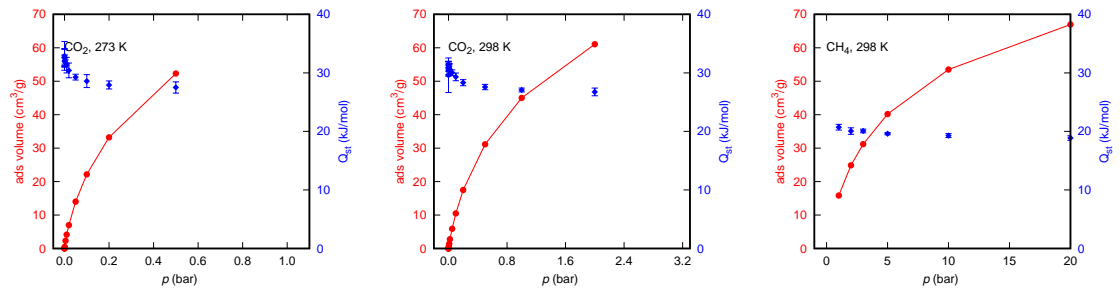


\section{PIM-Colina-id063}
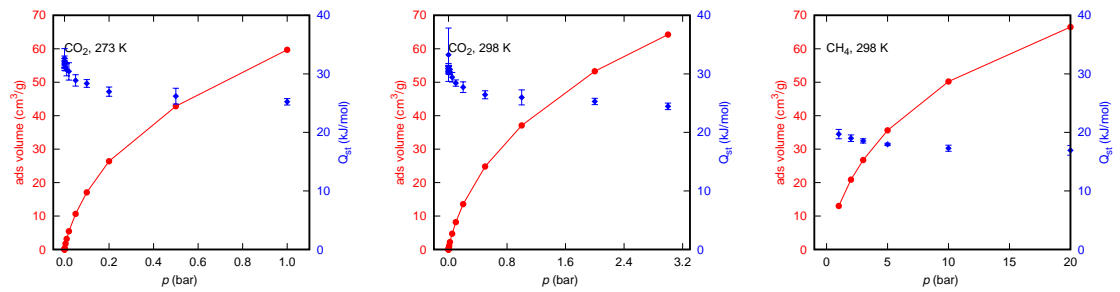


\section{PIM-Colina-id064}
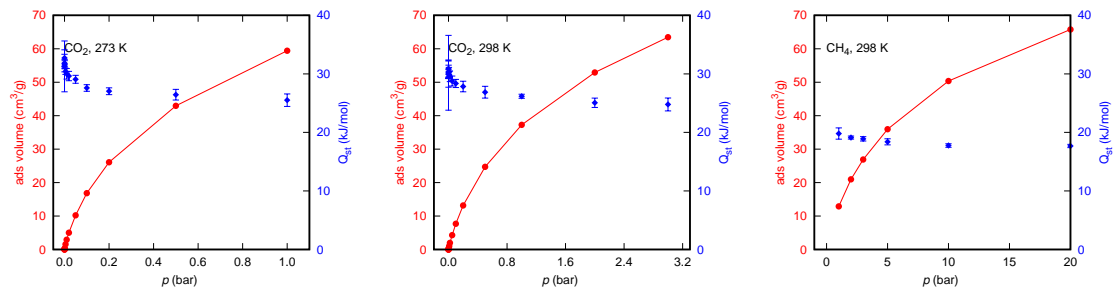


\section{PIM-Colina-id065}
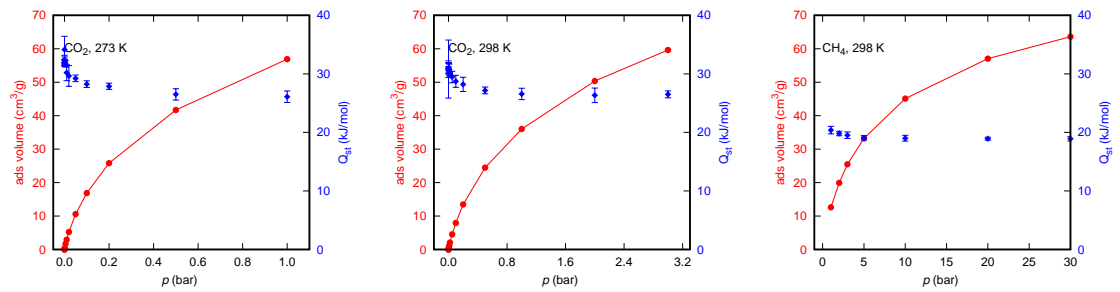


\section{PIM-Colina-id066}
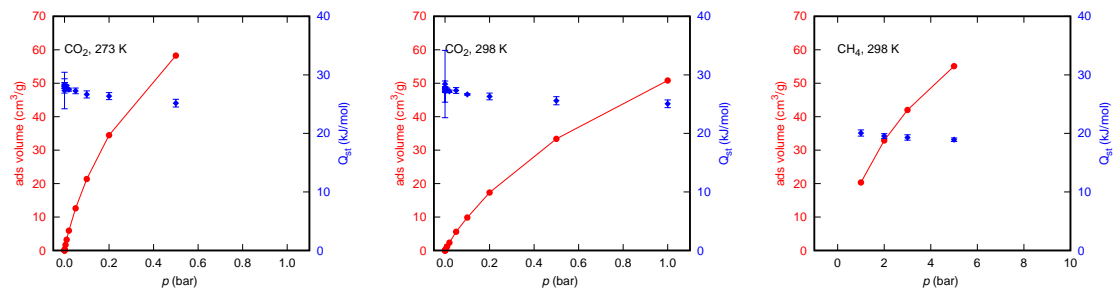


\section{PIM-Colina-id067}
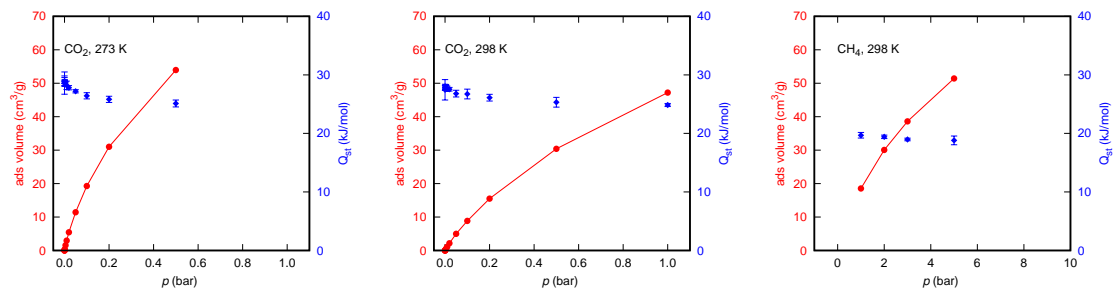


\section{PIM-Colina-id068}
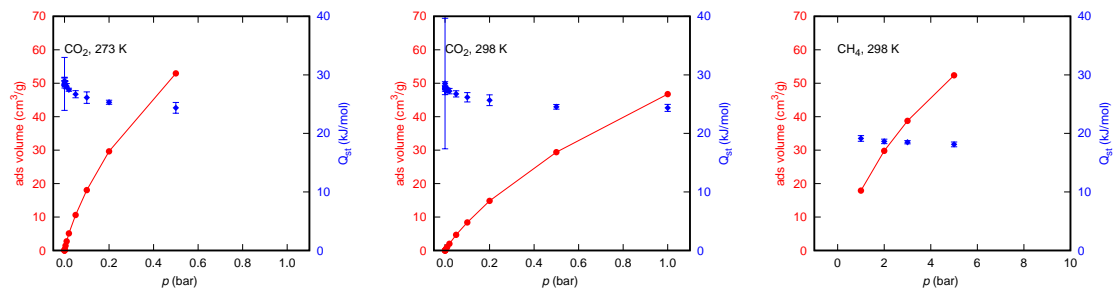


\section{PIM-Colina-id069}
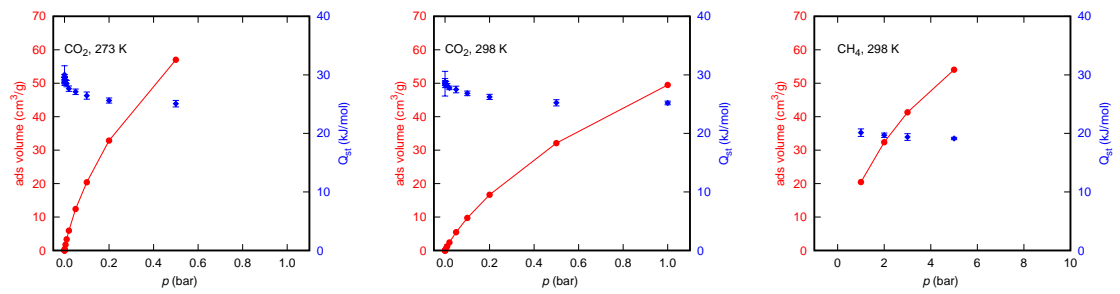


\section{PIM-Colina-id070}
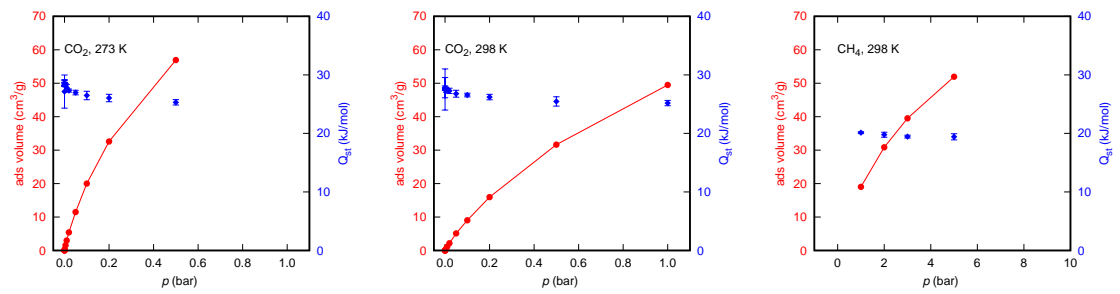


\section{PIM-Colina-id071}
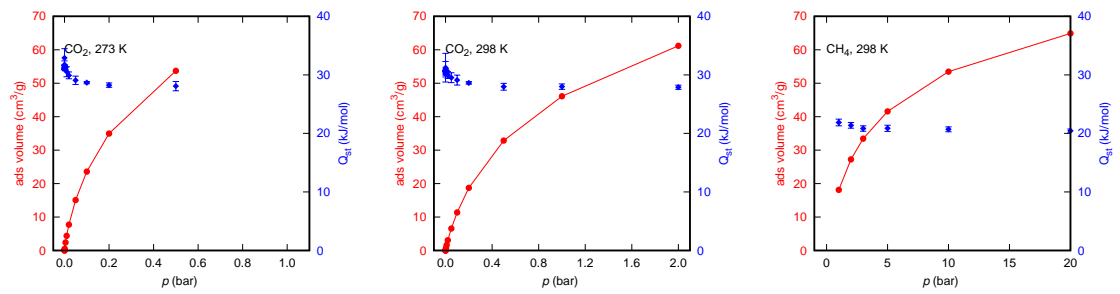


\section{PIM-Colina-id072}
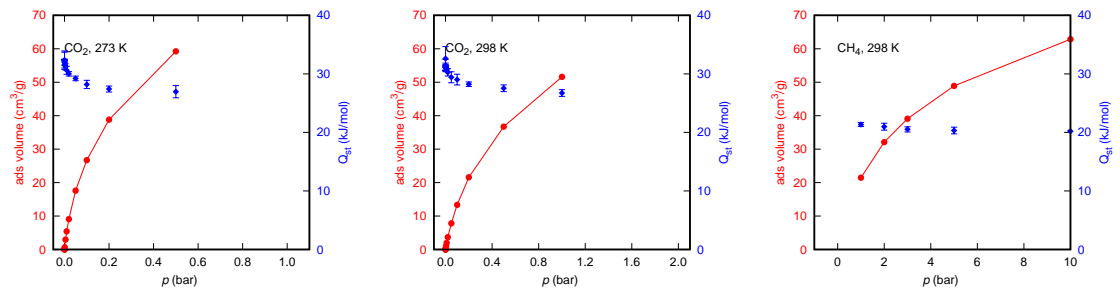


\section{PIM-Colina-id073}
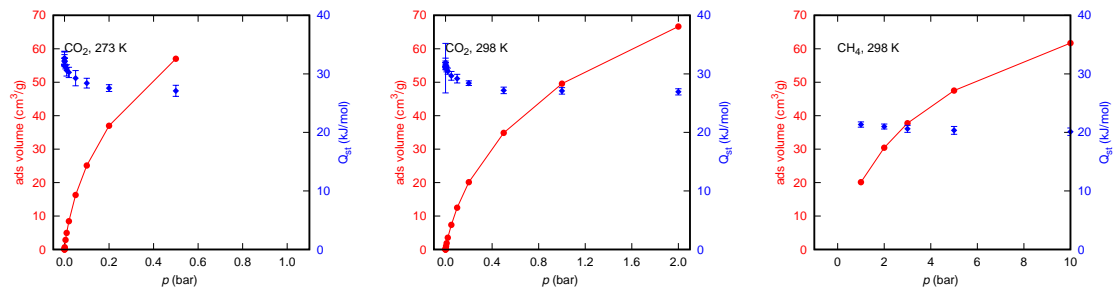


\section{PIM-Colina-id074}
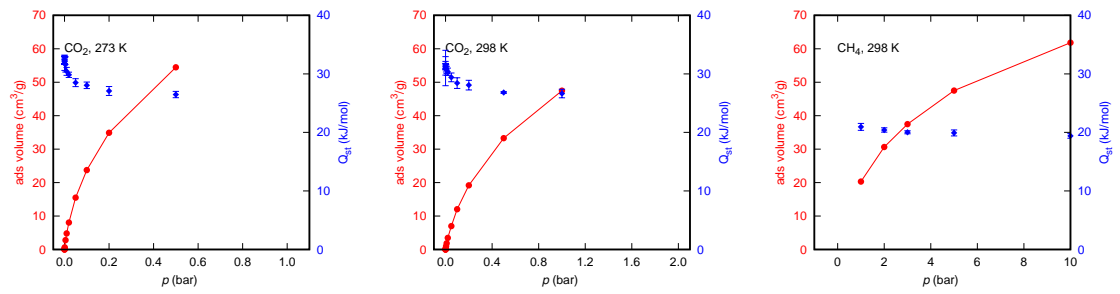


\section{PIM-Colina-id075}
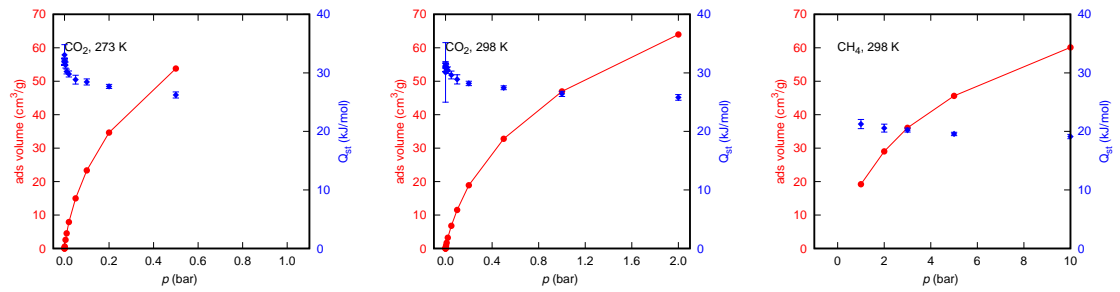


\section{aCarbon-Bhatia-id001}
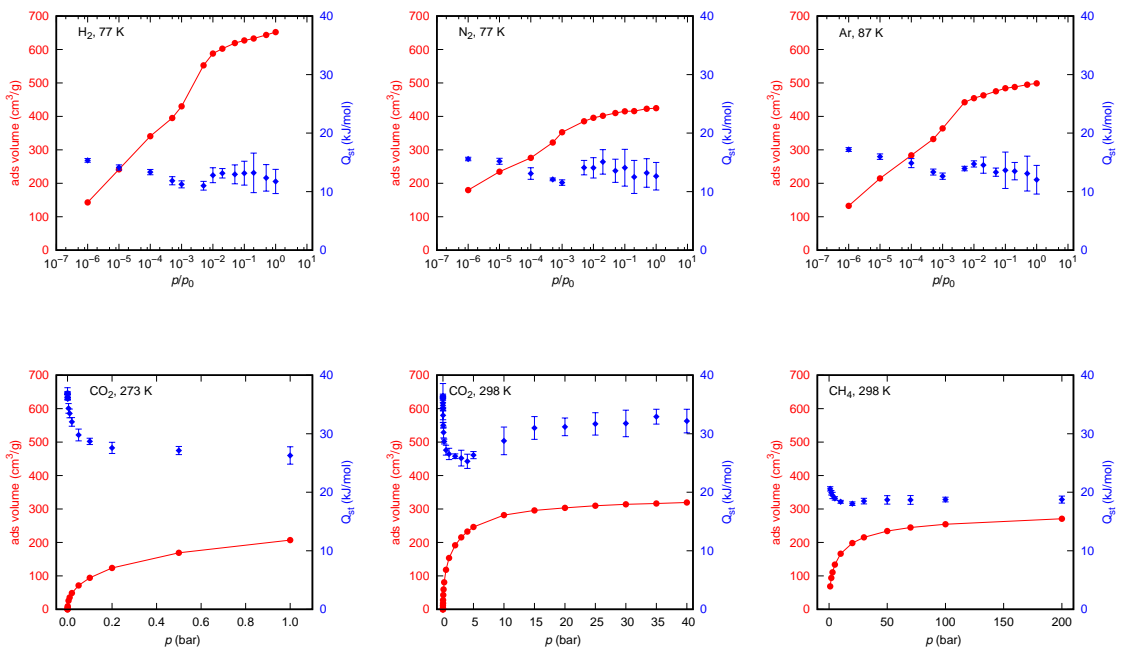


\section{aCarbon-Bhatia-id002}
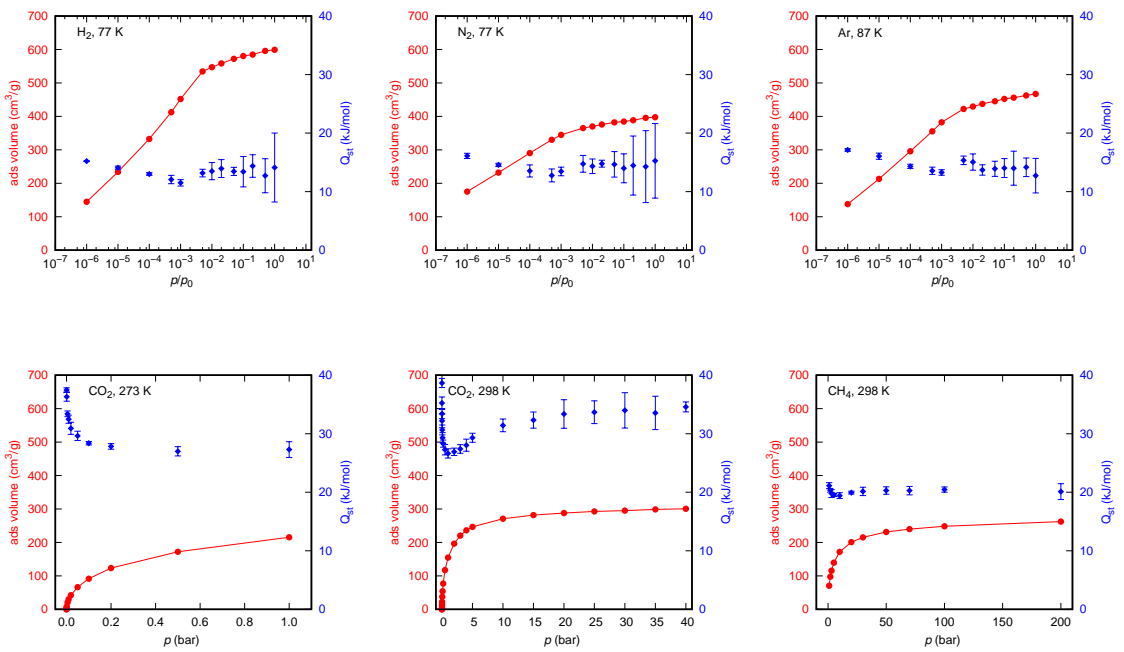


\section{aCarbon-Bhatia-id003}
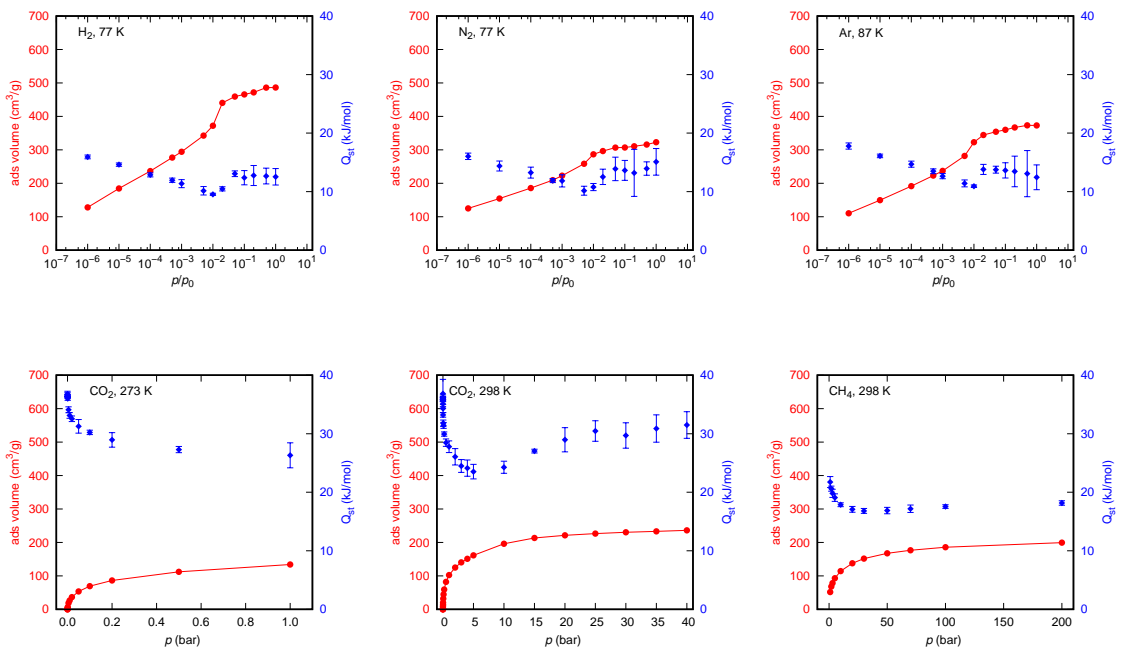


\section{aCarbon-Marks-id001}
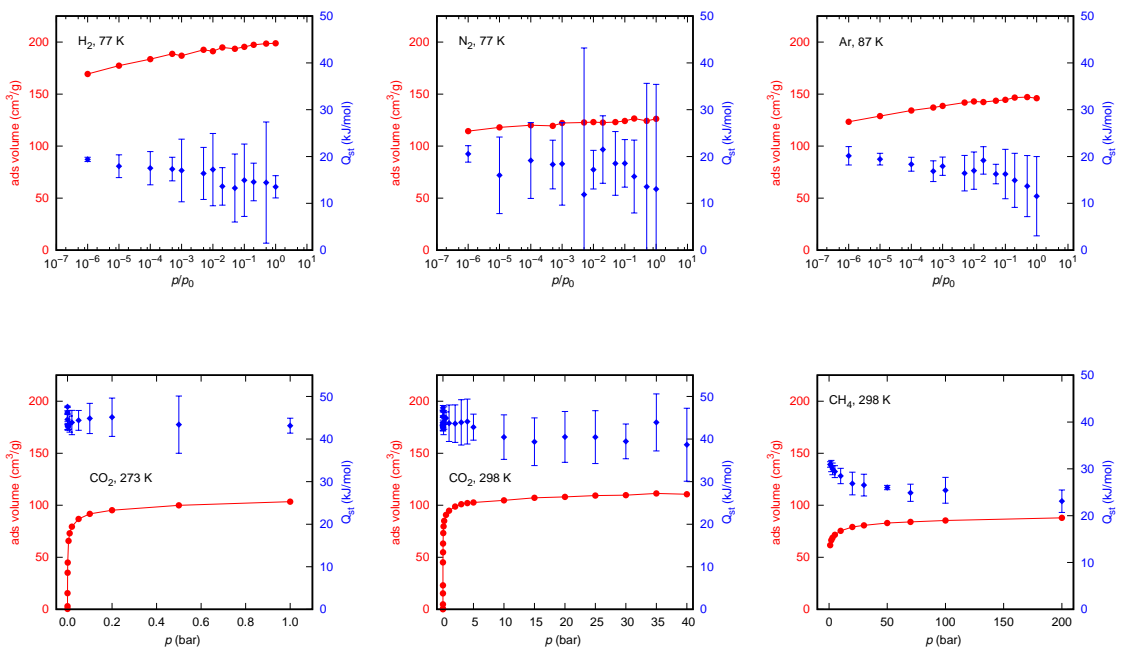


\section{aCarbon-Marks-id002}
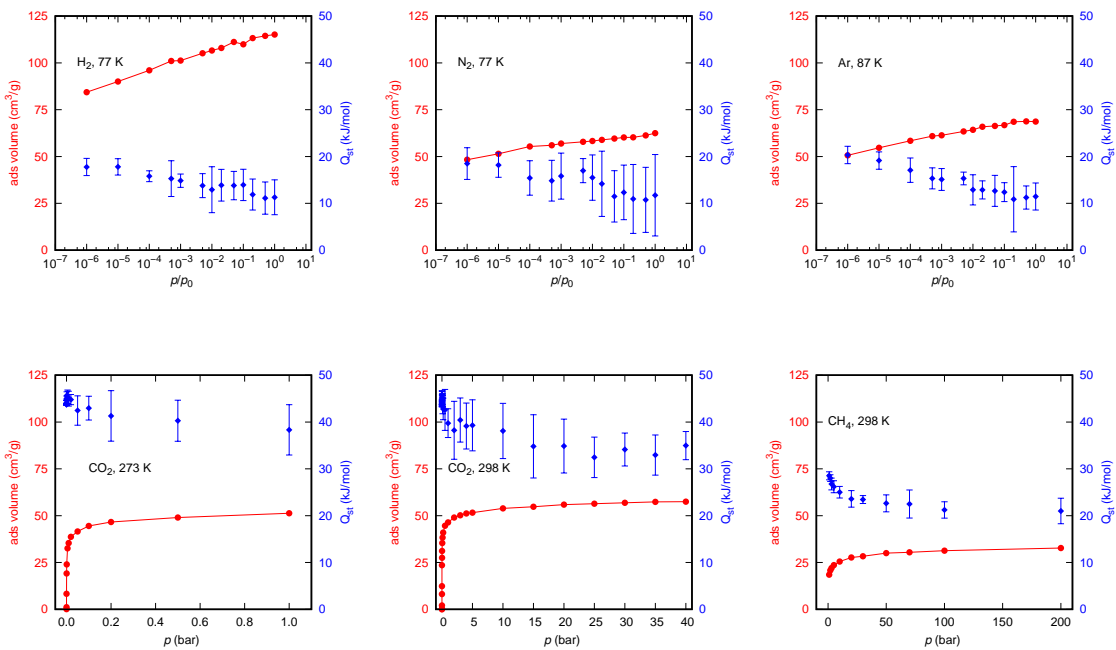


\section{HCP-Colina-id001}
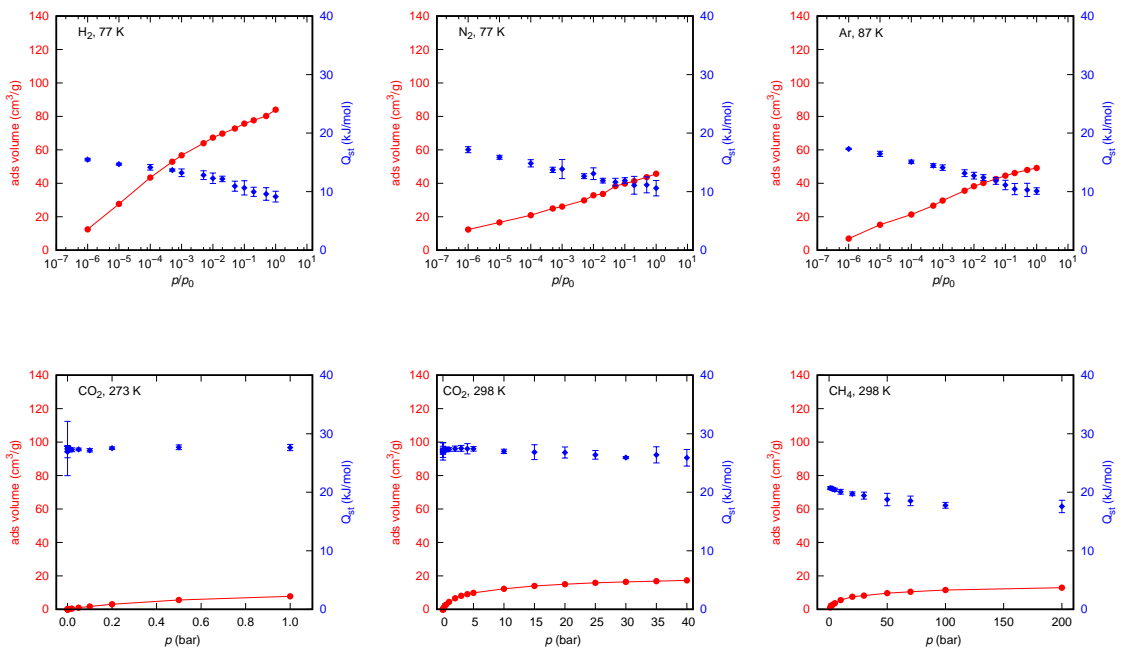


\section{HCP-Colina-id002}
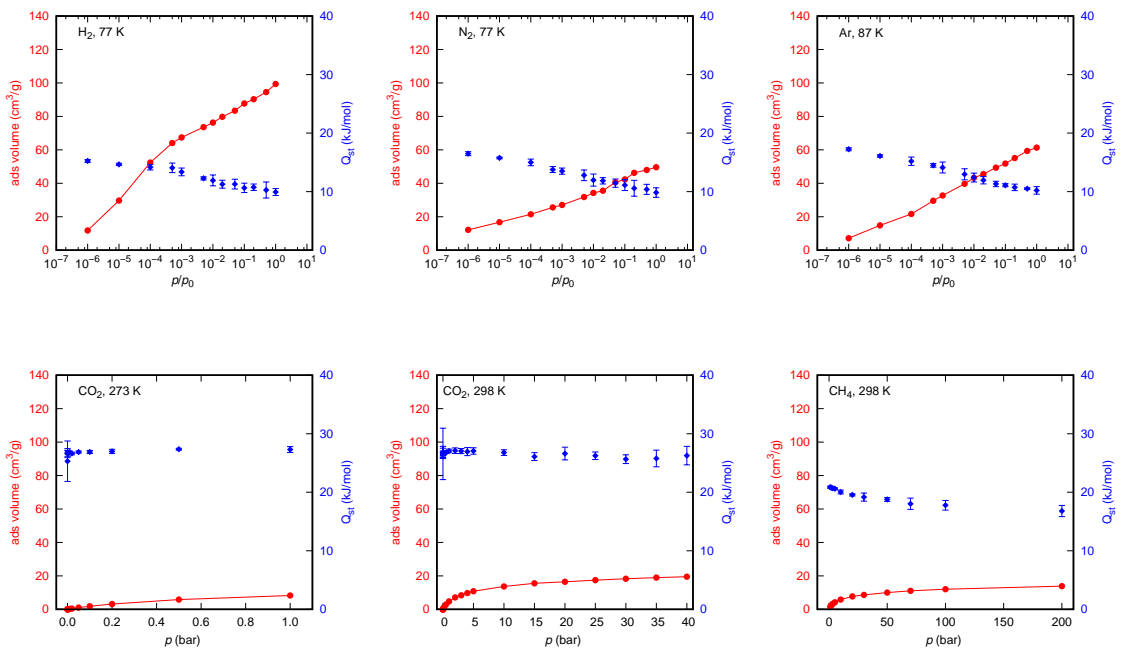


\section{HCP-Colina-id003}
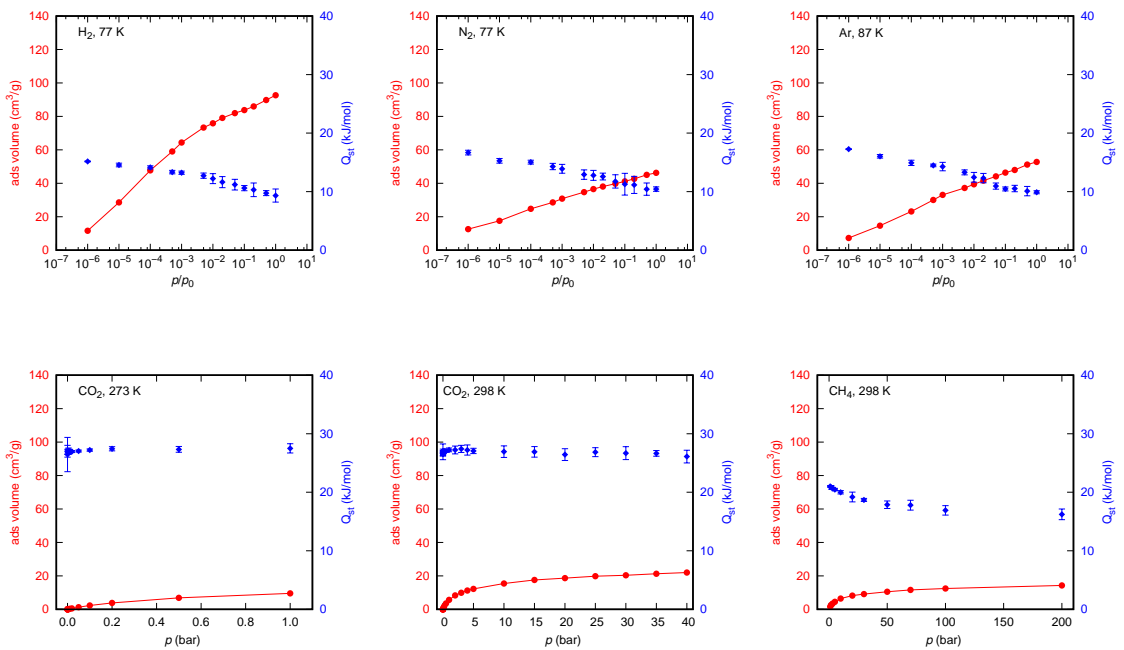


\section{HCP-Colina-id004}
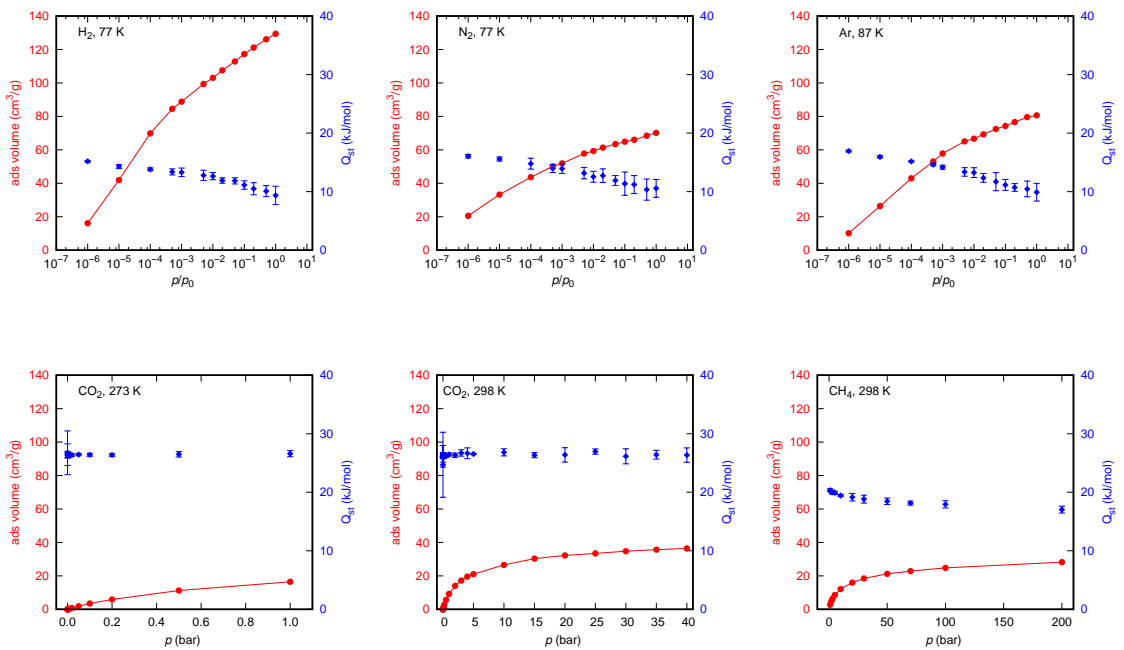


\section{HCP-Colina-id005}
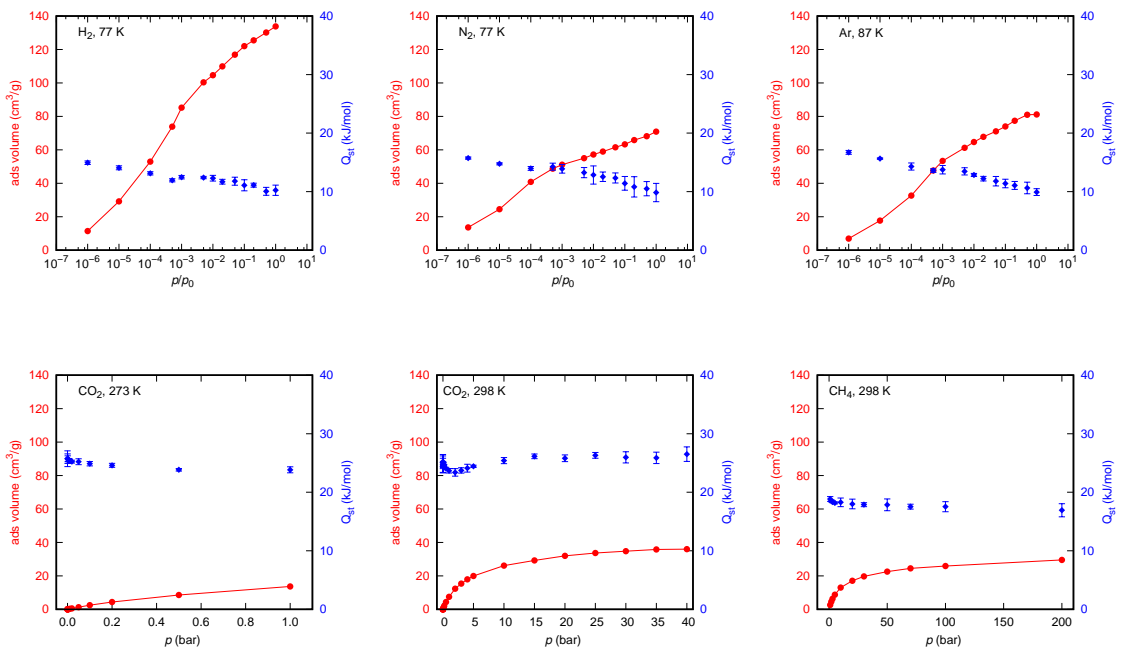


\section{HCP-Colina-id006}
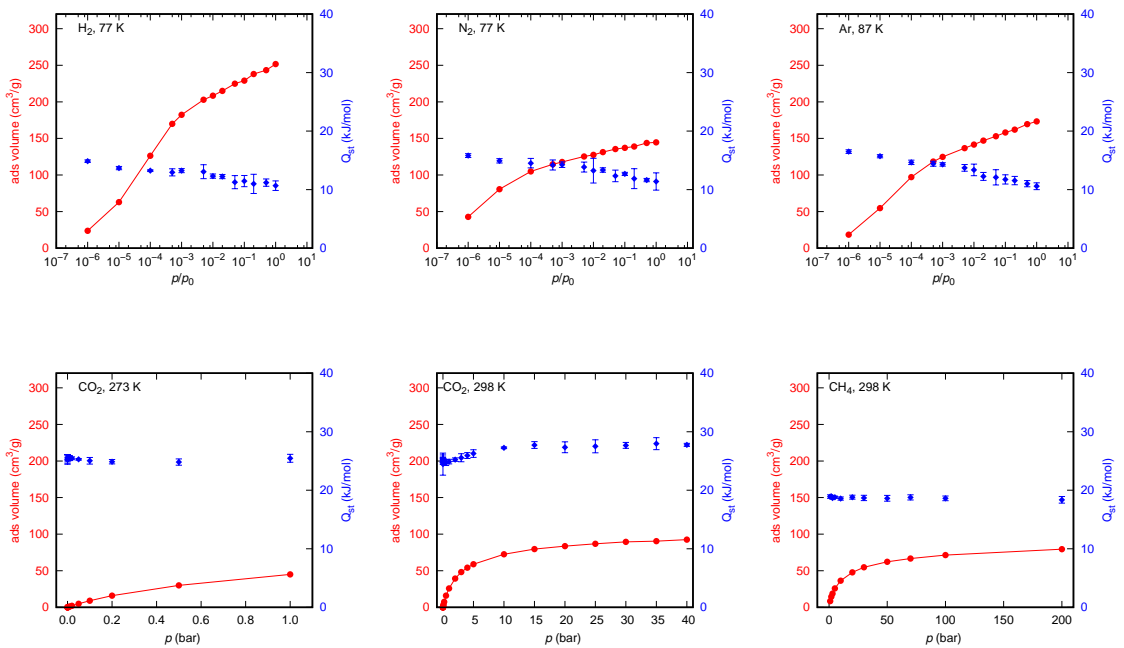


\section{HCP-Colina-id007}
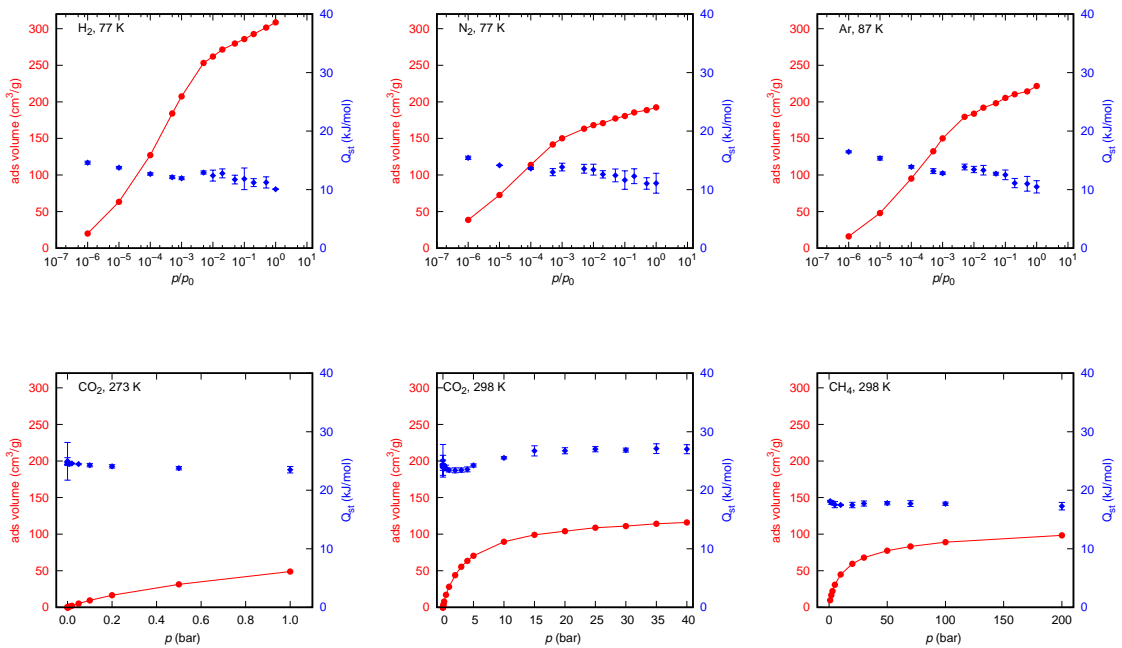


\section{HCP-Colina-id008}
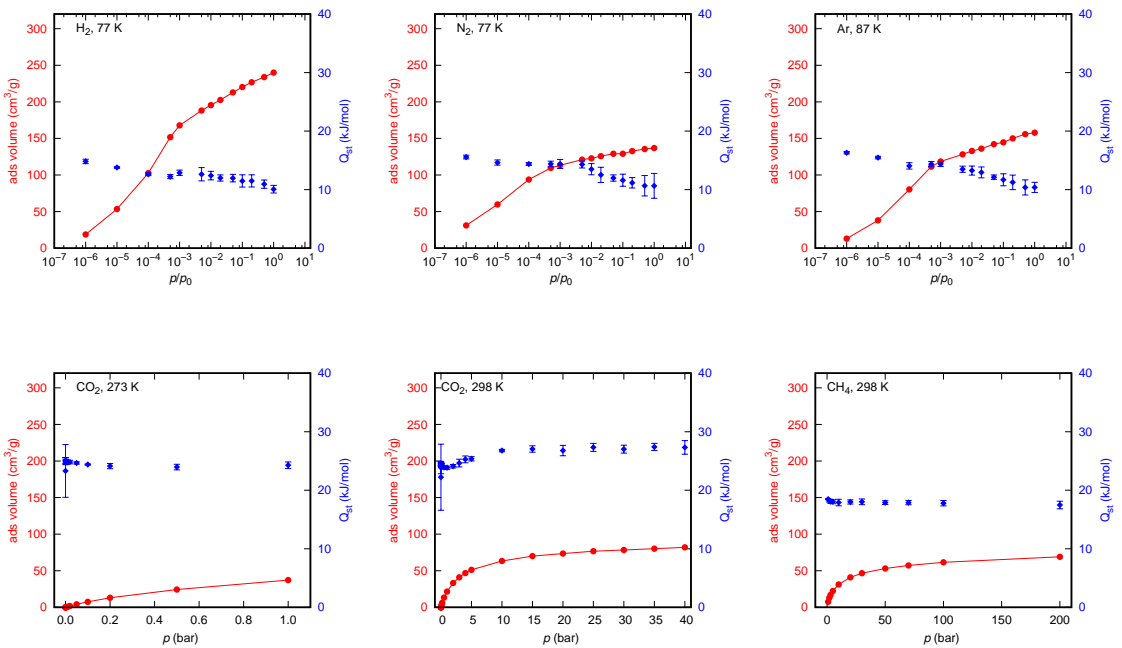


\section{HCP-Colina-id009}
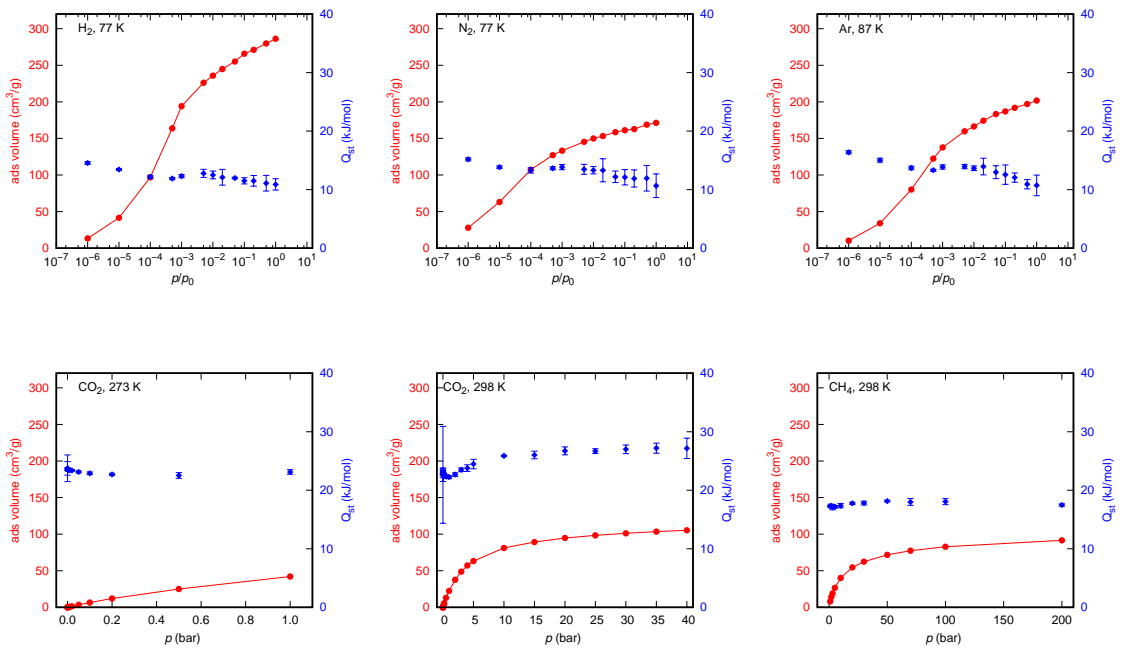


\section{HCP-Colina-id010}
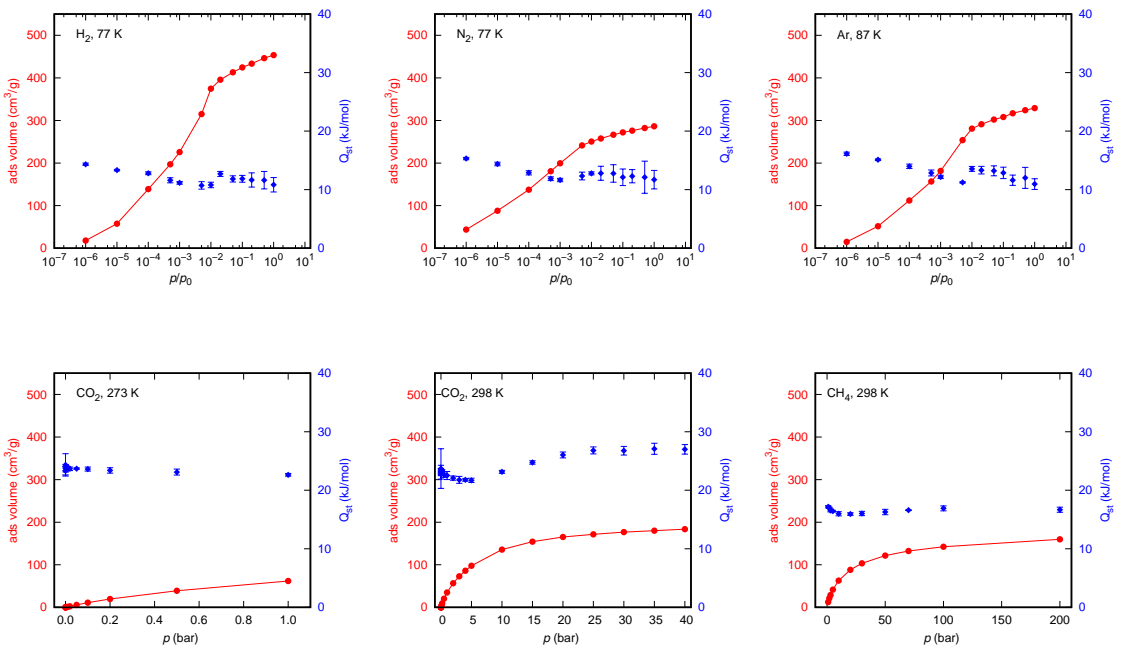


\section{HCP-Colina-id011}
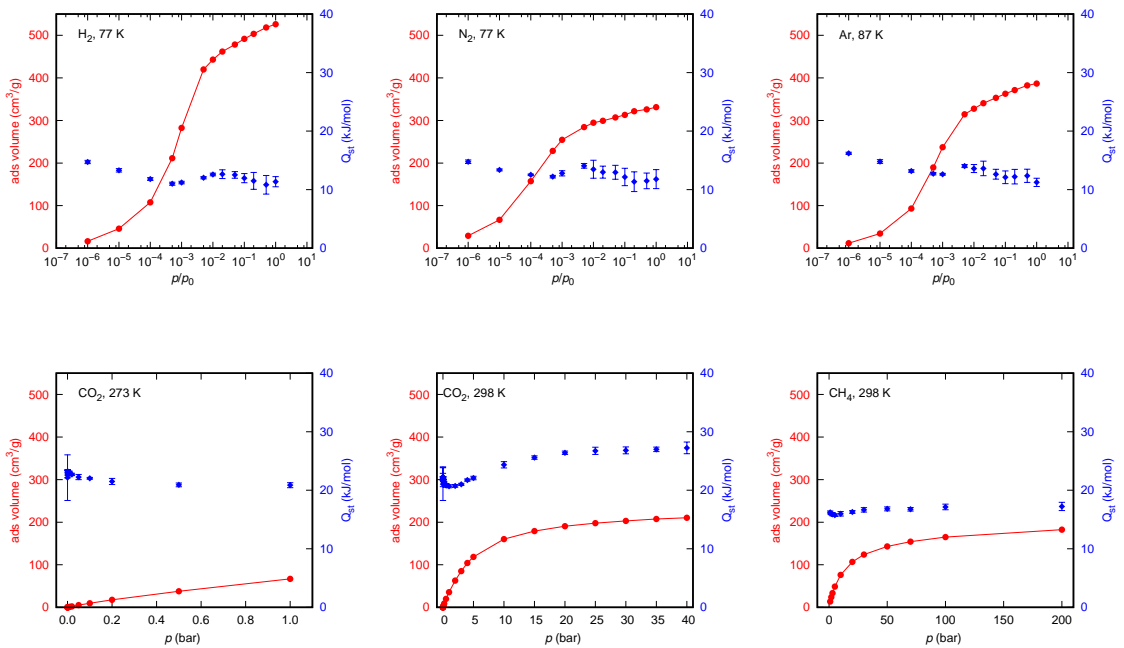


\section{HCP-Colina-id012}
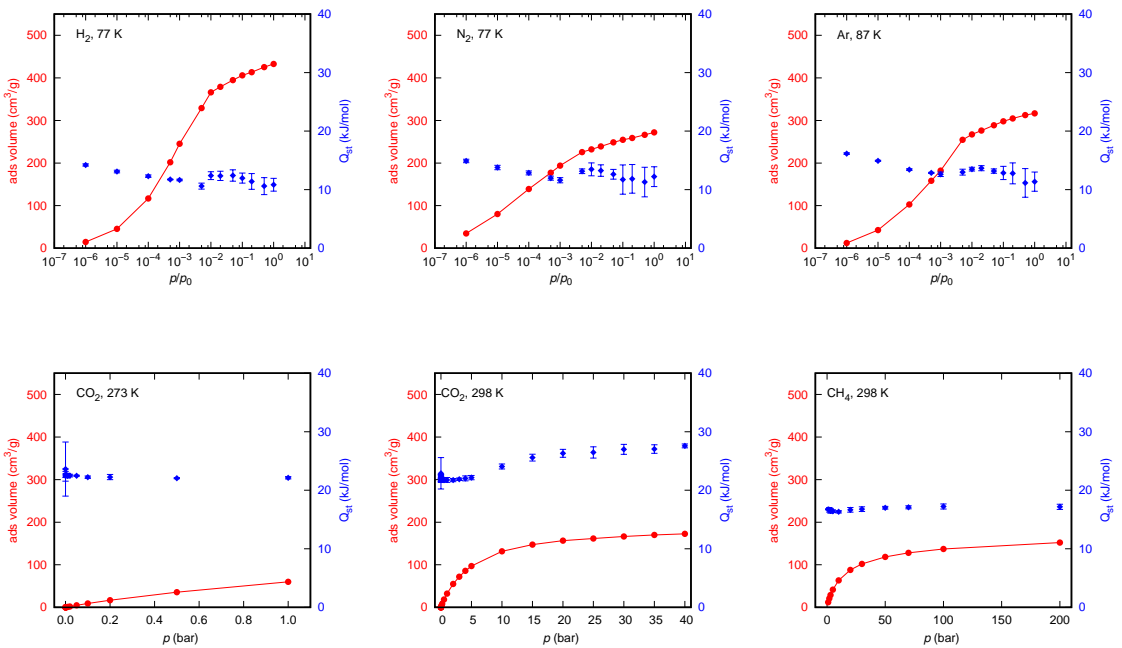


\section{HCP-Colina-id013}
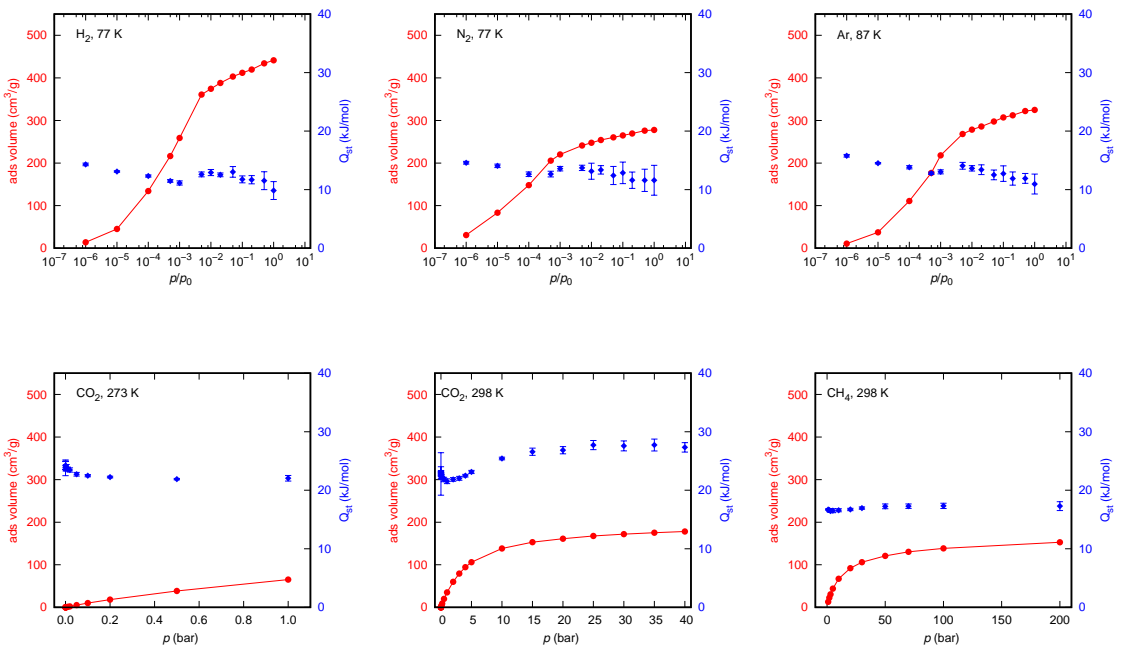


\section{HCP-Colina-id014}
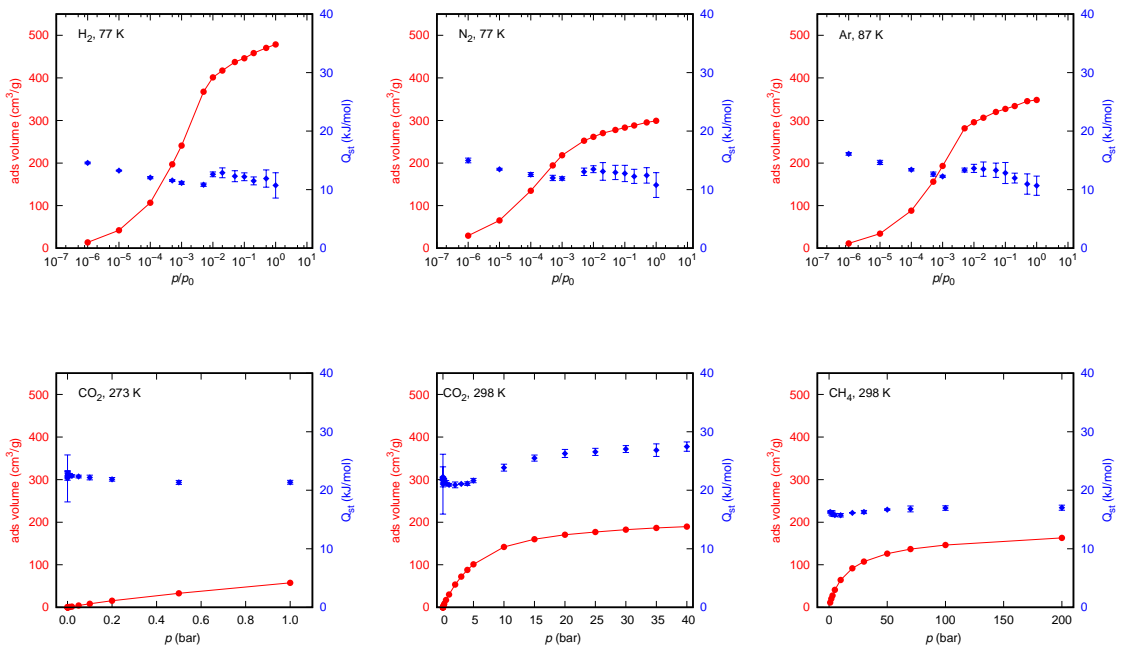


\section{HCP-Colina-id015}
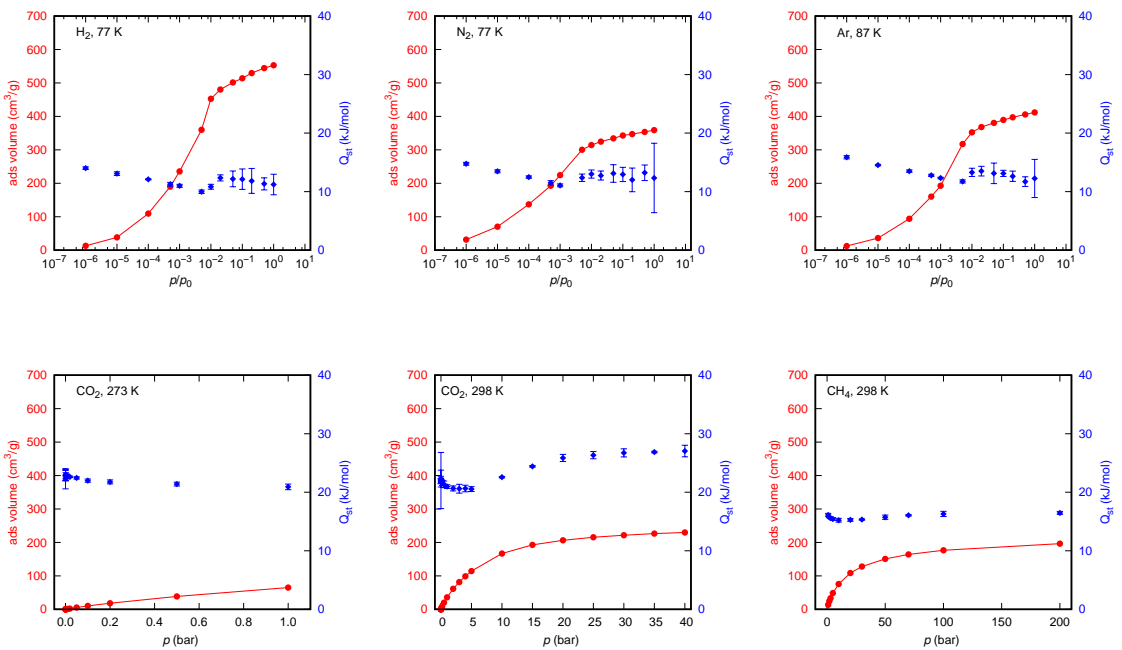


\section{HCP-Colina-id016}
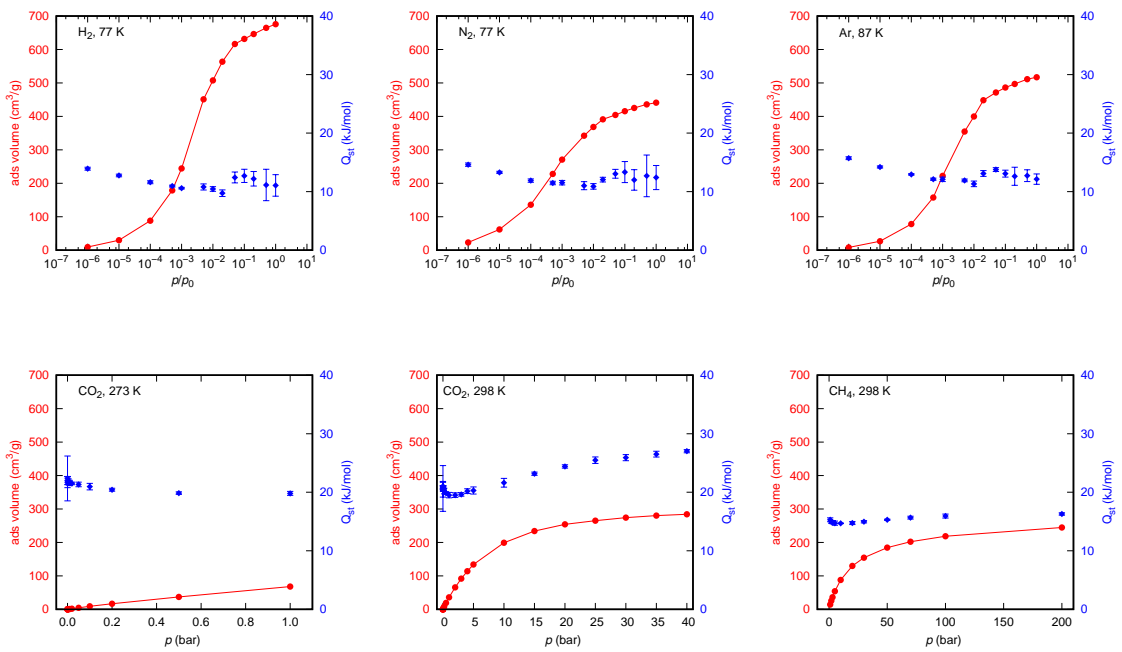


\section{HCP-Colina-id017}
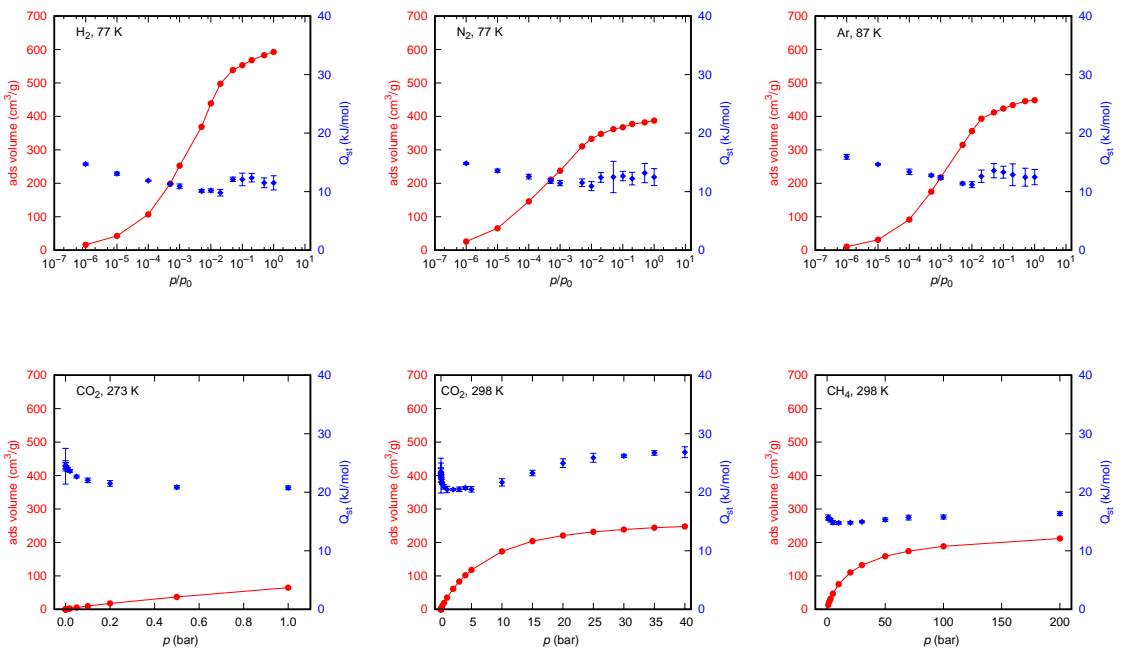


\section{HCP-Colina-id018}
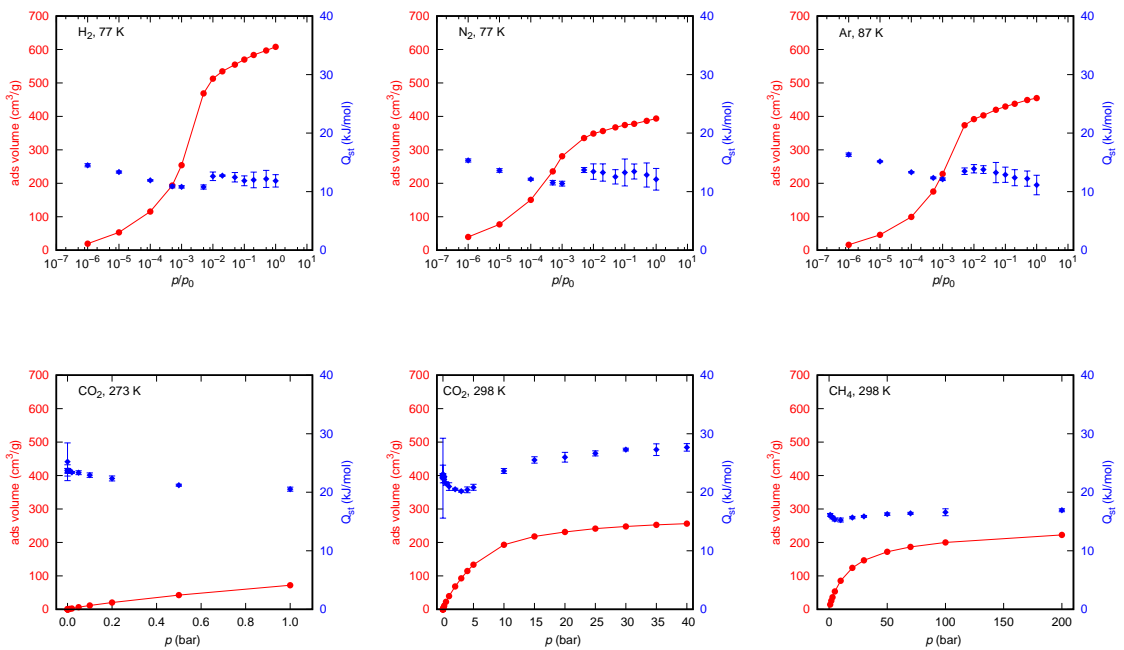


\section{HCP-Colina-id019}
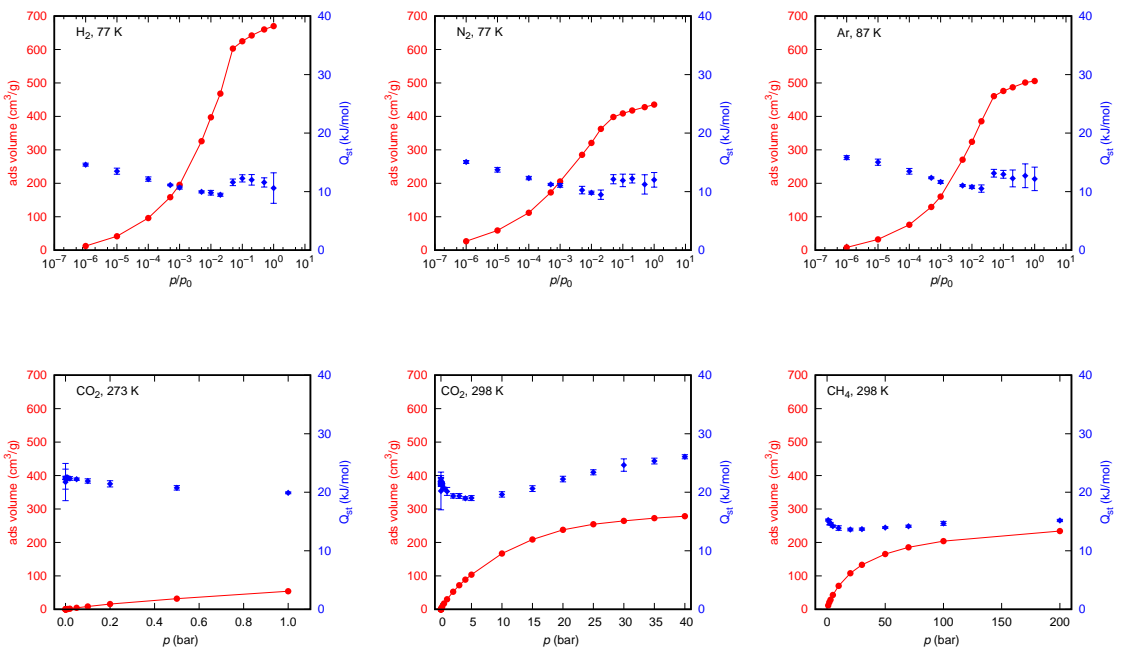


\section{HCP-Colina-id020}
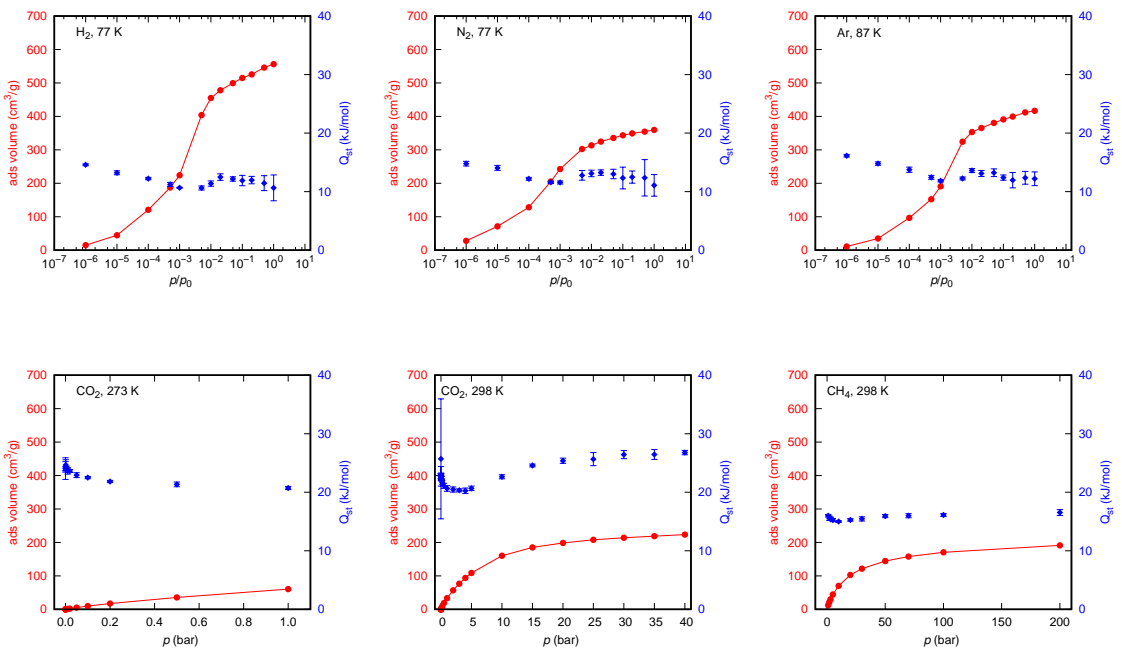


\section{HCP-Colina-id021}
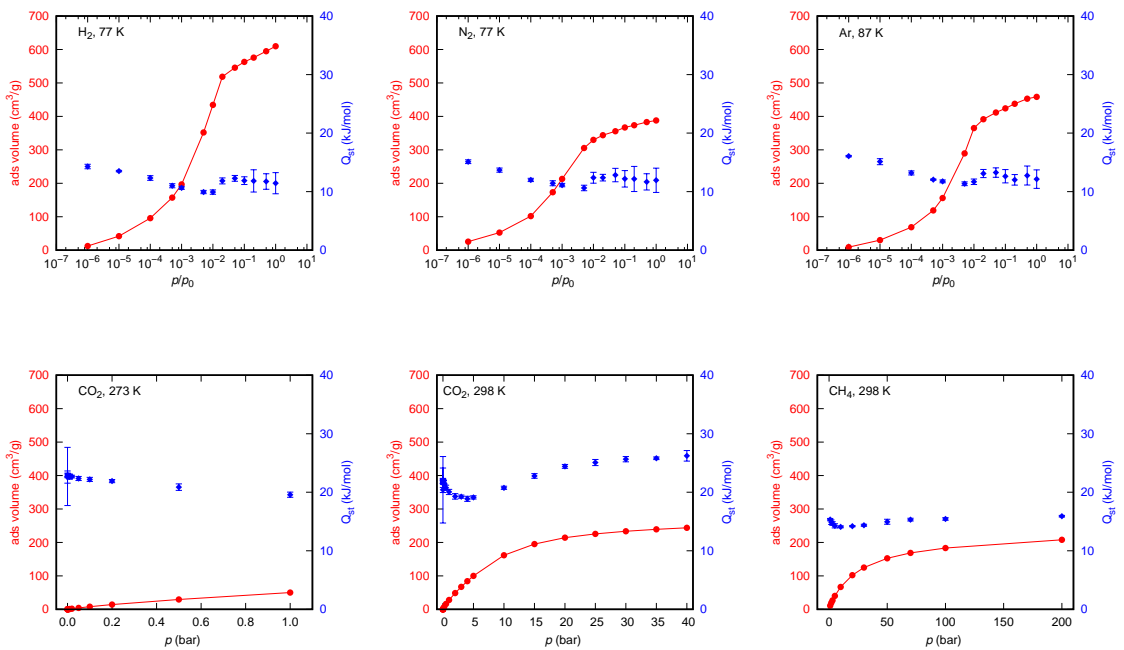


\section{HCP-Colina-id022}
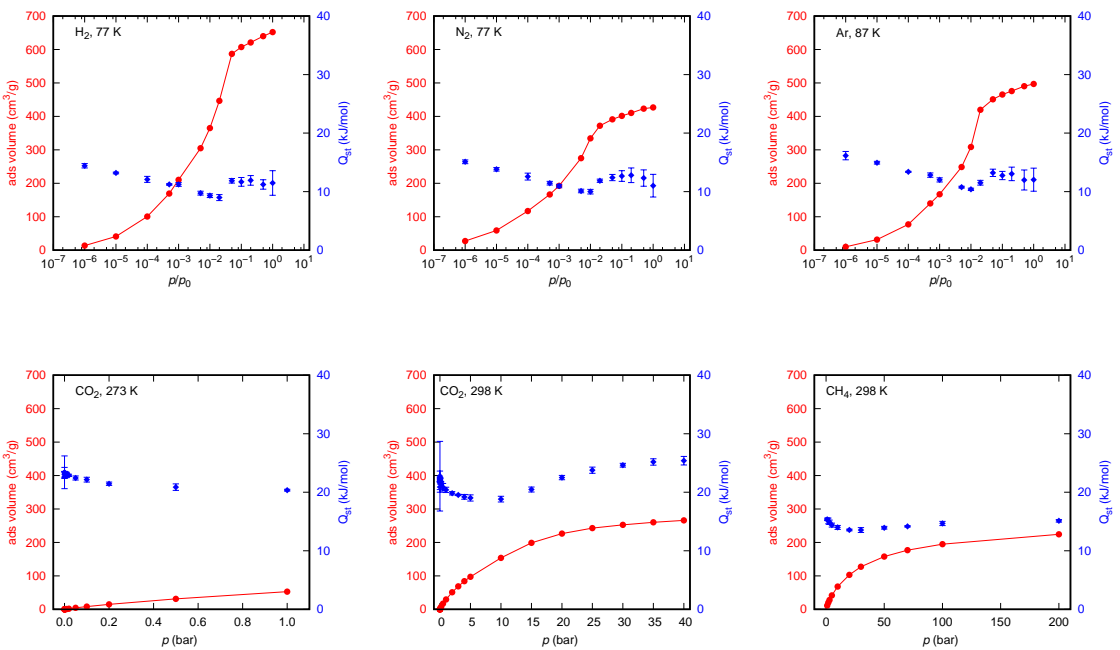


\section{HCP-Colina-id023}
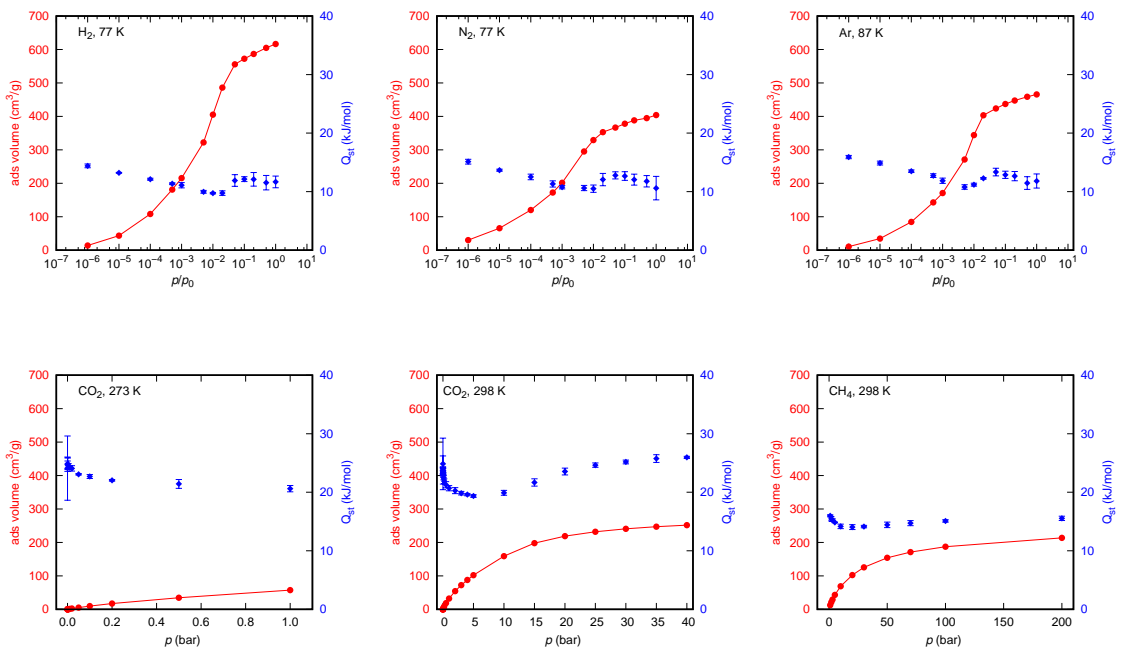


\section{HCP-Colina-id024}
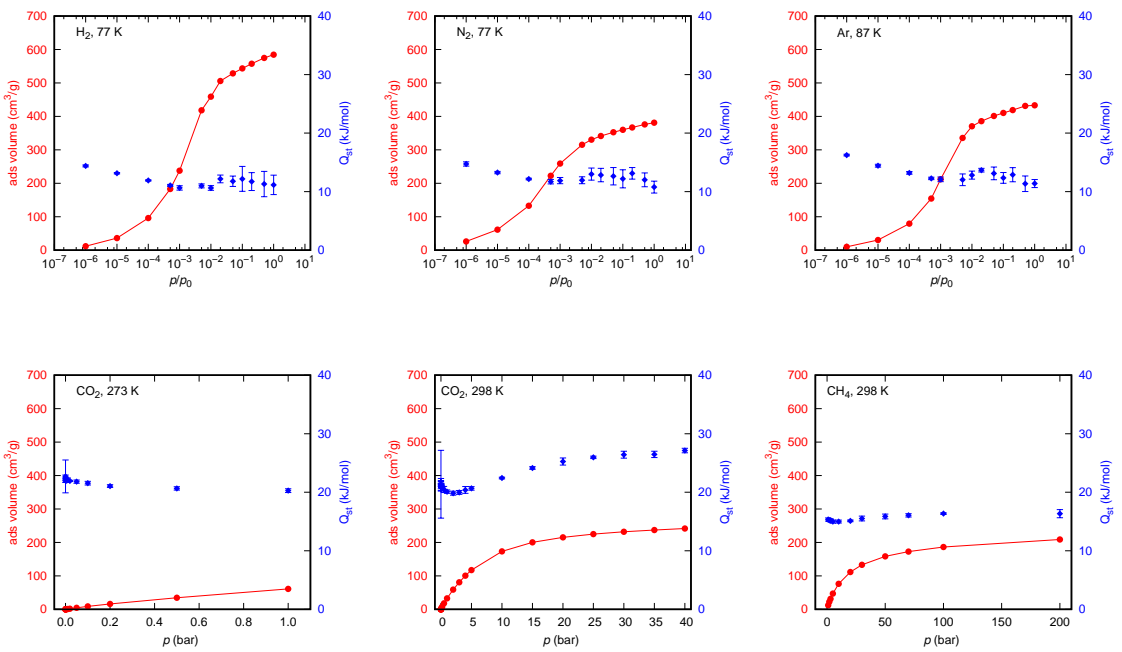


\section{HCP-Colina-id025}
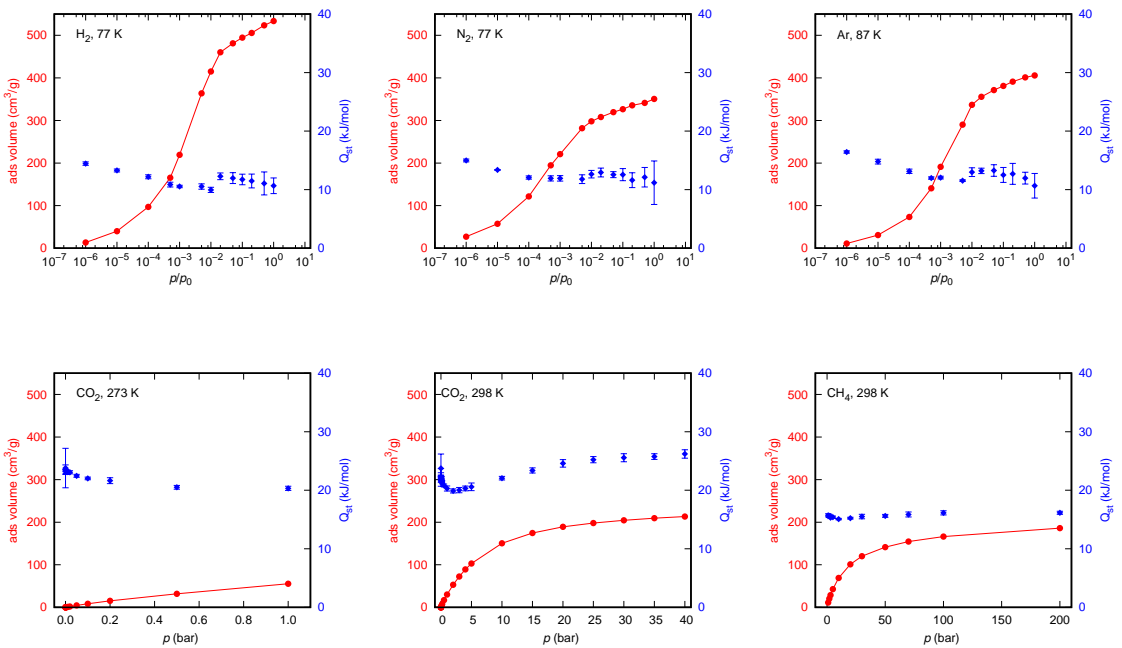


\section{HCP-Colina-id026}
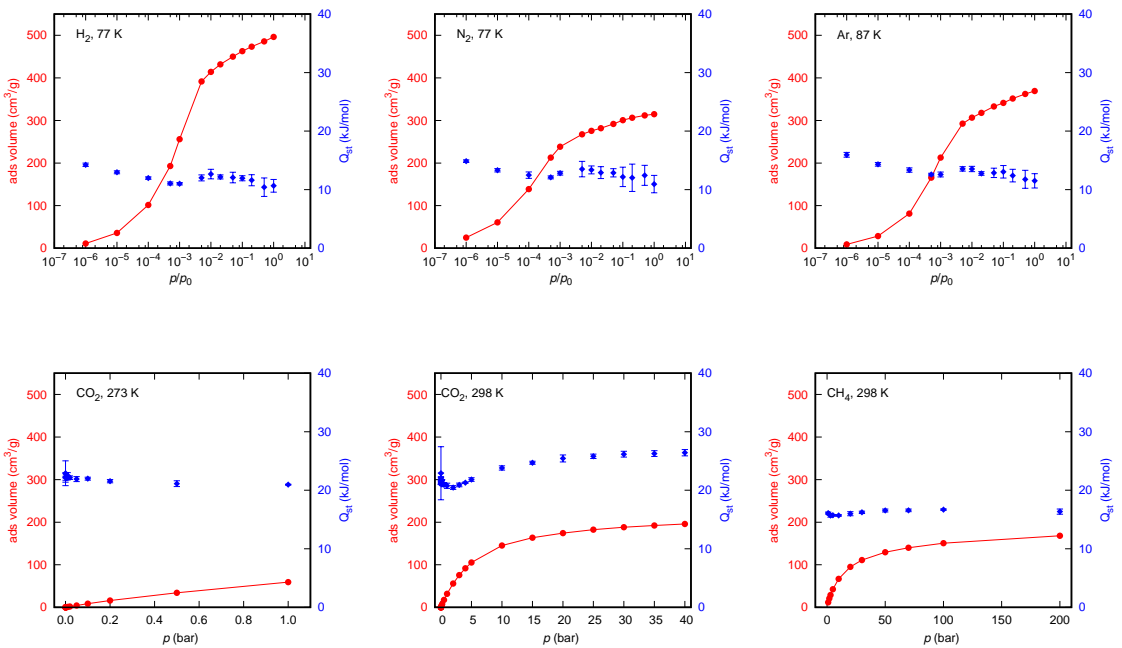


\section{HCP-Colina-id027}
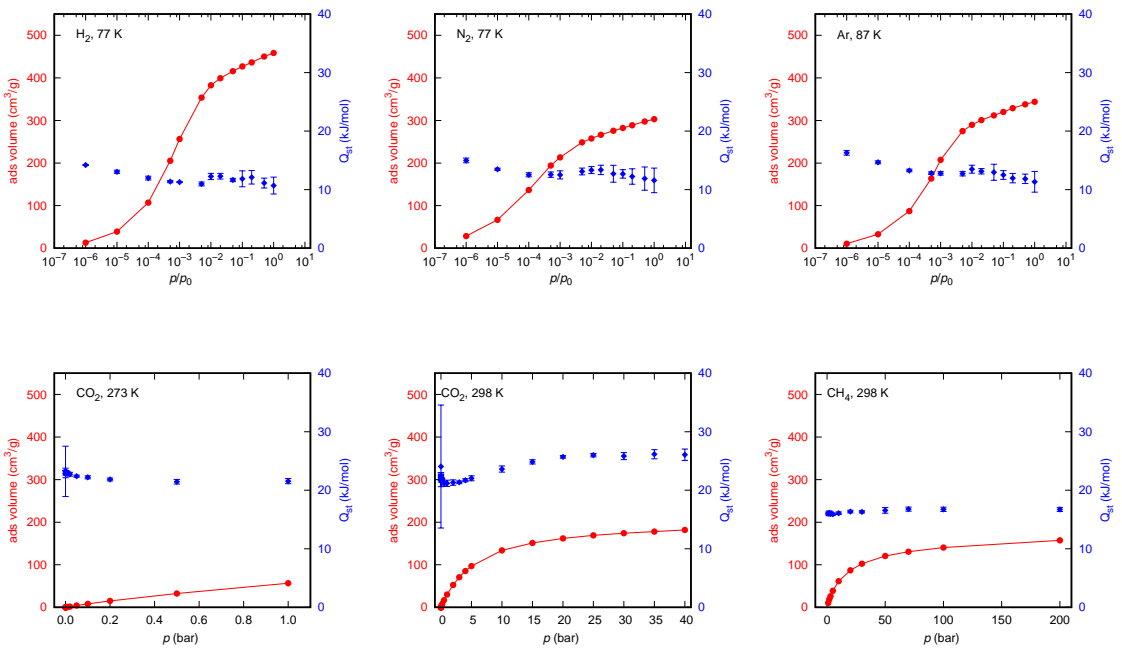


\section{HCP-Colina-id028}
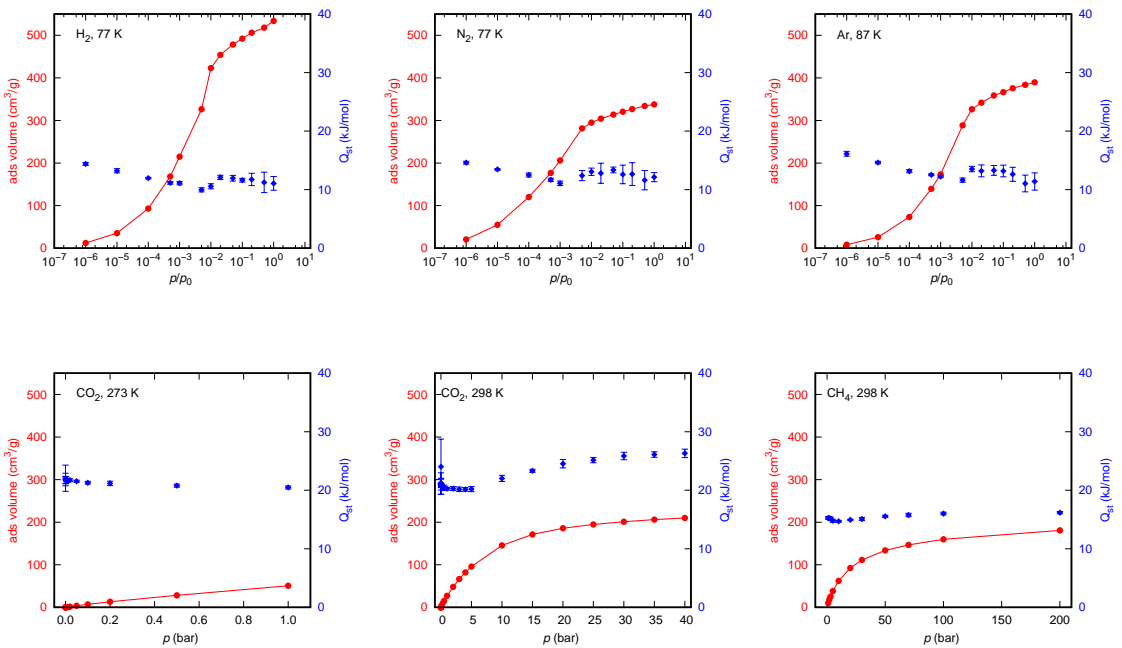


\section{HCP-Colina-id029}
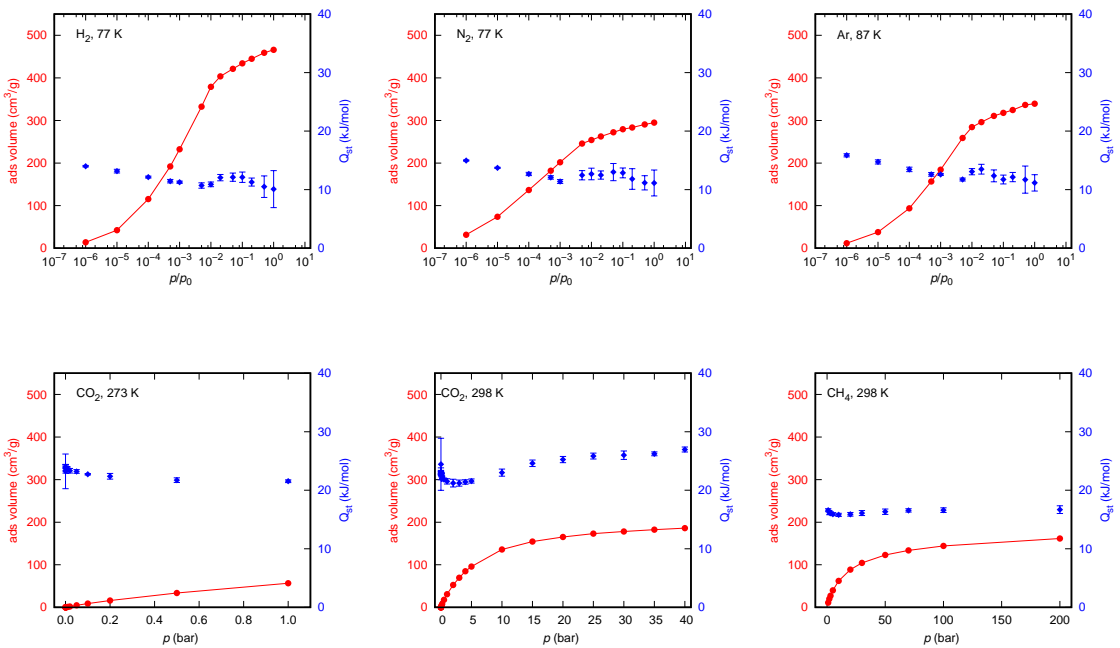


\section{HCP-Colina-id030}
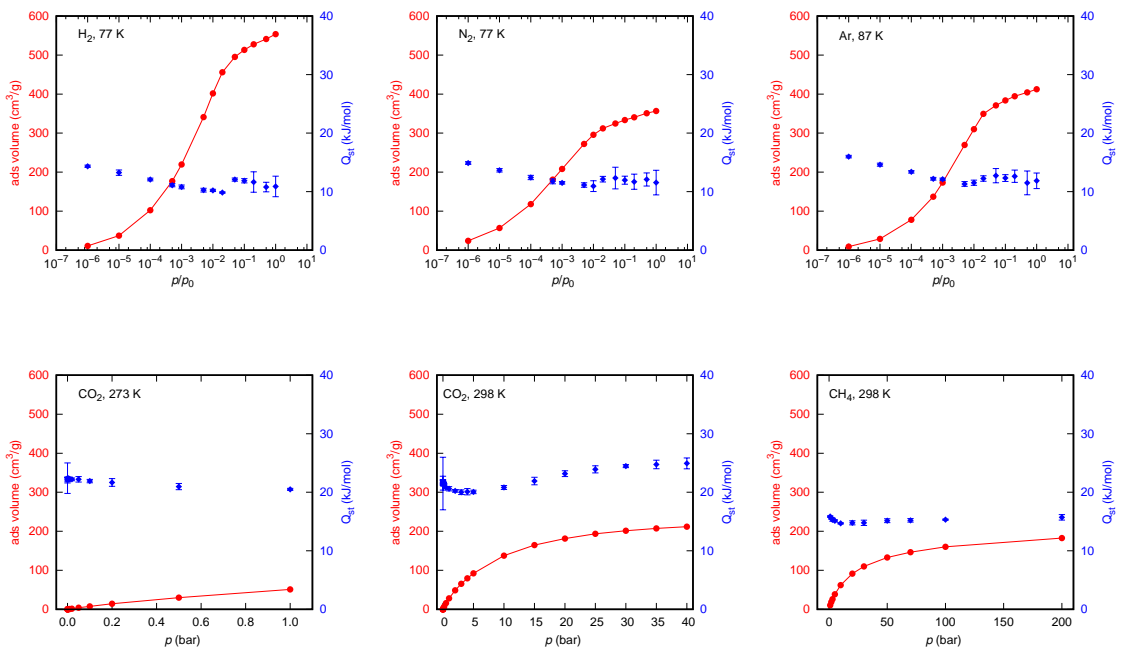


\section{HCP-Colina-id031}
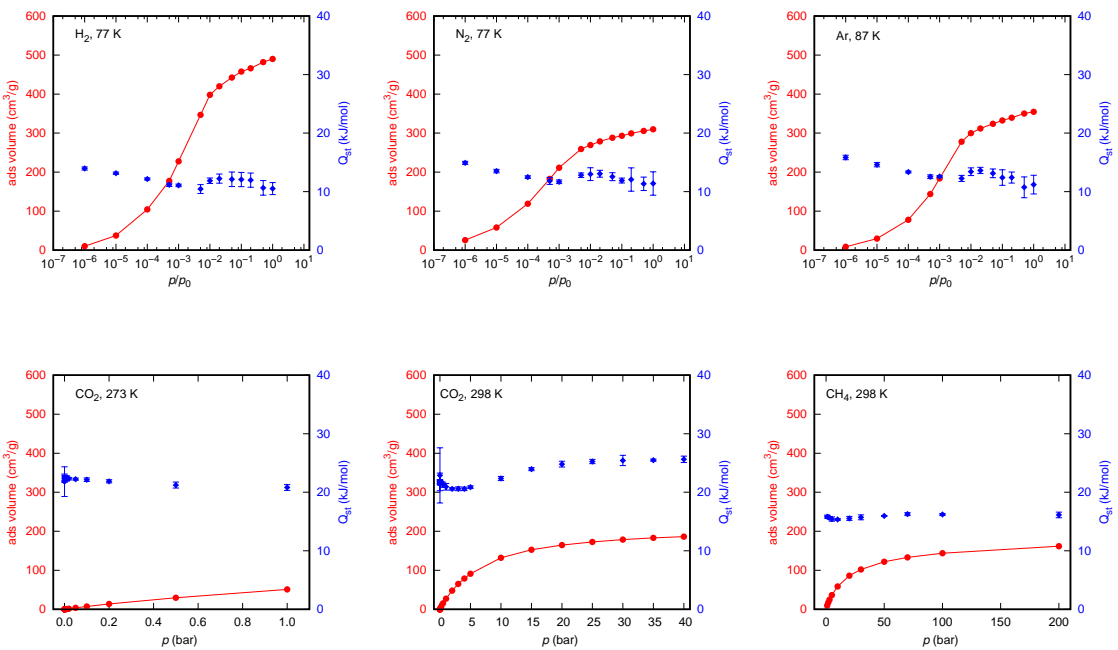


\section{HCP-Colina-id032}
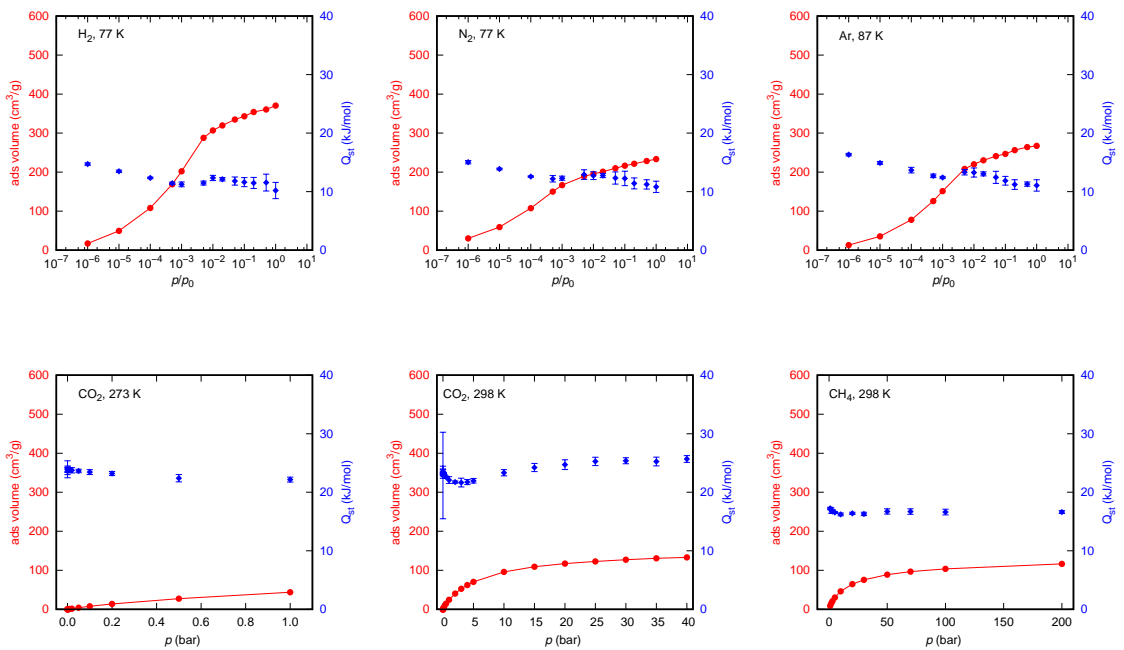


\section{HCP-Colina-id033}
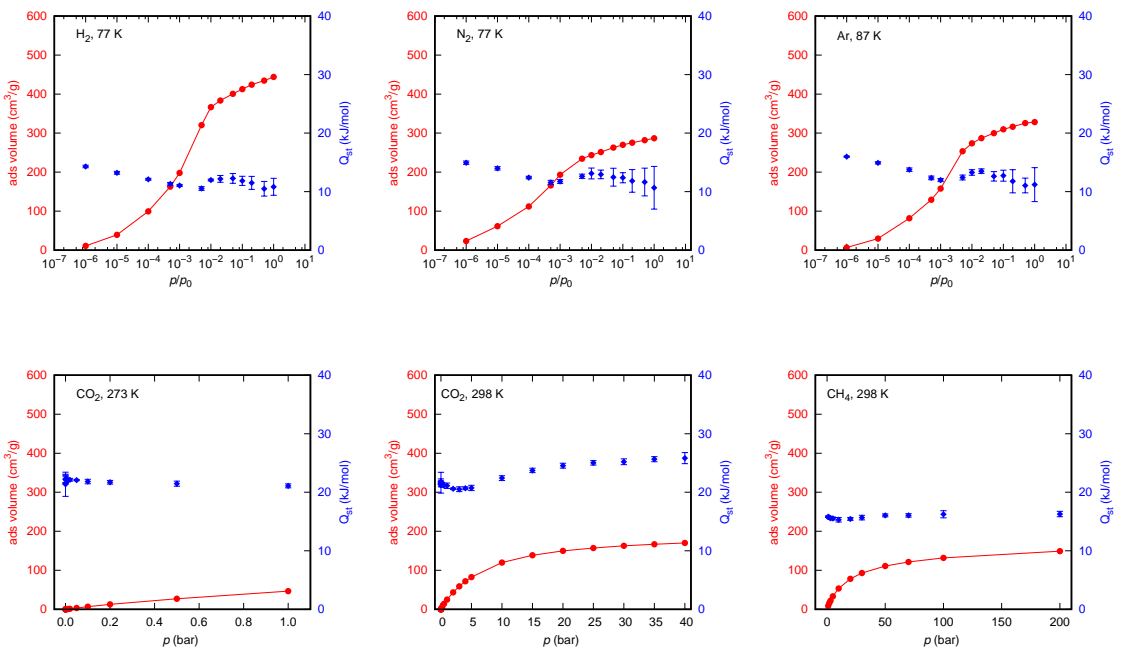


\section{HCP-Colina-id034}
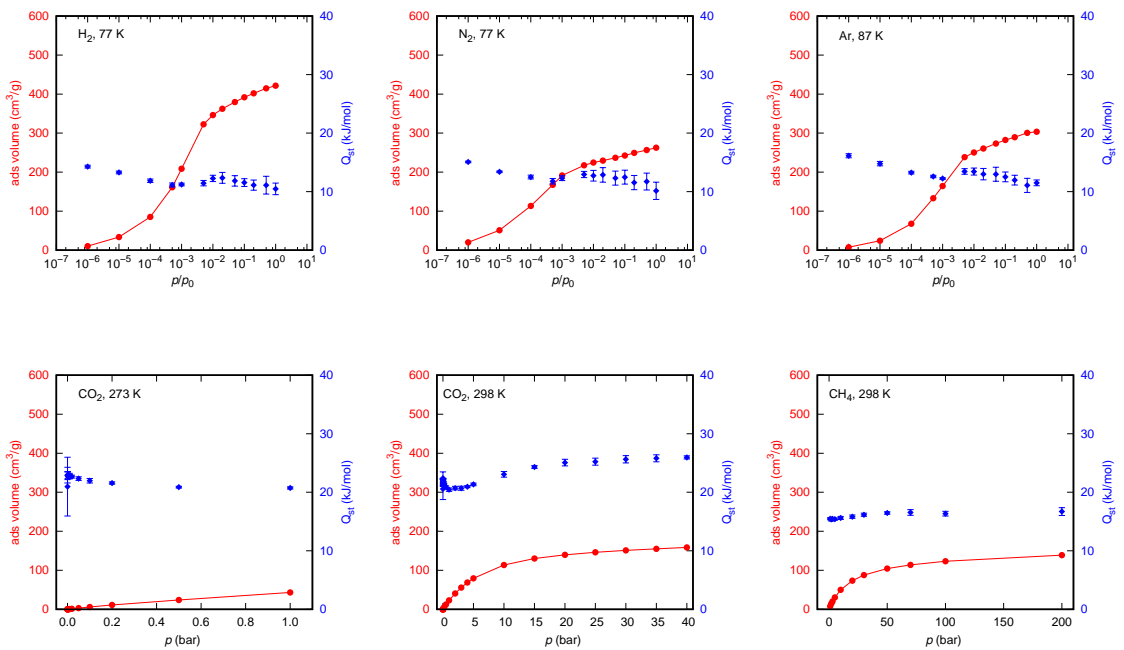


\section{HCP-Colina-id035}
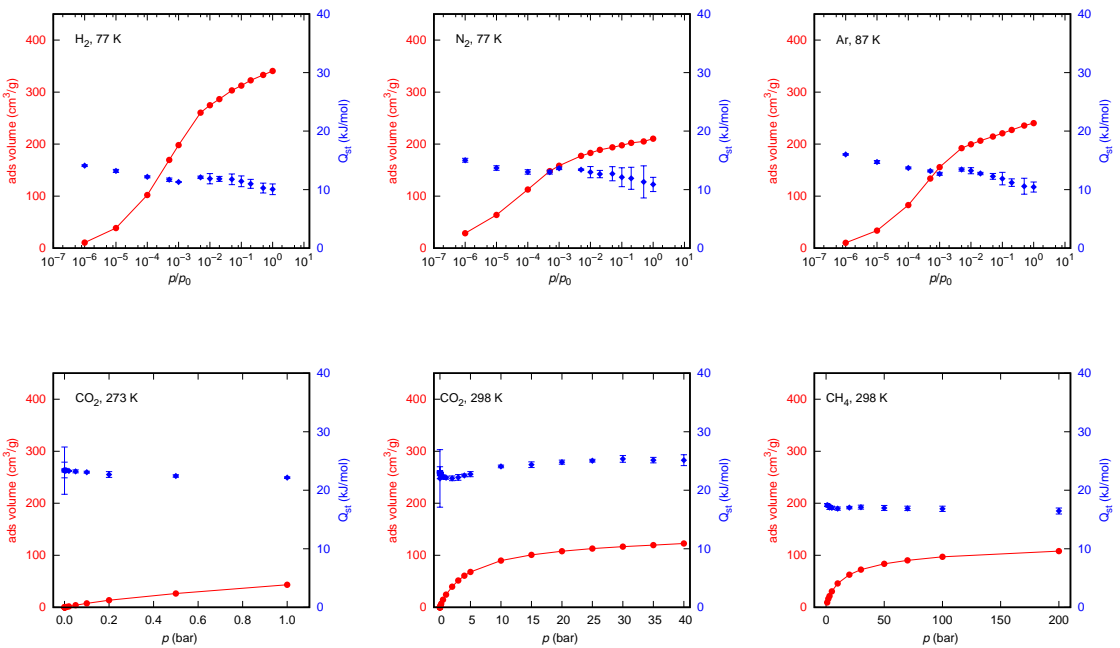


\section{HCP-Colina-id036}
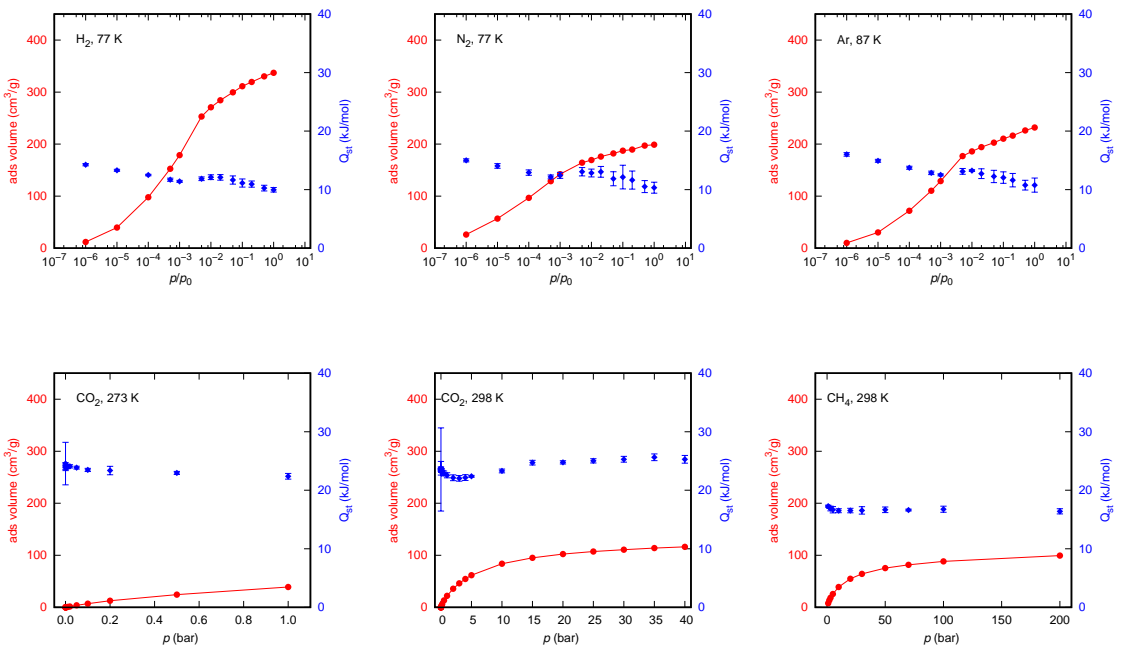


\section{HCP-Colina-id037}
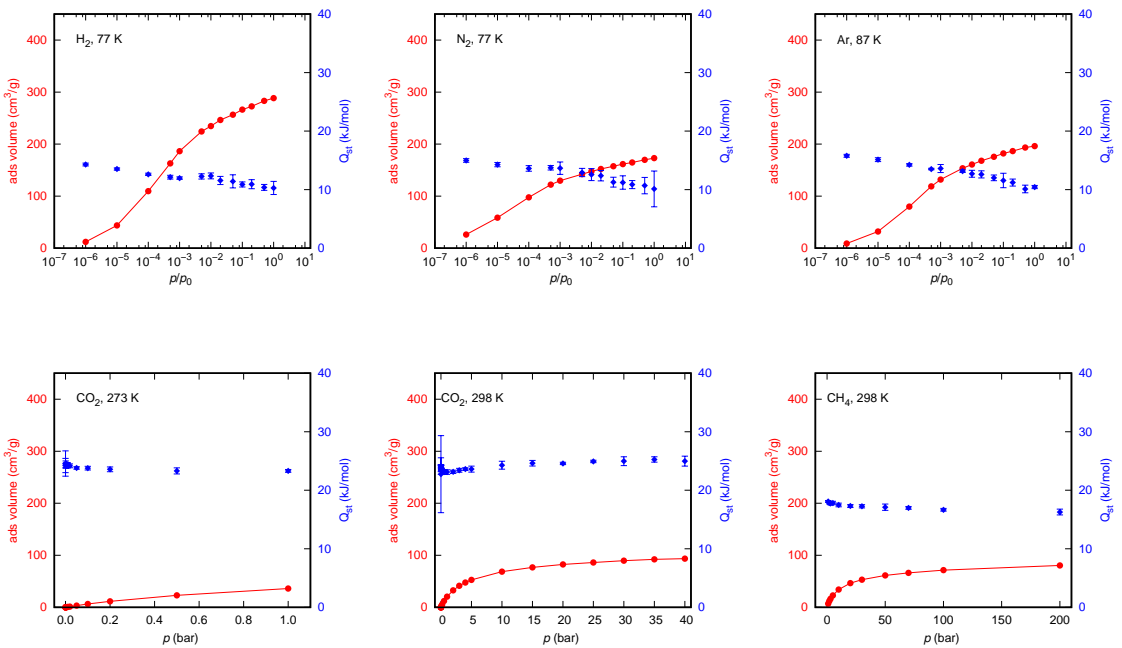


\section{HCP-Colina-id038}
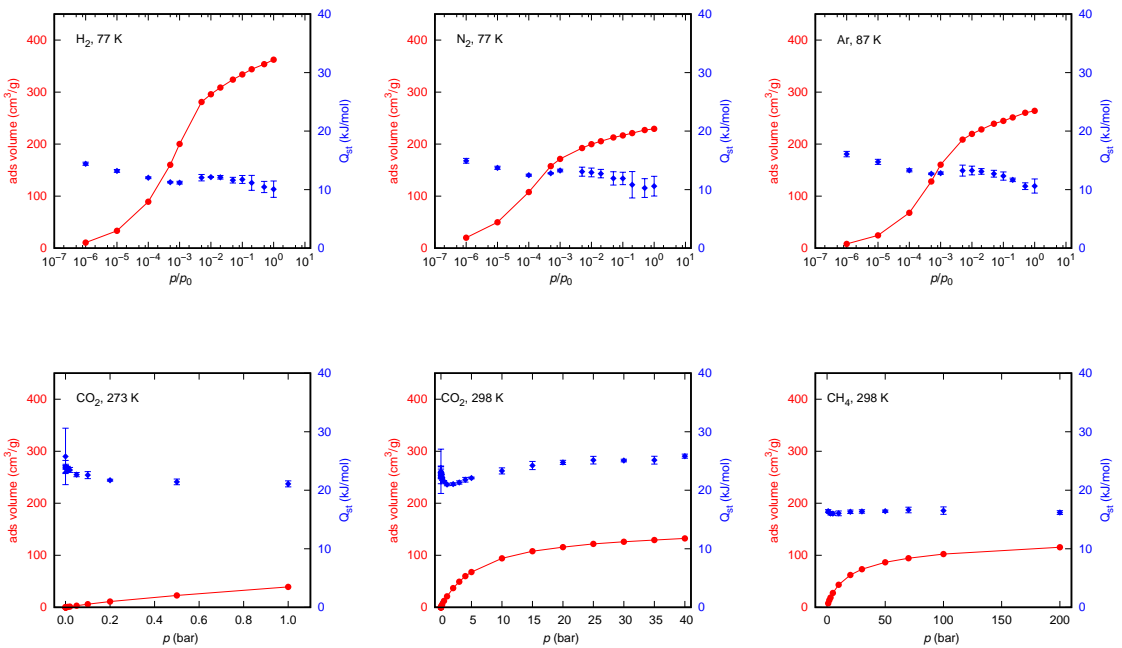


\section{HCP-Colina-id039}
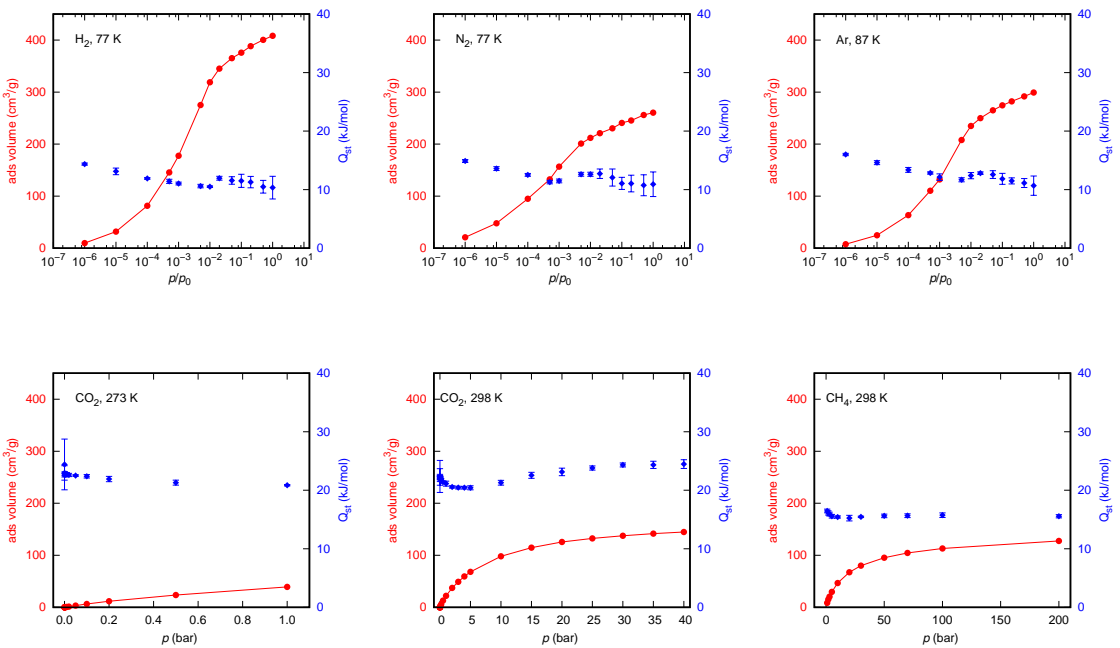


\section{HCP-Colina-id040}
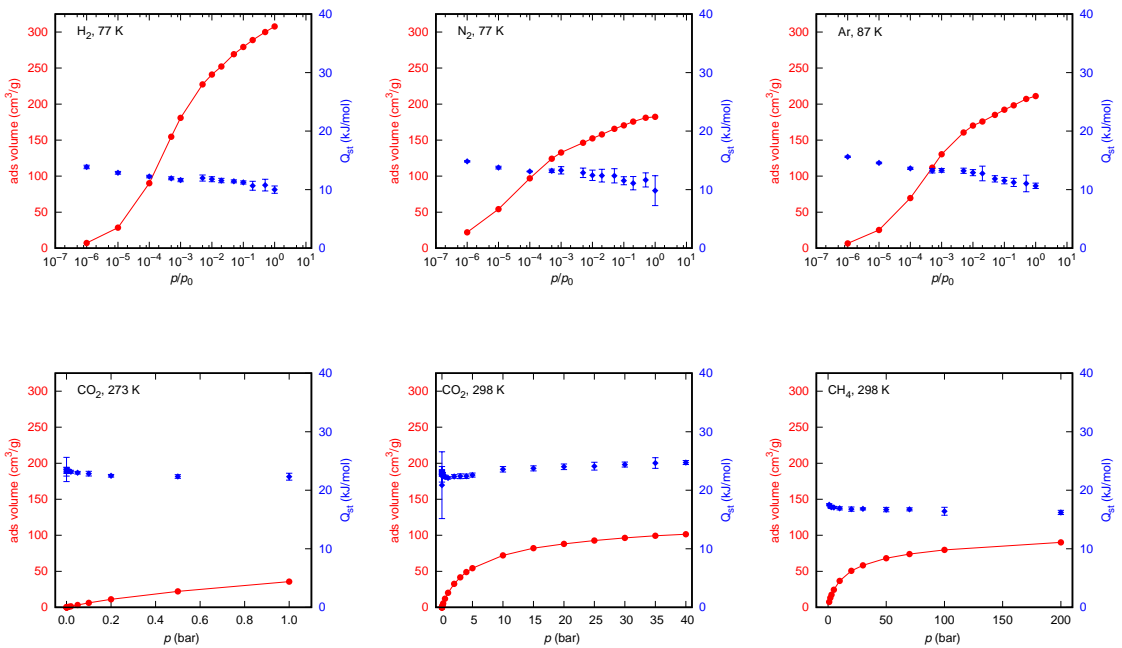


\section{HCP-Colina-id041}
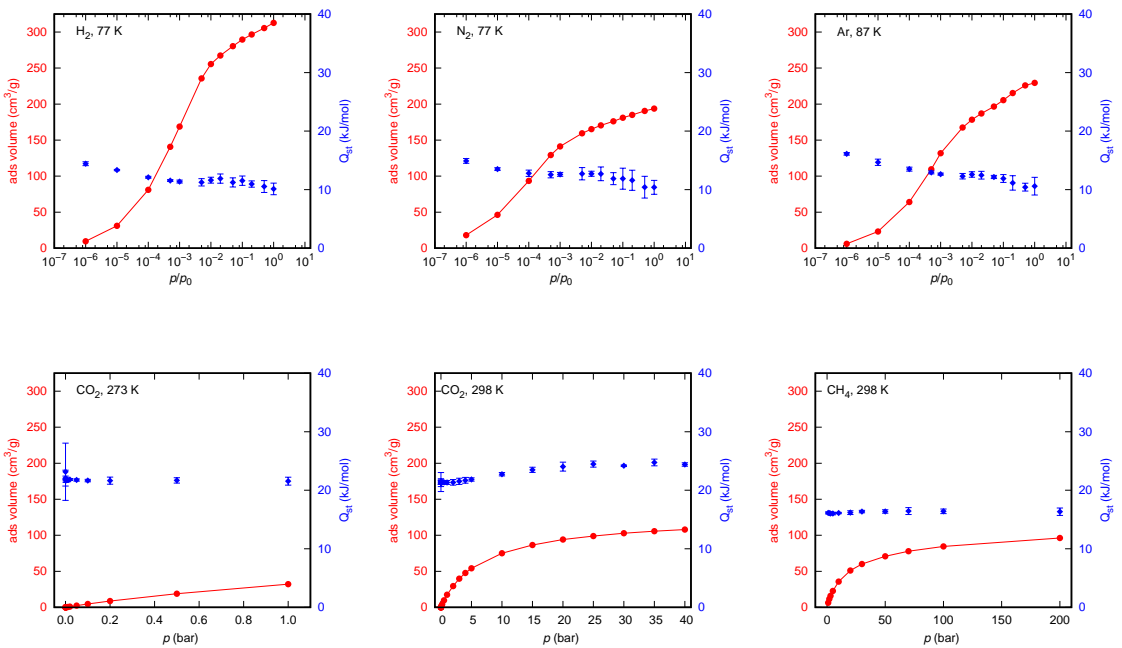


\section{HCP-Colina-id042}
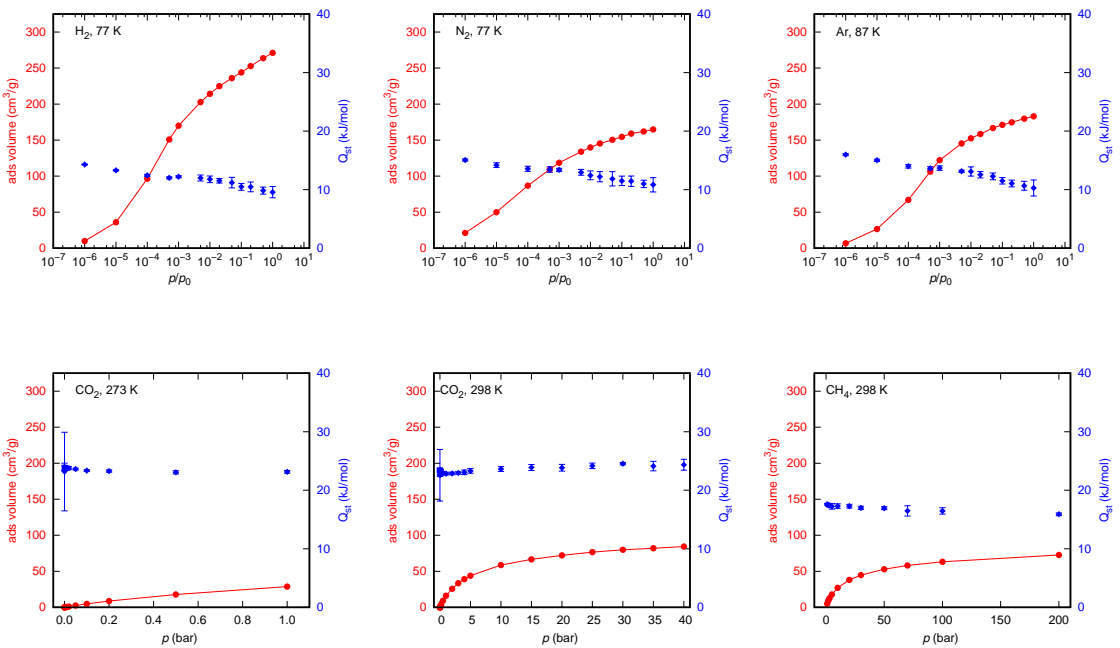


\section{HCP-Colina-id043}
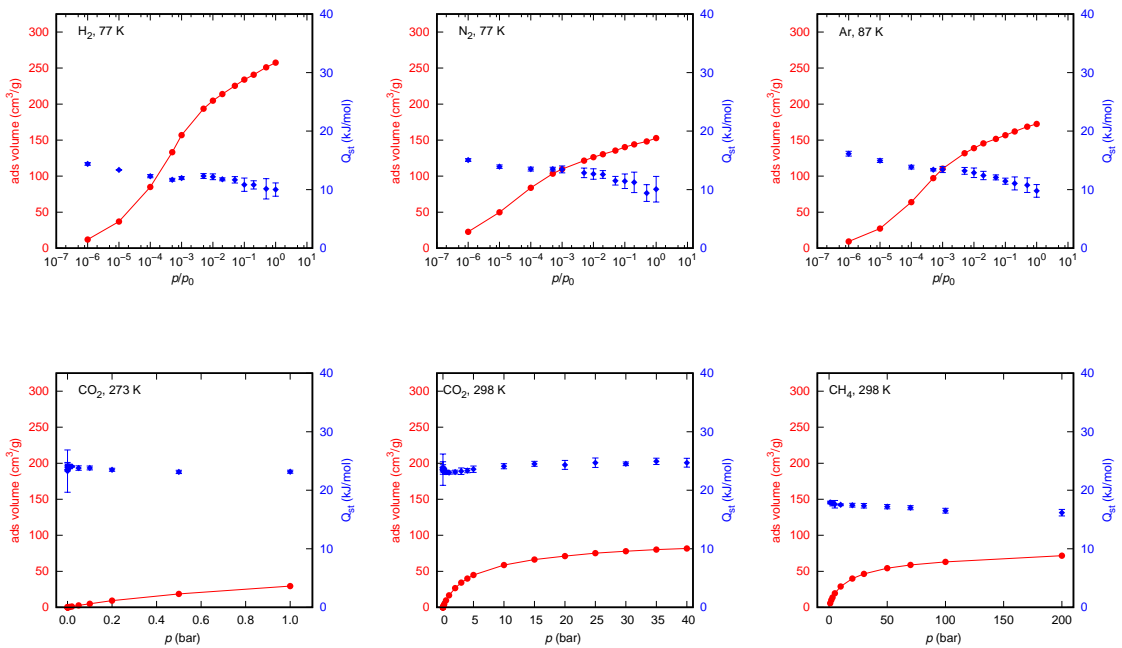


\section{HCP-Colina-id044}
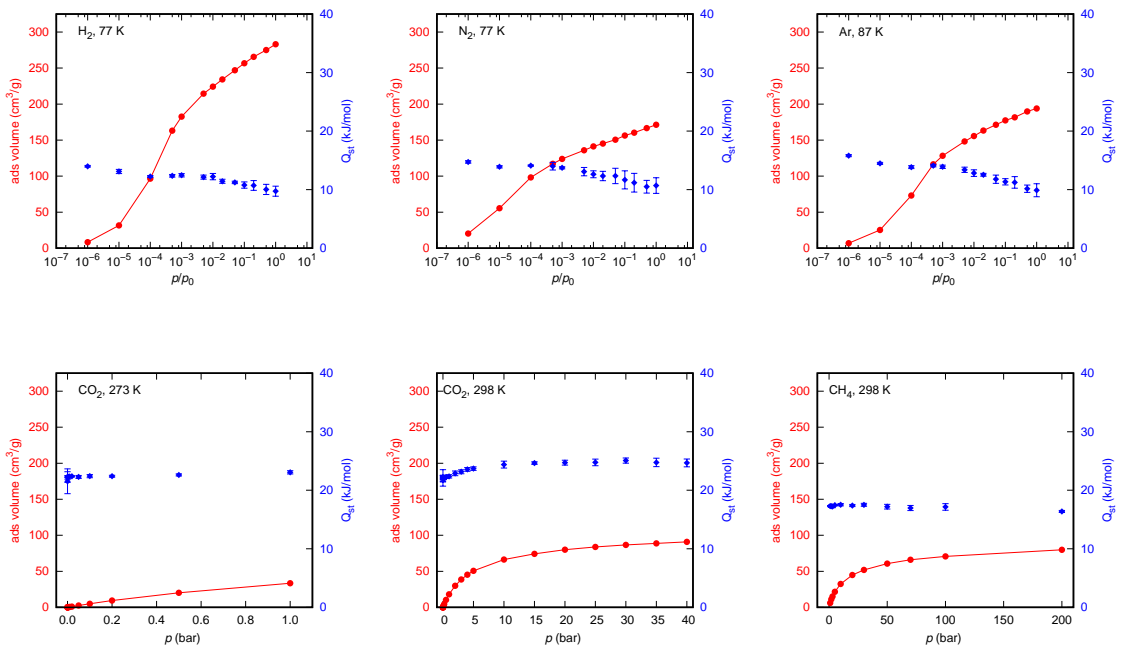


\section{Kerogen-Coasne-id001}
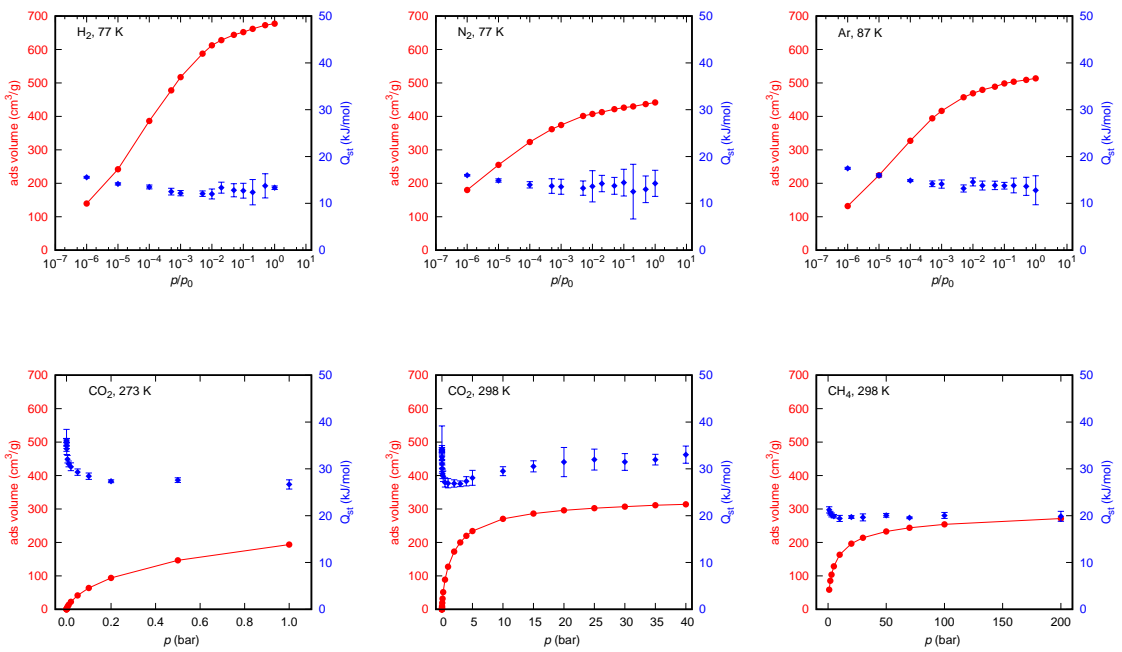


\section{Kerogen-Coasne-id002}
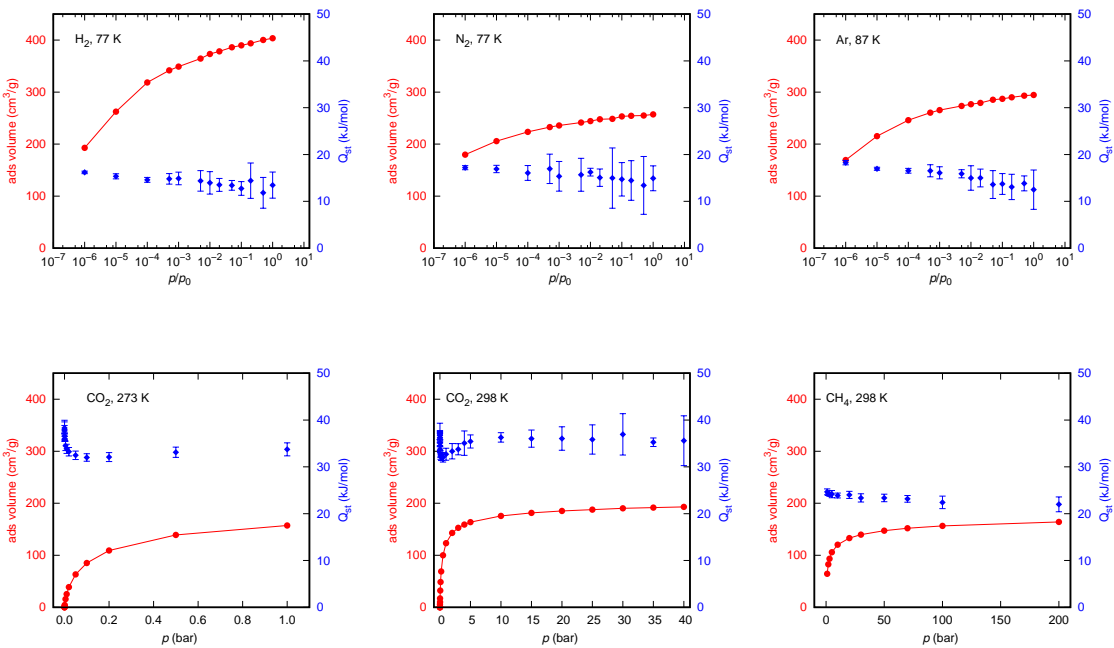


\section{Kerogen-Coasne-id003}
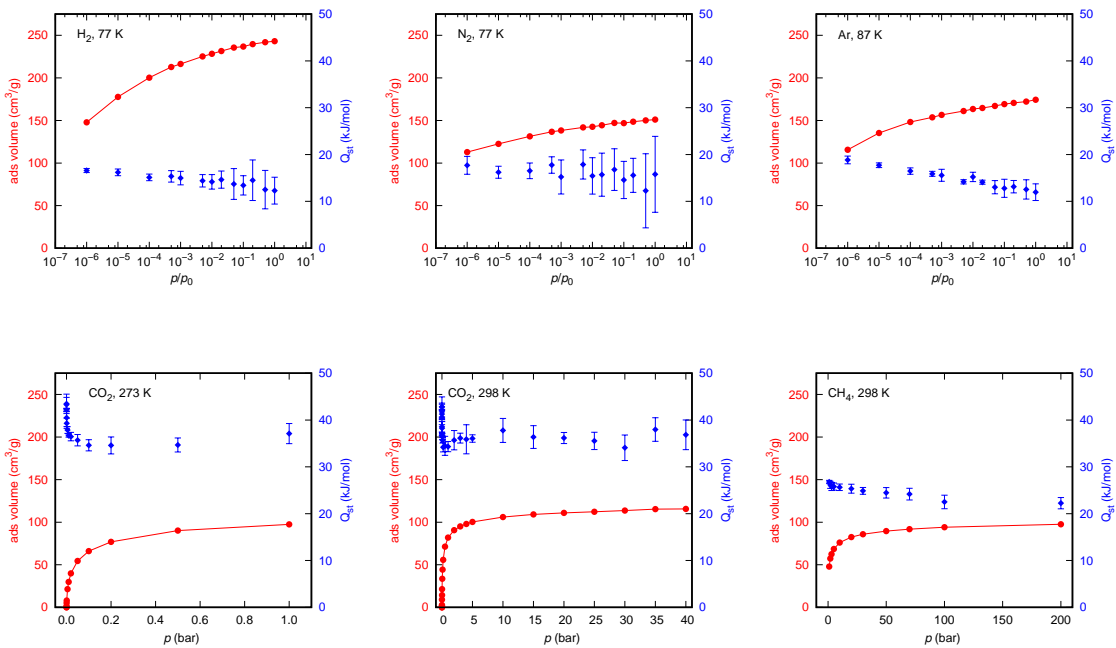


\section{Kerogen-Coasne-id004}
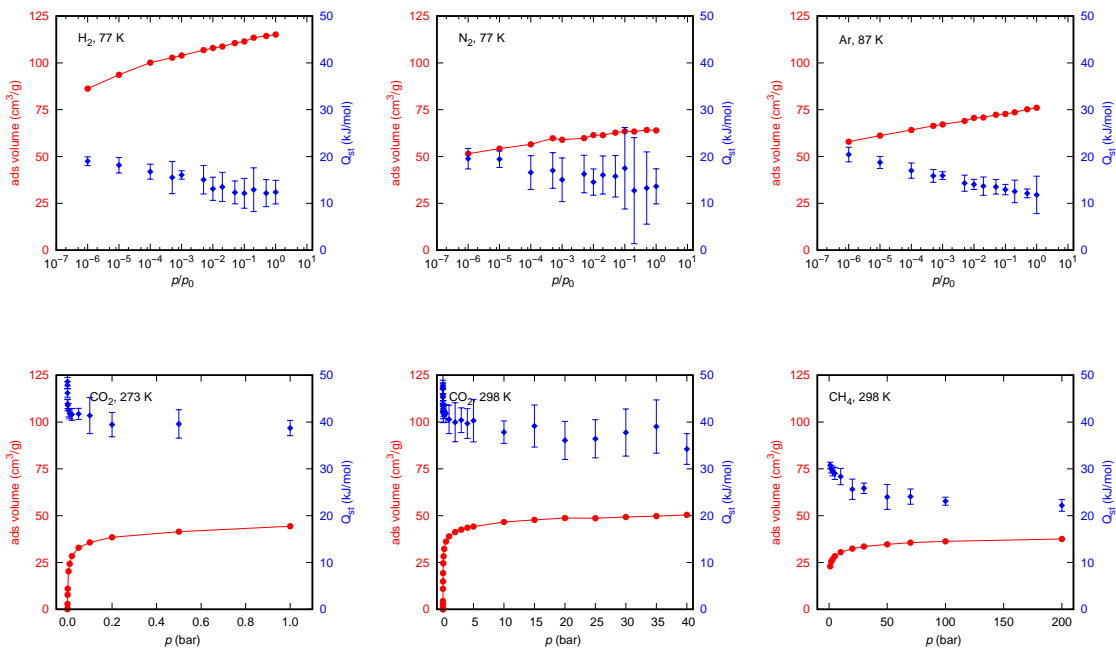


\section{Kerogen-Coasne-id005}
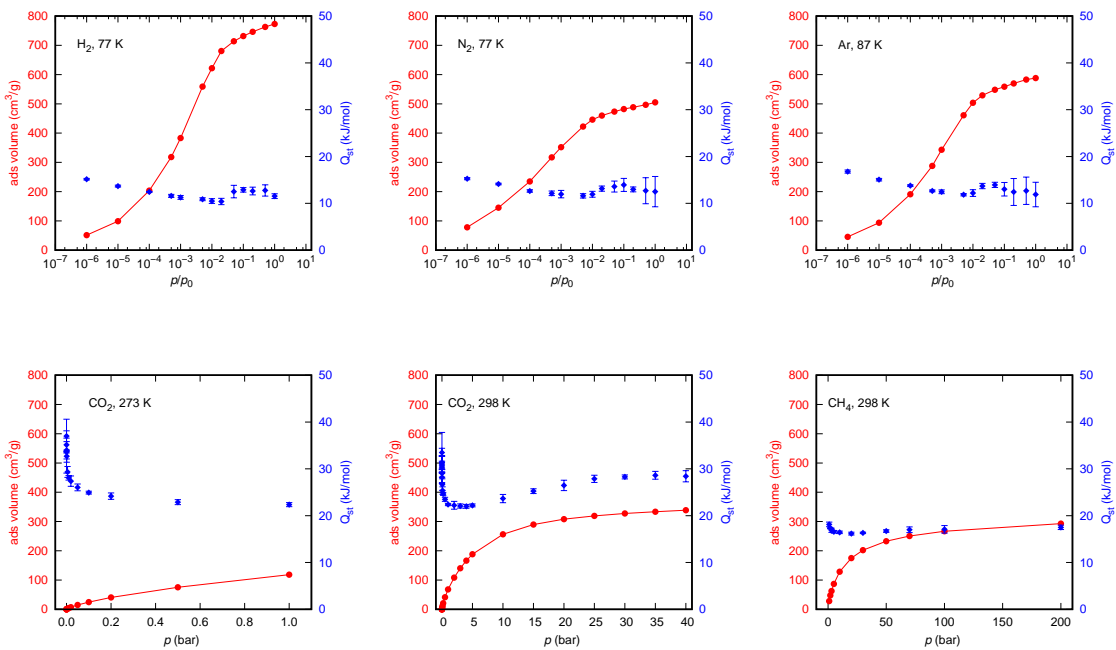


\section{Kerogen-Coasne-id006}
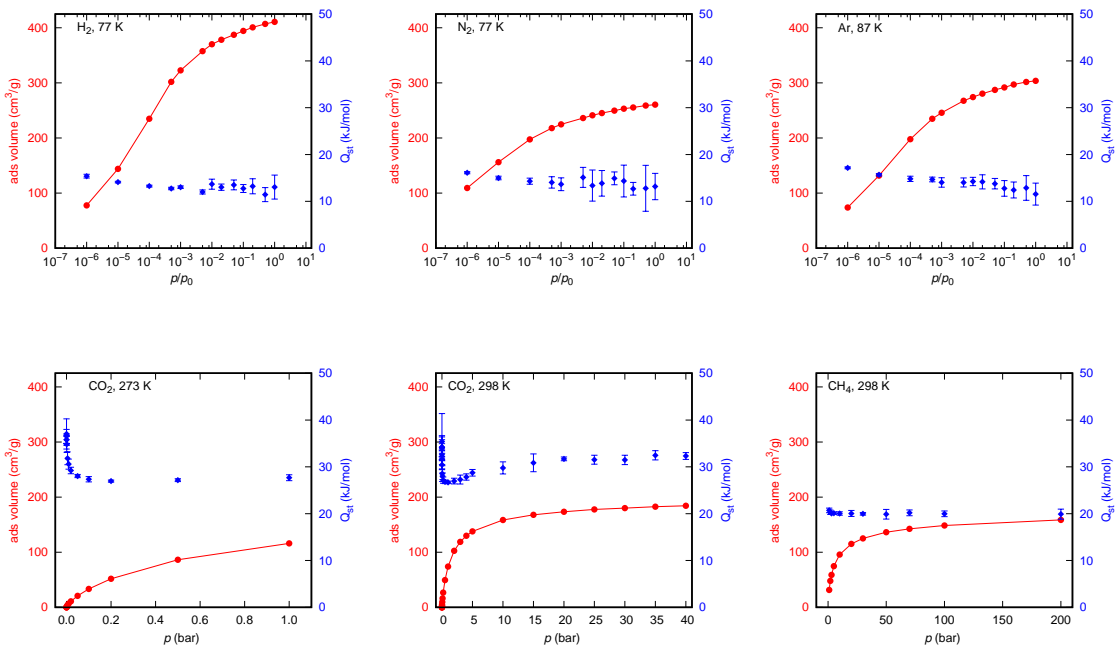


\section{Kerogen-Coasne-id007}
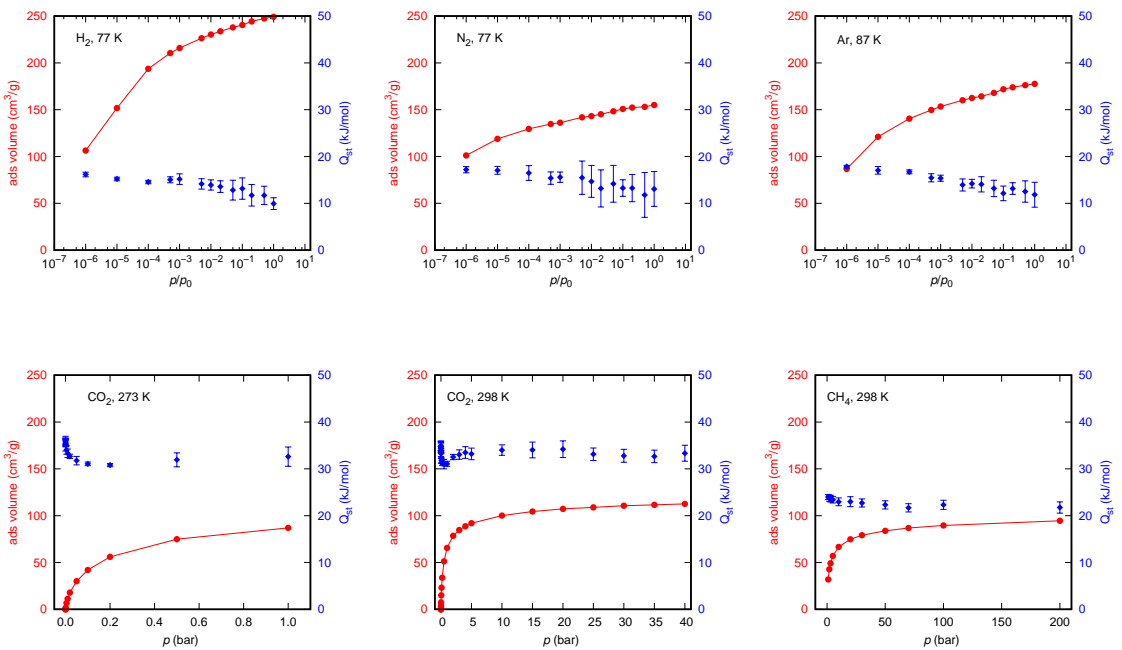


\section{Kerogen-Coasne-id008}
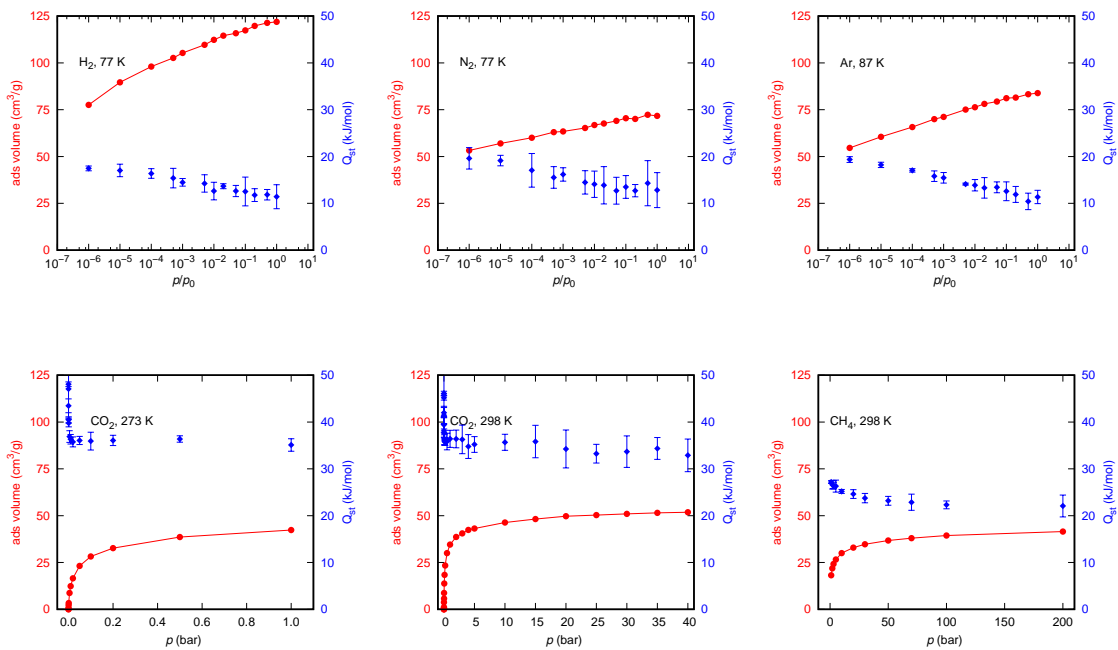


\section{Kerogen-Coasne-id009}
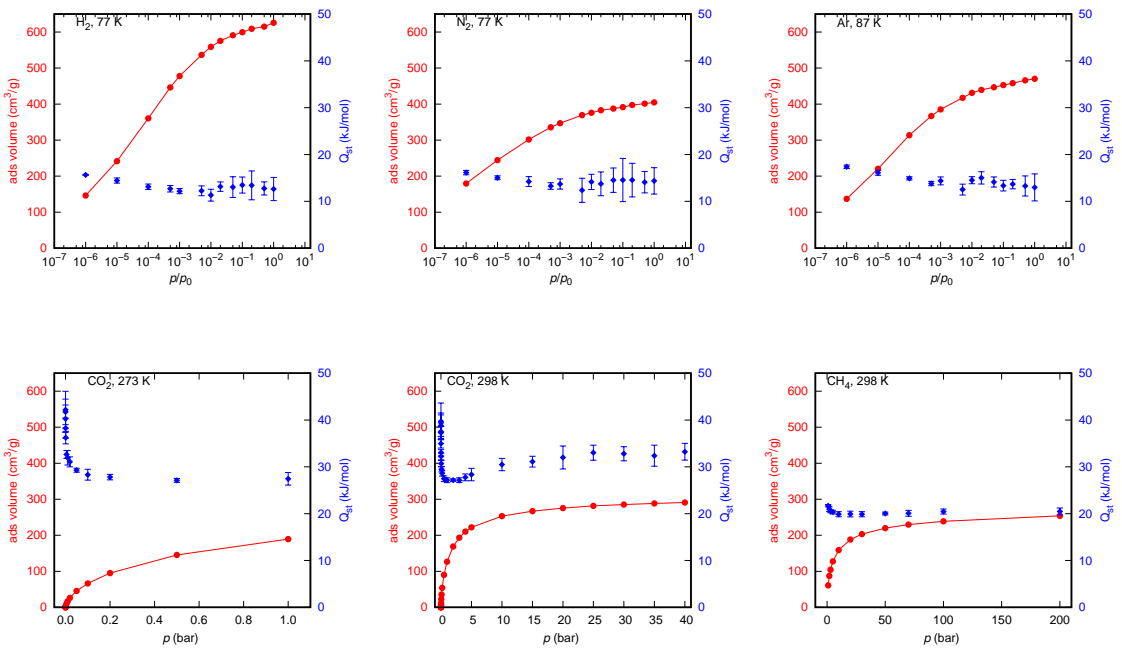


\section{Kerogen-Coasne-id010}
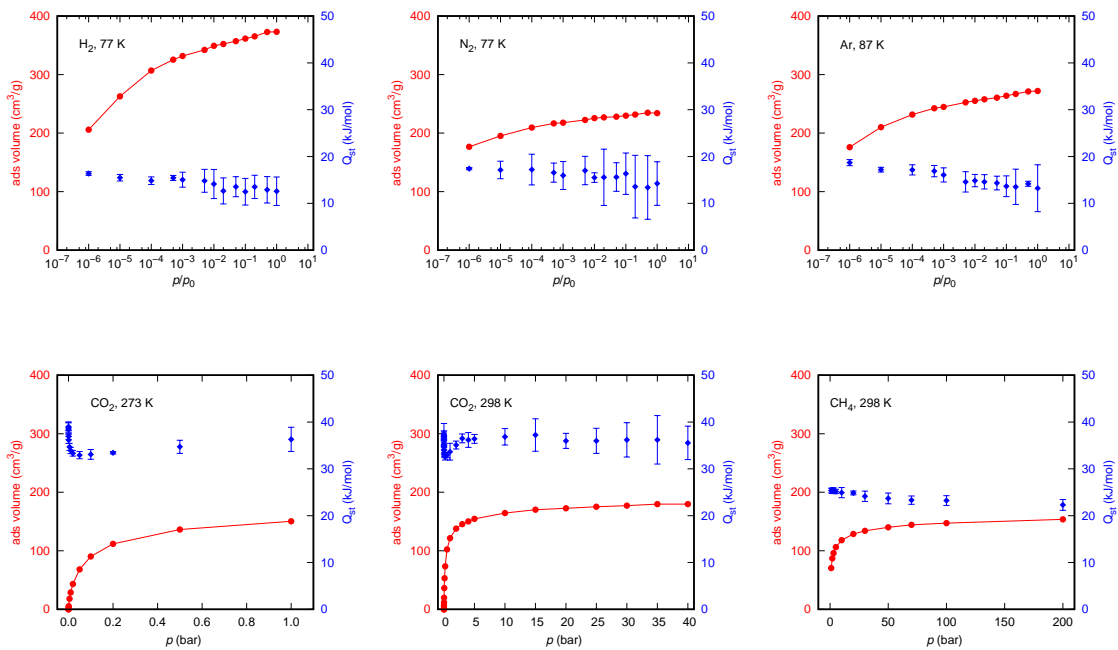


\section{Kerogen-Coasne-id011}
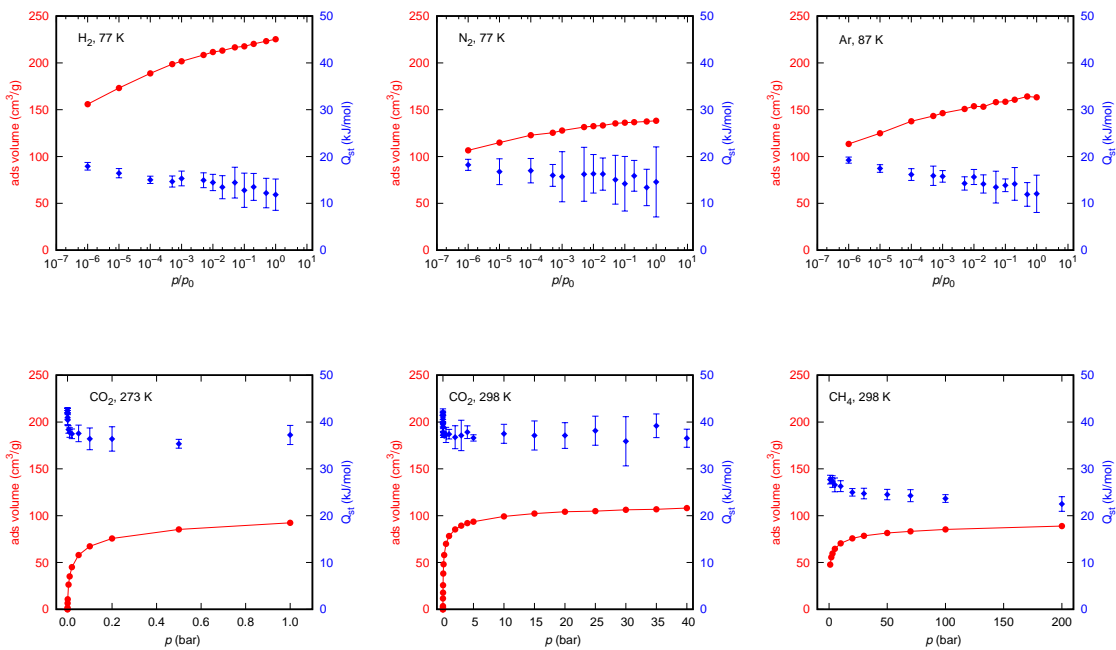


\section{Kerogen-Coasne-id012}
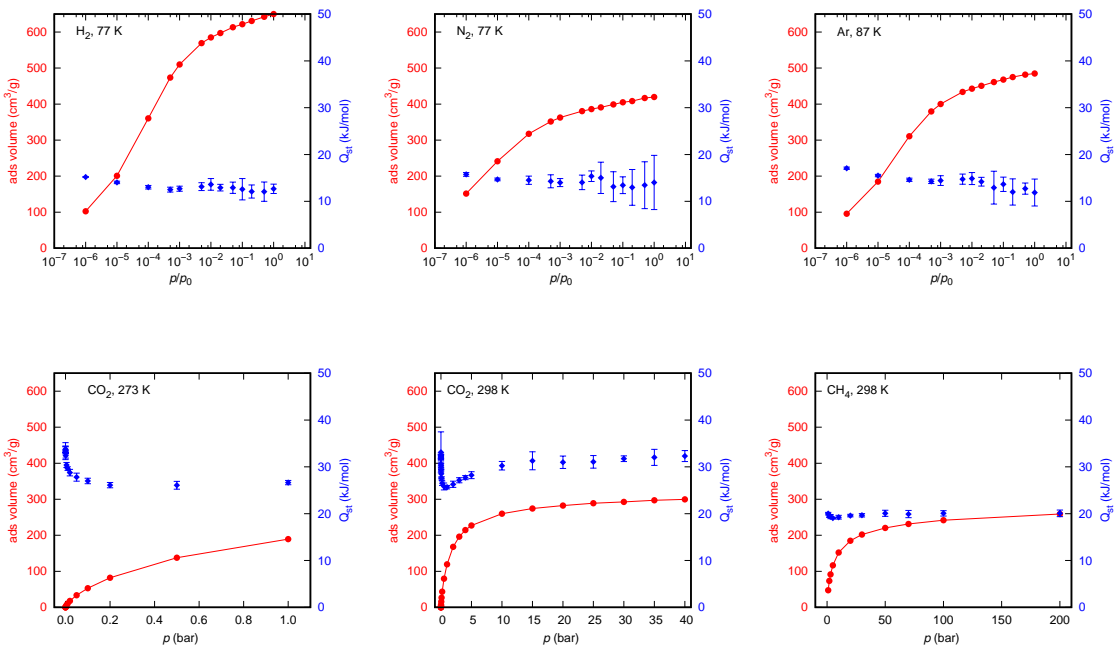


\section{Kerogen-Coasne-id013}
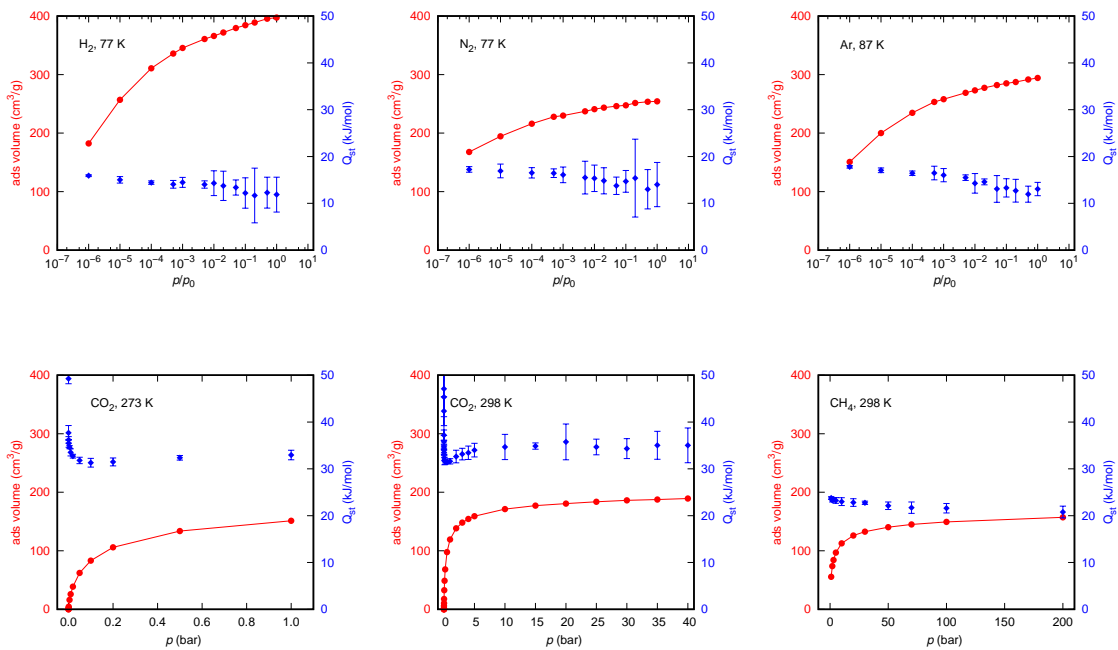


\section{Kerogen-Coasne-id014}
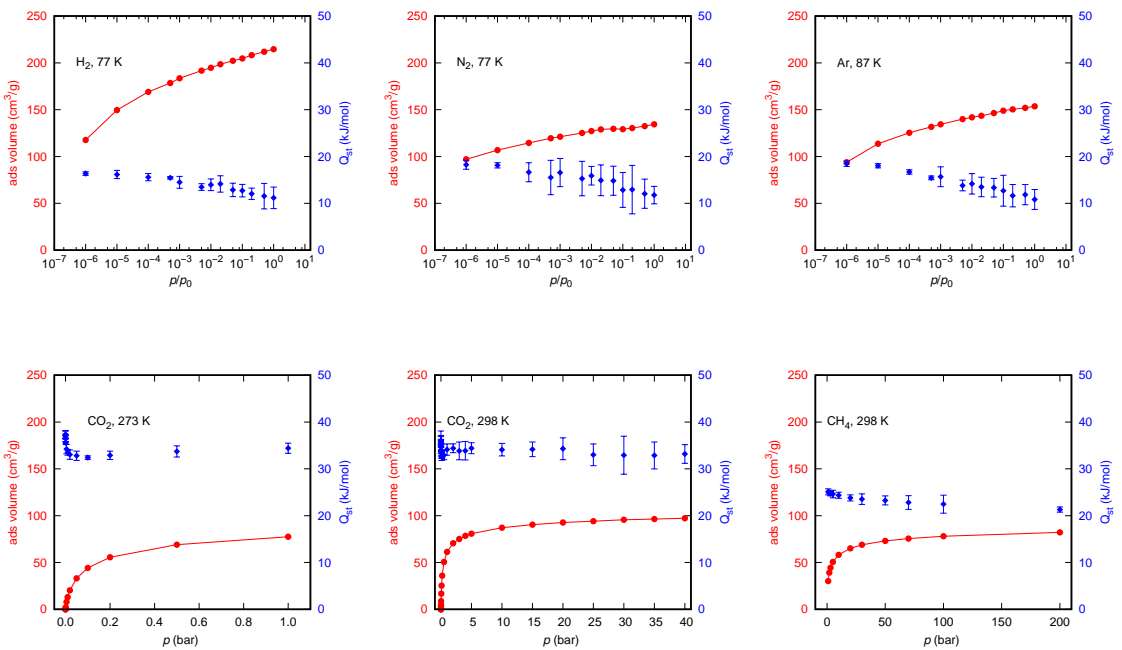


\section{Kerogen-Coasne-id015}
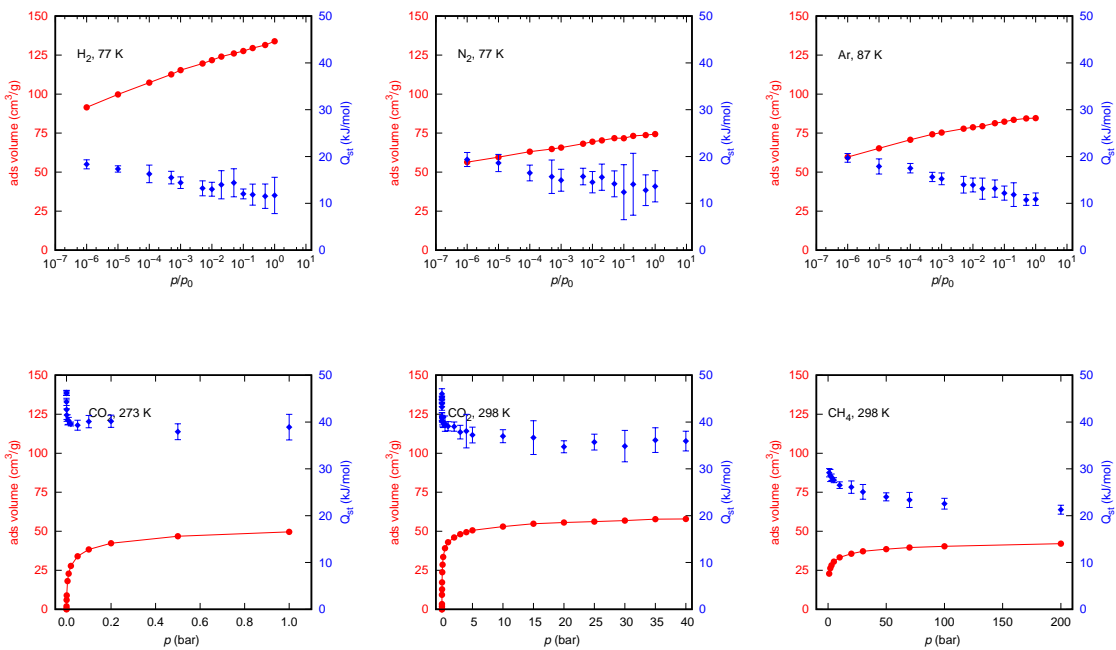


\section{aZIF-Bennett-id001}
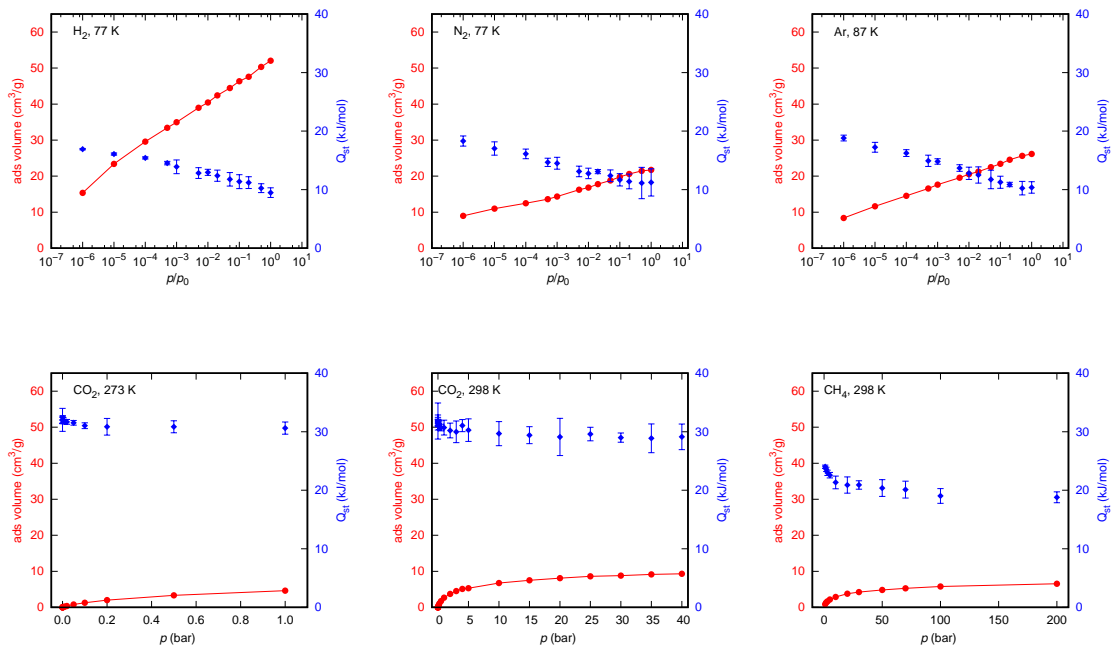